Western University

Scholarship@Western

Digitized Theses

Digitized Special Collections

1972

\title{
A Theory Of Household Grocery Inventory Holdings
}

Paul G. Reinhardt

Follow this and additional works at: https://ir.lib.uwo.ca/digitizedtheses

\section{Recommended Citation}

Reinhardt, Paul G., "A Theory Of Household Grocery Inventory Holdings" (1972). Digitized Theses. 570.

https://ir.lib.uwo.ca/digitizedtheses/570

This Dissertation is brought to you for free and open access by the Digitized Special Collections at Scholarship@Western. It has been accepted for inclusion in Digitized Theses by an authorized administrator of Scholarship@Western. For more information, please contact tadam@uwo.ca,

wlswadmin@uwo.ca. 
The author of this thesis has granted The University of Western Ontario a non-exclusive license to reproduce and distribute copies of this thesis to users of Western Libraries. Copyright remains with the author.

Electronic theses and dissertations available in The University of Western Ontario's institutional repository (Scholarship@Western) are solely for the purpose of private study and research. They may not be copied or reproduced, except as permitted by copyright laws, without written authority of the copyright owner. Any commercial use or publication is strictly prohibited.

The original copyright license attesting to these terms and signed by the author of this thesis may be found in the original print version of the thesis, held by Western Libraries.

The thesis approval page signed by the examining committee may also be found in the original print version of the thesis held in Western Libraries.

Please contact Western Libraries for further information:

E-mail: libadmin@uwo.ca

Telephone: (519) 661-2111 Ext. 84796

Web site: http://www.lib.uwo.ca/ 


\section{A THEORY OF HOUSEHOLD GROCERY INVENTORY HOLDINGS}

by

Paul G. Reinhardt

Department of Economics

Submitted in partial fulfillment of the requirements for the degree of

Doctor of Philosophy

Faculty of Graduate Studies

The University of Western Ontario

London, Canada

March 1972

(C) Paul G. Reinhardt, 1972 
The purpose of the paper is to investigate the properties of household inventory behaviour. A straightforward approach takes a Baumol-type inventory model and adapts it to commodity holdings of the consumer. In doing so, however, numerous difficulties arise which have not been investigated yet.

A major problem originates with the fact that the consumer can purchase a great many goods on the same shopping trip. As a consequence, the inventory cost functions for the various goods are interdependent. Moreover, in the presence of pervasive inducements, through quantity discounts, to purchase more of a good than needed for the consumption during the period between consecutive shopping trips, the optimum purchase frequencies will differ for the various goods and will also generally be less than the shopping frequency.

Allowing for both these complications, the present model determines inventory equilibrium for a pair of goods of which one is a perishable, the other a grocery good. The goods differ in that the former has a non-linear holding cost function, while that function for the latter is of linear form. The major property of the model which emerges is that it dichotomizes inventory equilibrium of the household: Optimum holdings of the grocery good are 
independent of the shopping frequency while that frequency's optimum hinges solely on the parameters of the perishable good.

This result is in keeping with the intuitive notion that perishable holdings bear overwhelmingly on the decision of how often to go to the store. At the same time, it permits inventory holdings of any given grocery item to be analyzed in a partial setting with all the conveniences it affords.

Because of difficult verification problems, the empirical objective is restricted to testing the qualitative properties of the grocery inventory equilibrium. Using the survey results of the Chicago Tribune Consumer Panel of 1960/61 for a large number of grocery purchases, conclusive evidence emerges that the model captures the broad pattern of household inventory behaviour reflected in these data. 
ACKNOWLEDGEMENTS

I wish to express my sincere appreciation to the members of my dissertation committee, Professors Joel Fried, Tom Courchene, Ernest Tanner and John Palmer for their invaluable help and suggestions while preparing the dissertation. I would also like to thank all those members of the Faculty who most willingly read drafts of the thesis and offered their comments. 
TABLE OF CONTENTS

\begin{tabular}{|c|c|c|}
\hline \multirow{2}{*}{\multicolumn{2}{|c|}{ Certificate of Examination............. }} & Page \\
\hline & & ii \\
\hline ABSTRACI & . & iii \\
\hline ACKNOWL I & GDGEMENTS . . . . . . . . . . . . . . & $\mathbf{v}$ \\
\hline TABLE 01 & CONTENTS . . . . . . . . . . . . . . & vi \\
\hline LIST OF & TABLES . . . . . . . . . . . . . . & viil \\
\hline LIST OF & FIGURES $\ldots \ldots \ldots \ldots \ldots \ldots \ldots \ldots \ldots \ldots$ & $i x$ \\
\hline \multicolumn{3}{|l|}{ CHAPTER } \\
\hline I & INTRODUCTION.................. & 1 \\
\hline \multirow[t]{3}{*}{ II } & BACKGROUND AND SYNTHESIS OF & \\
\hline & WRITINGS ON HOUSEHOLD INVENTORY & \\
\hline & 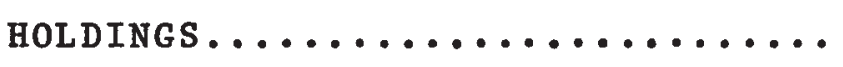 & 6 \\
\hline \multirow[t]{3}{*}{ III } & EXISTING INVENTORY THEORY AND ITS & \\
\hline & LIMITATIONS IN EXPLAINING INVEN-. & \\
\hline & TORY BEHAVINOR OF THE HOUSEHOLD... & 19 \\
\hline \multirow[t]{4}{*}{ IV } & SPECIFICAT ION OF THE HOUSEHOLD & \\
\hline & 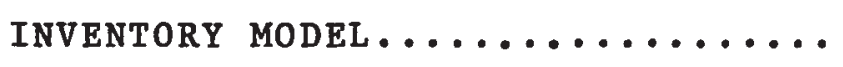 & 35 \\
\hline & APPENDIX TO CHAPTER IV: A THEORY & \\
\hline & OF QUANTITY DISCOUNTS.......... & 52 \\
\hline \multirow[t]{2}{*}{$\mathbf{V}$} & THE DETERMINATION OF HOUSEHOLD & \\
\hline & INVENTORY HOLDINGS . . . . . . . . & 63 \\
\hline \multirow[t]{2}{*}{ VI } & TEST OF MODEL $\ldots \ldots \ldots \ldots \ldots \ldots \ldots$ & 75 \\
\hline & APPENDIX TO CHAPTER VI.......... & 100 \\
\hline
\end{tabular}


TABLE OF CONTENTS

(continued)

\begin{tabular}{|c|c|c|}
\hline CHAPTER & & Page \\
\hline VII & CONCLUSIONS AND IMPLICATIONS...... & 116 \\
\hline & GLOSSARY $\ldots \ldots \ldots \ldots \ldots \ldots \ldots$ & 124 \\
\hline & BIBL IOGRAPHY . . . . . . . . . . . . & 127 \\
\hline & $\operatorname{vITA} \ldots \ldots \ldots \ldots \ldots \ldots \ldots \ldots$ & 131 \\
\hline
\end{tabular}




\section{LIST OF TABLES}

TABLE

Page

1 COMPARISON OF THREE DIFFERENT

ESTIMATING PROCEDURES IN THE

ESTIMATION OF THE RELATIVE

RATE OF HOLDING COSTS OF LOW

AND HIGH INCOME HOUSEHOLDS .........90

2 COMPARISON OF AVERAGE MEASURE OF

QUANTITY DISCOUNTS.............. 92

3 ESTIMATES OF $c_{G}$, THE RELATIVE RATE

OF HOLDING COSTS FOR LOW AND HIGH

INCOME HOUSEHOLDS .............. 96

4 ESTIMATES OF $c_{G}$ FOR VARIOUS GOODS

BY BRANDS................... 97

5 AVERAges DEMONStrating FLOUR...... 103

6 DIFFERENCES IN

7 SHOPPING BEHAVIOUR TEA....... 105

8 FOR HIGH AND LOW INCOME TOILET SOAP. 106

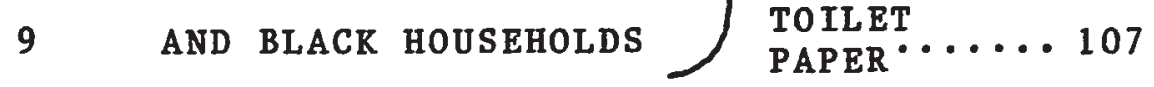

10 AVERAGE PRICES PAID BY BUYERS IN

ACCORDANCE WITH PURCHASE SIZE AND

INCOME..................... 110

11 THE EXTENT OF OUANTITY DISCOUNTS.... 113

12 LOW INCOME HOUSEHOLDS PAY MORE FOR

IDENTICAL BRANDS.............. 115 


\section{LIST OF FIGURES}

FIGURE

PAGE

1 THE RELATION OF STOCK-FLOW

AND HOUSEHOLD PRODUCTION

MODELS IN EXPLAINING HOUSEHOLD

INVENTORY BEHAVIOUR . . . . . . . . . 16

2 SCHEMATIC REPRESENTATION OF INVEN-

TORY HOLDINGS................. 20

3 HOUSEHOLD PRODUCTION OF INVENTORY

SERVICES .................... 56

4 THE HOUSEHOLD INVENTORY COST SUR-

FACE.......................... 69

5 PROJECTIONS OF COST SURFACE....... 70 .

6 ESTIMATING BIAS CAUSED BY THE

ASSUMPTION OF CONSTANT ANNUAL CON-

SUMPTION WHEN, IN FACT, CONSUMPTION

VARIES.................... 81

7 SKETCH ILLUSTRATING DIFFERENCES IN

SHOPPING BEHAVIOUR APPARENT FROM THE

DATA............................. 108

8 ESTIMATION OF QUANTITY DISCOUNTS... 112

9 DEMAND FOR CONSUMER CREDIT WITH A

CEILING ON THE AMOUNT AVAILABLE..... 122 
CHAPTER I

INTRODUCTION

The theory of consumption has been described by Lancaster as 'the most refined but least powerful branch' of economic theory. ${ }^{1}$ A notable deficiency, that prompted the present study, is its failure to recognize the inventory problem of the household, Except for some recent contributions, the vast literature on consumption remains virtually silent on the question of how the consumer is supposed to purchase the goods whose consumption flows he is optimizing. This is very surprising because for reasons of symmetry the explicit recognition of a producer's inventory decision shoulld have made the absence of one on the consumer's side all the more apparent.

It is true the stock holding problem of consumption has implicitly been recognized in the various explanations

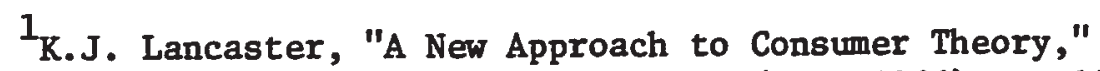
Journal of Political Economy, Vol. LXXIV (Feb. 1966), p. 155 
given for consumer durable purchases. ${ }^{2}$ However, no writer in this literature carries the logic to the point where durable holdings are viewed in a more general theoretical framework that accommodates the holdings of other types of goods as well. Such a generalization offers itself because the difference in the holding of durables and, for example, non-durables, is merely one of degree, and there is no justification for a separate treatment on the ground that non-durables exert a negligible influence as far as stock-adjustment expenditures are concerned. The cumulative effect of non-durable consumer inventory adjustments, by large numbers of buyers, may in effect yield very substantial variations in aggregate spending as exemplified by panic buying and consumer boycotts. It appears, therefore, that the case for relaxing the assumption, implicit in demand theory, that buying and consuming are two perfectly synchronized activities, is a rewarding one to pursue not only for logical reasons but also for practical ones because it moves consumer theory closer to reality. The problem then is one of explaining the mechanism by which the consumer provides for his consumption flows over time and this is the objective of the present study.

${ }^{2}$ See, for example, K. E. Boulding, "An Application of Population Analysis To the Automobile Population of the United States", Kyklos (1955), and J. N. Morgan, "Consumer Investment Expenditures", American Economic Review, XLVIII (1958). 


\section{LIST OF TABLES}

TABLE

Pa\&

1 COMPARISON OF THREE DIFFERENT

ESTIMATING PROCEDURES IN THE

ESTIMATION OF THE RELATIVE

RATE OF HOLDING COSTS OF LOW

AND HIGH INCOME HOUSEHOLDS ..........9

2 COMPARISON OF AVERAGE MEASURE OF

QUANTITY DISCOUNTS............. 9

3 ESTIMATES OF $c_{G}$, THE RELATIVE RATE

OF HOLDING COSTS FOR LOW AND HIGH

INCOME HOUSEHOLDS.............. 9

4 ESTIMATES OF $c_{G}$ FOR VARIOUS GOODS

BY BRANDS ...................... 9

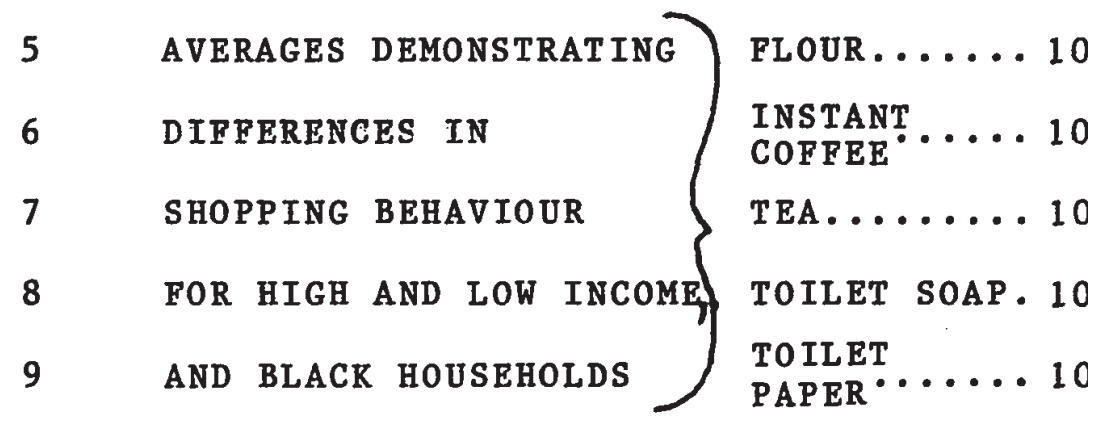

10 AVERAGE PRICES PAID BY BUYERS IN

ACCORDANCE WITH PURCHASE SIZE AND

INCOME .................... 11

11 THE EXTENT OF OUANTITY DISCOUNTS.... 11

12 LOW INCOME HOUSEHOLDS PAY MORE FOR

IDENTICAL BRANDS ................. 1] 


\section{LIST OF FIGURES}

FIGURE

PAGE

1 THE RELATION OF STOCK-FLOW

AND HOUSEHOLD PRODUCTION

MODELS IN EXPLAINING HOUSEHOLD

INVENTORY BEHAVIOUR........... 16

2 SCHEMATIC REPRESENTATION OF INVEN-

TORY HOLDINGS............... 20

3 HOUSEHOLD PRODUCTION OF INVENTORY

SERVICES.................. 56

4 THE HOUSEHOLD INVENTORY COST SUR-

FACE..................... 69

5 PROJECTIONS OF COST SURFACE....... 70

6 ESTIMATING BIAS CAUSED BY THE

ASSUMPTION OF CONSTANT ANNUAL CON-

SUMPTION WHEN, IN FACT, CONSUMPTION

VARIES.................... 81

7 SKETCH ILLUSTRATING DIFFERENCES IN

SHOPPING BEHAVIOUR APPARENT FROM THE

DATA....................... 108

8 ESTIMATION OF QUANTITY DISCOUNTS.... 112

9 DEMAND FOR CONSUMER CREDIT WITH A

CEILING ON THE AMOUNT AVAILABLE.... 122 
CHAPTER I

INTRODUCTION

The theory of consumption has been described by Lancaster as 'the most refined but least powerful branch' of economic theory. ${ }^{1}$ A notable deficiency, that prompted the present study, is its failure to recognize the inventory problem of the household, Except for some recent contributions, the vast literature on consumption remains virtually silent on the question of how the consumer is supposed to purchase the goods whose consumption flows he is optimizing. This is very surprising because for reasons of symmetry the explicit recognition of a producer's inventory decision shoulld have made the absence of one on the consumer's side all the more apparent.

It is true the stock holding problem of consumption has implicitly been recognized in the various explanations

$1_{\text {K.J. Lancaster, "A New Approach to Consumer Theory," }}$ Journal of Political Economy, Vol. LXXIV (Feb. 1966), p. 155 
given for consumer durable purchases. ${ }^{2}$ However, no writer in this Iiterature carries the logic to the point where durable holdings are viewed in a more general theoretical framework that accommodates the holdings of other types of goods as well. Such a generalization offers itself because the difference in the holding of durables and, for example, non-durables, is merely one of degree, and there is no justification for a separate treatment on the ground that non-durables exert a negligible influence as far as stock-adjustment expenditures are concerned. The cumulative effect of non-durable consumer inventory adjustments, by large numbers of buyers, may in effect yield very substantial variations in aggregate spending as exemplified by panic buying and consumer boycotts. It appears, therefore, that the case for relaxing the assumption, implicit in demand theory, that buying and consuming are two perfectly synchronized activities, is a rewarding one to pursue not only for logical reasons but also for practical ones because it moves consumer theory closer to reality. The problem then is one of explaining the mechanism by which the consumer provides for his consumption flows over time and this is the objective of the present study.

${ }^{2}$ See, for example, K. E. Boulding, "An Application of Population Analysis To the Automobile Population of the United States", Kyklos (1955), and J. N. Morgan, "Consumer Investment Expenditures", American Economic Review, XIVIII (1958). 
As the title of this paper indicates the study restricts itself to an investigation of grocery holdings. Although the model is initially specified to encompass non-durable goods in general, the interdependence of the inventory cost functions creates too many difficulties in the way of a general solution. For this reason, and in view of the avallability of data on grocery shopping, the model is developed to explore inventory behaviour toward this particular type of good only.

Before developing the arguments, it seems useful to reason through the sequence in which they will be presented.

\section{Logic of Presentation}

As a point of departure, the 1iterature is probed into for material relevant to the study and to stake out precisely the area for which research is needed. This is the aim of CHAPTER II which presents an outline of the groundwork laid in this field by stock-flow and household production analysts and, because of analytical similarities, tries to synthesize their contributions.

A basic framework for the model is drawn up in CHAPTER III by assembling a simple inventory model from existing inventory theory whose deficiencles are elaborated to bring out the challenges facing research. Recognizing the magnitude of the problems, however, the subsequent discussion in this chapter is designed to scale down the difficulties by simplifying assumptions, by definitions and by abandoning outright the problems arising out of a treatment of speculative and 
precautionary holdings.

Having settled basic issues, the specification of the model itself is next being tackled in CHAPTER IV. First is a treatment of procurement costs which must consider both the length of time required for shopping and the price which the shopper attaches to his time. In this context, recent contributions to the discussion on the opportunity cost of shopping must be reviewed and related to the specification. This discussion is followed by a treatment of holding costs and of quantity discounts. The introduction of quantity discounts gives rise to a varying unit price which has the consequence that the cost per period of a given level of real consumption depends on the lot size of the purchases. Thus, an additional inventory cost has come into existence which must be analyzed.

With the three inventory costs specified inventory equilibrium can now be determined in CHAPTER $V$ and its properties elaborated.

The objective of the empirical CHAPTER VI is to test the relatively accessible equilibrium condition that emerges for the grocery good. After discussing the data and the appropriateness of the test used, the results of the test are presented and interpreted.

The data contain interesting additional information on shopping habits which is reported in the APPENDIX to CHAPTER VI. Even though this evidence has no direct bearing on the main thesis, it is considered significant on account 
of its implications, especially in view of the fact that this information has not been compiled before.

The final CHAPTER VII is intended as an overview,

presenting conclusions and implications of the study and elaborating their significance. 


\section{BACKGROUND AND SYNTHESIS OF WRITINES ON HOUSEHOLD INVENTORY HOLDINGS}

Hicks observed some time ago that "it is only if the two match: if the acquisition of new consumption goods just matches the using up of old ones that we can say consumption equals spending". ${ }^{3}$ But having thus recognized consumer inventory holdings, Hicks immediately disposed of the problem again as a theoretical nicety. This view of the problem must have been widely shared by economists since inventory holdings are still absent from conventional consumption models.

In the last decade, there have been several innovations in demand theory which have a bearing on the development of a consumer inventory model. Chronologically enumerated they are found in the works of clower ${ }^{4}$,

${ }^{3}$ J.R. Hicks, Value and Capital, at the Clarendon Press, Oxford, 1939, p. 176.

${ }^{4}$ See for example, D.W. Bushaw and R.W. Clower, Introduction to Mathematical Economics, R.D. Irwin; Homewood, II1., 1957.

R.W. Clower, "Stock Flow," Encyclopedia of the Social Sciences, Collier Mackillan; New York, 1966. paper, 1969. , "On the Technology of Exchange", unpublished , "Is there an Optimal Money Supply?" Journal of Finance, Vol. XXV (June 1970) 
Becker $^{5}$ and Lancaster ${ }^{6}$ and in subsequent responses by others $^{7}$. The first task in proceeding with the study is, therefore, to link the present research endeavours to these writings and to try and synthesize the various contributions as far as they relate to the present investigation.

Before reviewing these major models, however, a recent dissertation by S. Sharir on "Consumer Buying Behaviour and the Structure of Retail Industries," 8 is of interest and should be discussed. It fully recognizes the consumer inventory problem within the wider context of an allocation of time analysis of the marketing activities of an economy. Goods have to be transferred from the point

${ }^{5}$ G.S. Becker, "A Theory of the Allocation of Time," Economic Journal, LXXV (Sept. 1965)

6ancaster, "New Approach"

7 See for example,

S. Sharir, Consumer Buying Behaviour and the Structure of Retail Industries, unpublished $\mathrm{PhD}$. dissertation, Columbia University, 1970.

R. Gronau, The Value of Time in Passanger Transportation: The Demand for Air Travel, National Bureau of Economic Research, occasional paper 109, New York, 1970.

J. Hadar, "A Note on Stock-Flow Models of Consumer Behaviour," Quarterly Journal of Economics, LXXIV (1965)

R.G. Lipsey and G. Rosenbluth, "A Contribution to the new Theory of Demand: A Rehabilitation of the Giffen Good," Canadian Journal of Economics, IV (May 1971)

J.D. Owen, The Price of Leisure, An Economic Analysis of the Demand for Leisure Time, McGill - Queens University Press, 1970.

$$
{ }^{8} \text { Sharir, op.cit. }
$$


of production to the point of consumption, a service which Sharir terms 'Commercial Distribution'. The service is in part provided by the retail industry and in part by the household. Its total value is measured by the sum of the time which households use to provide the service for themselves and by the amount of time households save because retailers provide the rest of the service.

Households periodically sacrifice time on shopping trips to collect commodities and then hold these goods in inventories. The model treats shopping time, and the resources used up in holding goods, as substitutable inputs and thus recognizes a basic property of household inventory behaviour. However, by analyzing the problems involved in allocating the total time required for 'Commercial Distribution' Sharir is confronted with many issues additional to those arising at the household level. His dissertation thus studies a different dimension of the problem than the present paper attempts to explore.

\section{Clower's Stock-Flow Analysis}

In 1959, Clower, in cooperation with Bushaw, developed a stock-flow theory of consumption ${ }^{9}$ and thereby provided the first general treatment of stocks of commodities held by consumers. The theory asserts

\footnotetext{
${ }^{9}$ Bushaw and Clower, op. cit.
} 
that the holding of any commodity facilitates consumption and must therefore yield utility to the consumer. Because utility is derived from consuming as well as holding the commodity, consumer behaviour must be analyzed in terms of his utility recelved from holding and consuming commodities.

The theory postulates the existence of an optimum inventory stock for each commodity consumed. Therefore, spending is for inventory accumulation as well as for consumption itself.

This theory of consumption lends rigor to demand theory by using the stock-flow analysis as an explanation of consumer spending behaviour. Aside from its theoretical appeal, the stock-flow model also suggests a wealth of realistic approaches to conventional theories as well as to economic phenomena not yet explained.

In a more recent paper 'On the Technology of exchange, 10 and in a refined follow-up version "Is there an Optimal Money Supply," 11 Clower specifies his consumption model in a manner very similar to Baumol's cash inventory model. ${ }^{12}$ Households want to hold comodity inventories because these holdings enable households to earn income in terms of the leisure gains available from fewer shopping trips. These income benefits will have to be compared to the cost of

${ }^{10}$ Clower, "On Technology"

${ }^{11}$ Clower, "Is there Optimal Supply?"

12 w.J. Baumol, "The Transaction Demand for Cash: An Inventory Theoretic Approach," Quarterly Journal of Economics, LXI (Nov. 1952) 
holding inventories consisting of interest, storage and deterioration costs. Optimum inventory holdings are attained when the marginal income gain is equal to the marginal cost of holding the goods.

In treating leisure time explicitly as a scarce resource, Clower is in line with other recent attempts to introduce the cost of time systematically into consumption analysis. ${ }^{13}$ While these papers stress the opportunity cost of time to the exclusion of the other opportunity costs of consumption, Clower's, Sharir's, and the present, model, recognize these costs in their entirety. Just as the procurement of market goods involves costs because it requires the shopper's time, the holding of these goods for consumption will incur a series of holding costs that must also be considered. With this symmetrical treatment of holding costs the stock-flow model contributes to the consistency of the debate on opportunity costs.

Clower's model is deficient on a different score, however. The introduction of an explicit time constraint raises a number of analytical questions which the

$$
{ }^{13} \text { See, for example, }
$$

J.G. Stigler, "The Economics of Information," Journal of Political Economy, LXIX (June, 1961)

J. Mincer, "Market Prices, Opportunity Costs and Income Effects", in Measurements in Economics, ed. Christ, et al.; Stanford University Press, Stanford, 1963. 
classical work-leisure analysis is silent on, and which Clower does not seem to realize either.

\section{Becker's Allocation of Time Analysis}

In the traditional theory, the consumer finds an optimal division of his total time between leisure and working time, and then the value of leisure is measured in terms of the earnings foregone by not working.

As Becker points out, ${ }^{14}$ the approach represents a simplification of a complex decision process that is usefül? for some problems, but too crude for others. The leisure activity to which the model relates is a case in point. Far from being a state of suspended animation, leisure time can be spent very productively by earning income in kind. For example, an office worker who exerts himself strenuously at home as handy man, may attain a level: of income whose money value exceeds that of his less practical colleague. The latter may earn the same money income from work but prefers to stay idle at home. Clearly, the market opportunity costs of their leisure times must be different at the margin. According to traditional theory, however, the value of time for the two office workers would have to be the same because it would equal their 1dentical wage rates.

It is not even meaningful to talk about a "leisure time", lumping together in it a heterogeneous collection

\footnotetext{
${ }^{14}$ Becker, op. cit.
} 
of activities which individuals perform off the job. Only a small, though varying, proportion of non-working time will be used for what is commonly meant by "leisure" or for non-productive consumption, as Becker prefers to call it. During most of the "leisure" time, the household engages in activities that differ greatly in their earnings productiveness. The household, therefore, faces the question of how to allocate time among a multitude of alternative uses to maximize welfare.

Becker solves the problem by treating the household as a production as well as a consumption unit. The household combines market goods $\mathrm{X}_{j i}$ and time inputs $\mathrm{T}_{j i}$, $i=1, \ldots m_{j}$, of varying productive capacities, to produce commodity $Z_{j}$. This commodity then enters the household's utility function as arguments, eg. $U=U\left(z_{1}, \ldots \ldots z_{j}\right)$, where the $z_{j}$ 's are consumption activities produced by $j$ production functions of the form $z_{j}=Z_{j}\left(x_{j 1}, x_{j 2} \ldots, x_{j m_{j}}\right.$, $\left.T_{j 1}, T_{j 2}, \ldots T_{j m_{j}}\right)$.

In the short run it is reasonable to argue that the amount of work supplied by the household, $T_{w}$, is given. With an exogenously determined amount of time available for consumption, $T_{c}$, household production is now subject to two constraints, the total time available for non-work activities

$$
\mathrm{T}_{\mathrm{c}}=\sum_{1}^{\mathrm{m}} \mathrm{T}_{i}
$$

and the budget constraint I, limiting the total expenditure on market inputs

$$
\sum_{1}^{m} P_{i} X_{i}=w T_{w}+V \equiv I
$$


where $w$ is the market wage rate and $V$ the amount of non-work money income, assumed unrelated to $T_{c}$.

The condition for maximum welfare of the household now requires that utility is maximized and that the optimizing set of activities is produced at maximum output combinations of all the $X$ and $T$ inputs.

This condition is derived formally by using the Lagrangian method. According to it a function $W$ is formed

$$
W=U\left(Z_{1}, \ldots Z_{j}\right)+\lambda\left(I-\Sigma P_{i} X_{i}\right)+\mu\left(T_{c}-\Sigma T_{i}\right)
$$

which is maximized by setting its partial derivatives equal

to zero:

$$
\begin{aligned}
& \frac{\partial W}{\partial \mathrm{X}_{i}}=\frac{\partial \mathrm{U}}{\partial \mathrm{Z}_{i}} \quad \frac{\partial \mathrm{Z}_{1}}{\partial \mathrm{X}_{i}}-\lambda \mathrm{P}_{i}=0 \\
& \frac{\partial \mathrm{W}}{\partial \mathrm{T}_{i}}=\frac{\partial U}{\partial \mathrm{Z}_{i}} \frac{\partial \mathrm{Z}_{i}}{\partial \mathrm{T}_{i}}-\dot{\mu}=0
\end{aligned}
$$

and

$$
\frac{\partial W}{\partial \lambda}=\frac{\partial W}{\partial \mu}=0
$$

The equilibrium condition is therefore

$$
\frac{\frac{\partial Z_{i}}{\partial T_{i}}}{R}=\frac{\frac{\partial Z_{i}}{\partial X_{i}}}{P_{i}}
$$

where $K$ is the imputed price of time which is the ratio of the marginal utilities of time and income, ie. $\frac{\mu}{\lambda}$. 
Lancaster's New Approach to Demand Theory ${ }^{15}$

The analytical relevance of Clower's Stock-Flow and Becker's Allocation of Time Analyses now are greatly enhanced by Lancaster's Household Production Model. It provides a generalized theoretical setting for analyzing household activities, including the particular problems singled out by Clower and Becker.

The approach was prompted by Lancaster's dissatisfaction with conventional consumption theory whose axioms he considers too weak to support any kind of substantive propositions. He sets out by distinguishing a commodity from its consumption characteristics. Commodities are considered agents for the production of consumption characteristics with the latter measurable on a cardinal scale. These characteristics enter the utility function as arguments and it is these measurable characteristics which give rise to utility. The market demand for a commodity is now a derived demand and as such will depend very closely on the other derived demands for commodities producing the same given characteristic. By the same token, this market demand will be largely independent of the goods which produce other unrelated characteristics. For this reason, Lancaster's demand functions contain more definite information than those derived from conventional ordinal utility functions. The reason is that in the latter type of function every good is a potential

${ }^{15}$ Lancaster, "New Approach". 
substitute of another.

Aside from its ability to accommodate the stock-flow mechanism of consumption, and to cope with time as a factor input, Lancaster's approach has another advantage for our purposes that will become apparent shortly. Consumption rates for individual goods, relative to which the inventory optima are determined, are very unstable because many goods are continually substituted for each other. Determining inventory holdings necessary to maintain a $\vec{g}$ iven consumption characteristic, may thus be a great deal more useful than finding the holdings for a much larger number of commodities which are consumed very irregularly.

The Relation of Stock-Flow and Household Production Models When Explaining Household Inventory Behaviour

The introduction to consumer analysis of a household production function has the consequence that consumption activities acquire technological properties. By viewing the maintanance of an Inventory as another service produced and consumed by the household these production relations can now be specified to describe the stock-flow mechanism of consumption.

Using, as an example, the simple inventory model that will be elaborated in CHAPTER III, the level of the inventory service can be measured in terms of the number of units $q$ consumed of a good annually which the inventory helps to maintain. Referring to panel (a) in FIGURE 1 total annual 


\section{FIGURE 1 .}

THE RELATION OF STOCK-FLOW AND HOUSEHOLD PRODUCTION MODELS IN EXPLAINING HOUSEHOLD INVENTORY BEHAVIOUR
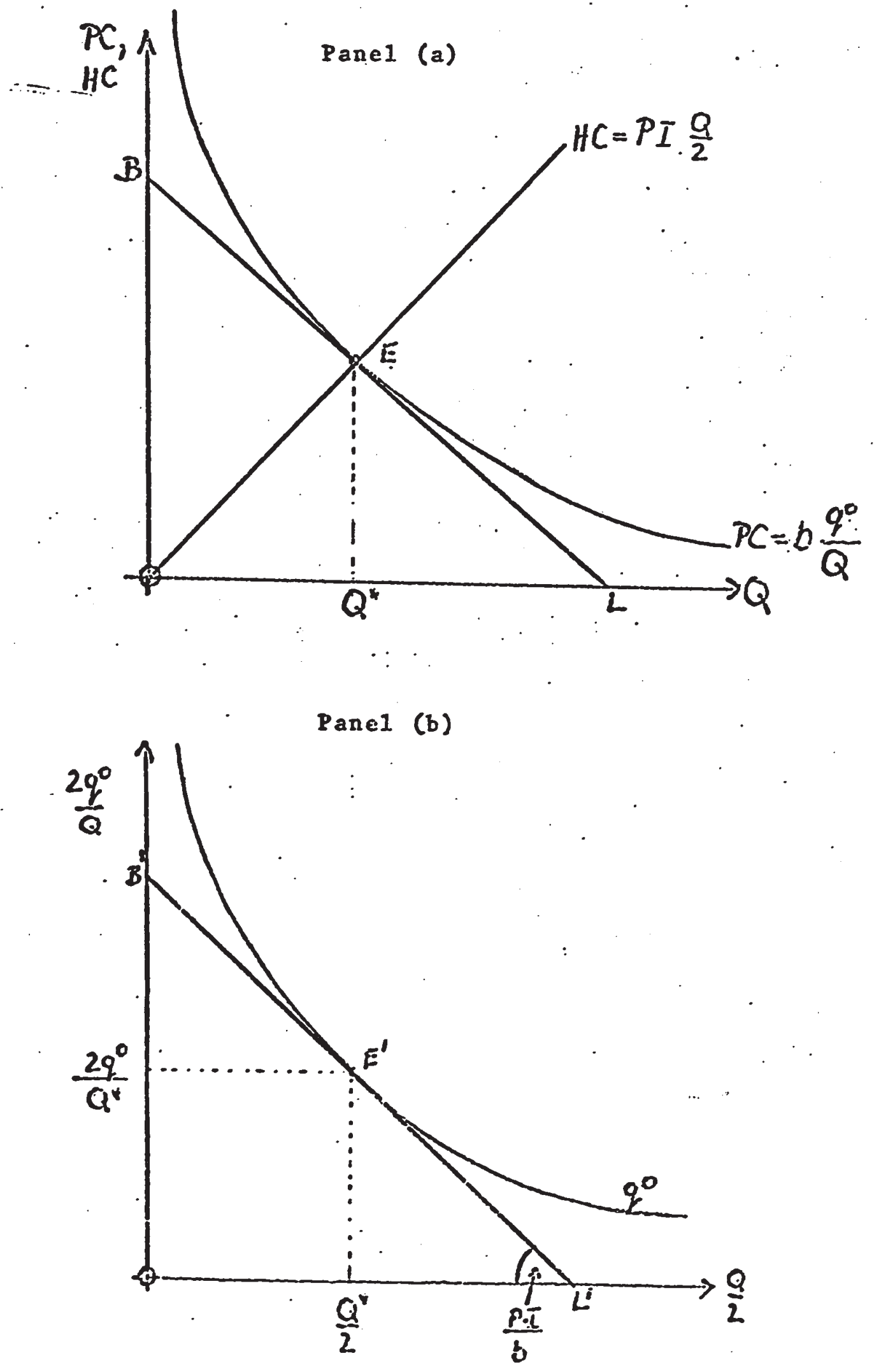
procurment costs in dollars are represented by the rectangular hyperbola

$$
P C=b \frac{g o}{Q}
$$

as for a given qo and a variable purchase size of $Q$ units the annual shopping frequency is $\frac{\text { go }}{Q}$, letting $b$ represent the total opportunity cost incurred per trip. Holding costs HC in dollars are assumed to increase linearly with the amount of average holdings $\frac{Q}{2}$, so that

$$
\mathrm{HC}=\mathrm{IP} \frac{\mathrm{Q}}{2}
$$

where $I$ is the total rate at which holding costs accrue annually, and $P$ the unit price of the good.

With this specification, inventory equilibrium is achieved where the curves $P: I \frac{Q}{2}$ and $b \frac{\text { go }}{Q}$ intersect. At the point of intersection, the absolute values of the slopes of the two curves are equal. Geometrically this follows because $b \frac{90}{Q}$ is a rectangular hyperbola and its slope is always equal to the negative of the slope of any ray from the origin intersecting the hyperbola. The slope of the tangent BL to curve PC at point $\mathrm{E}$ has, of course, also the same absolute value as the slope of either cost function. All this is. just a diagrammatic interpretation of the condition for total costs to have a minimum, obtained by differentiating the sum $b \frac{q 0}{Q}+P I \frac{Q}{2}$, namely of the condition

$$
\frac{P I}{2}=b \frac{G o}{Q^{2}}
$$

But since we can transcribe this condition as 


$$
\frac{P \cdot I}{b}=\frac{q o}{\frac{Q^{2}}{2}}
$$

We can interpret $\frac{Q^{*}}{2}$ and $\frac{q}{Q^{*}}$ as an optimal input combination on a household production isoquant with slope $\frac{\text { go }}{\frac{Q^{2}}{2}}$ for

the cost ratio $\frac{P \cdot I}{b}$, as indicated in panel (b) of FIGURE I. We merely have to view $\frac{\text { go }}{Q}$, the annual number of shopping trips, and $\frac{Q}{2}$, the average number of units of inventory of the good as substitutable inputs of the household production function.

It is interesting to note that now cash transactions behaviour is explained by household behaviour in general because Bamol's ${ }^{16}$ and Tobin's ${ }^{17}$ models can also be conceived as particular specifications of the household production function.

An additional conclusion that may be drawn from this link to well established inventory theory suggests that, at least the inventory aspect of, household production cannot be described by linear homogeneous production functions as Muth ${ }^{18}$, for example, has done with household production in general.

${ }^{16}$ Baumol, op. cit.

17 J. Tobin, "The Interest Elasticity of the Transactions Demand for Cash", Review of Economics and Statistics, XXXVIII (1956)

${ }^{18}$ R.F. Muth, "Household Production and Consumer Demand Functions," Econometrica, XXXIV (1966) 
CHAPTER III

EXISTING INVENTORY THEORY AND ITS LIMITATIONS IN EXPLAINING

INVENTORY BEHAVIOUR OF THE HOUSEHOLD

As a point of departure for developing a theory of household inventories, the simple model introduced earlier will now be elaborated. While this simple model anticipates, qualitatively, many of the later results, it will, at the same time, highlight the challenges facing research. Recognizing the magnitude of the problems this chapter will try to scale down the difficulties to pave the way for the specification of the model.

Basic Inventory Theory as Adapted to the Household

Assume the household consumes only one good. Consumption is at the rate of $q$ units per annum and is constant over time. To provide for this consumption flow, the consumer must obtain the good from the store in lot sizes of $Q$ units everytime, and at a procurment cost of $\$ b$ per trip. b reflects the expenditure of time, transportation expenses and the trouble associated with shopping.

Assuming, for simplicity, that the good is purchased whenever holdings reach the zero level, the average amount of the good held over time will be $\frac{Q}{2}$ units. FIGURE 2 represents, schematically, these variables. The consumption flow $q$ is the rate at which the initial stock $Q$ is depleted. 
FIGURE 2

SCHEMATIC REPRESENTATION OF TIME PATTERN OF INUENTORY HOLDINGS

$Q$

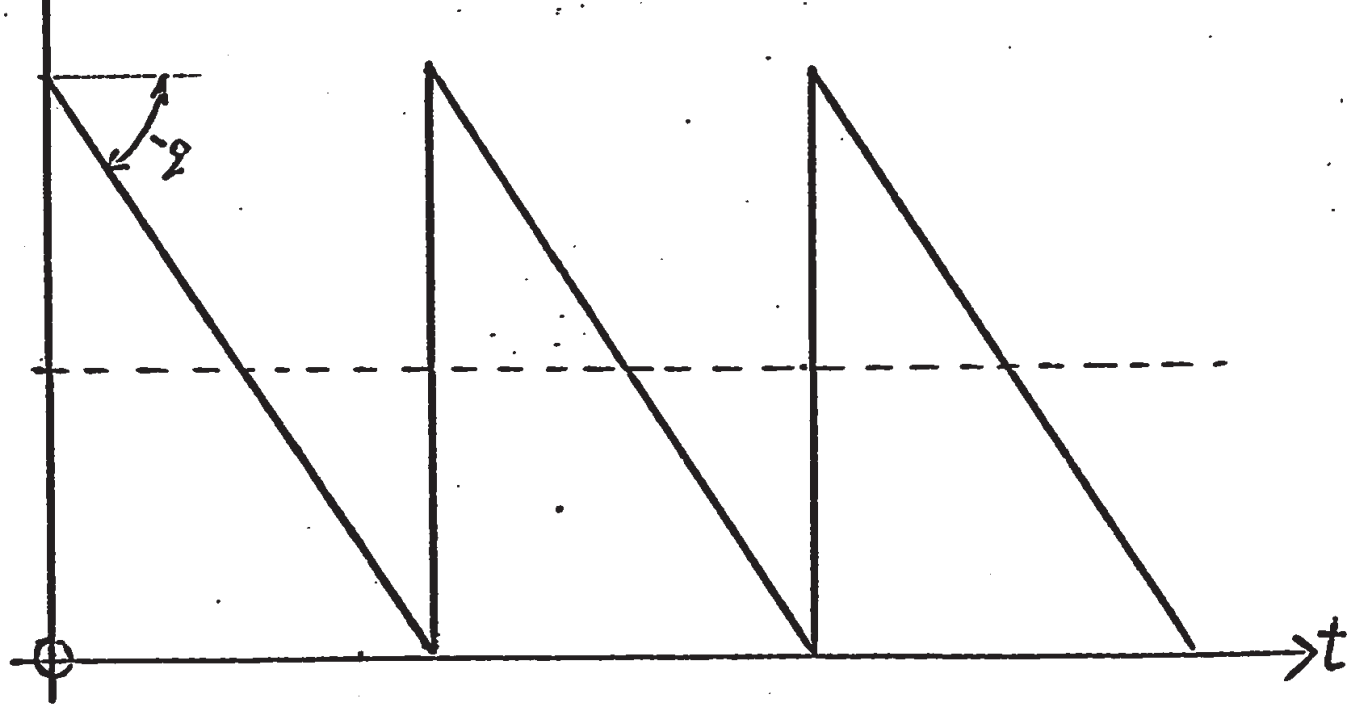


The downward sloping line thus depicts the instantaneous amount of the holdings at any point in time. Under the assumptions of the model, the pattern repeats itself continuously to yield an average inventory position of $\frac{Q}{2}$ units.

Costs associated with consumption purchases can be broken into two general classes: Holding Costs and Procurement Costs. By holding costs are meant all those costs that result from foregoing interest earnings, from storage and deterioration when holding the good for consumption. Let these costs accrue at rate $I$ per annum and let the unit price of the good be p, then nominal holding costs per year.will be $\$ I_{p} \frac{Q}{2}$.

Average holdings of $\frac{Q}{2}$ units will have to be maintained by a flow of purchases over time. Since $\frac{g}{Q}$ is the frequency of purchases per year, annual procurment costs will be $\$ b \frac{q}{Q}$.

The total cost \$TC per annum of obtaining, and holding, the good for consumption is thus

$$
\text { (3.1) } \quad \$ T C=p q+b \frac{q}{Q}+I p \frac{Q}{2}
$$

The condition for a minimum is that $\frac{d(T C)}{d Q}=0$, ie. that

$$
\text { (3.2) } \quad \mathrm{b}_{\mathrm{Q}}^{\mathrm{g}}=\frac{\mathrm{PI}}{\mathrm{Q}}
$$

The optimum purchase quantity $Q^{*}$ is therefore

$$
\text { (3.3) } \quad Q^{*}=\sqrt{\frac{2 b q}{P I}}
$$

provided that

$$
\frac{d^{2}(T C)}{d Q^{2}}>0 \text { and } Q *>0
$$


and the optimum inventory position is given by $\frac{Q}{2} \cdot$ Because of the assumption of a constant purchase price, the value of annual consumption pq is also constant. The cost of consumption thus has no effect on inventory costs and can be eliminated from the model.

The model has several important properties which will be discussed next.

(1) Minimum total inventory costs per annum, $T C *$, are found by substituting equation (3.3) into (3.1). This yields

$$
\begin{aligned}
\mathrm{TC} & =\frac{\mathrm{bq}}{\sqrt{\frac{2 \mathrm{bq}}{\mathrm{Ip}}}}+\frac{\mathrm{pI}}{2} \sqrt{\frac{2 \mathrm{bq}}{\mathrm{Ip}}} \text {, or } \\
\text { (3.4) } \quad \mathrm{TC} * & =\sqrt{2 \mathrm{bIpq}}
\end{aligned}
$$

(2) Inventory costs accrue at a rate of $2 I$ per year.

The minimum total inventory cost of equation (3.4) must be related to the average value of the resources that are tied up in inventories during the year. Under the assumptions of model these resources value $\frac{\$ p Q}{2}$ on the average.

Thus, average total costs, as a fraction of the resources committed to inventories is

$$
\frac{T C^{*}}{p^{*}}=\frac{\sqrt[2]{2 b I p q}}{\frac{p}{2} / \frac{2 b q}{I p}}=2 I
$$

This last result also follows directly from the property of the total cost function which is at a minimum when procurement and holding costs are equal. The rational household thus tends to charge identical amounts for procuring 
and holding the good. 19

(3) The force that moves inventories toward an

optimum level of holding is the tendency by households to to minimize costs.

The magnitude of the equilibrating forces may be studied by examining the relation of inventory costs $\mathrm{TC}$, when holdings are non-optimal, and the level of total costs, $\mathrm{TC} *$, when they are. Computing this relation we obtain

$$
\begin{aligned}
\frac{\mathrm{TC}}{\mathrm{TC} *} & =\frac{q^{b}}{\sqrt{2 b I p q}}+\frac{\mathrm{pIQ}}{\sqrt{2 b I \overline{p q}}} \\
& =\frac{1}{2} \frac{Q^{*}}{Q}+\frac{Q}{Q^{*}}
\end{aligned}
$$

By way of example, suppose inventory holdings differ from their optimum by a factor of 2 in either direction, relation (3.6) now indicates that costs increase by $25 \%$. This is because for an optimum we have $\frac{Q}{Q^{*}}=1$, if $Q$ is $\frac{1}{2}$ of $Q^{*}$, then $\frac{Q}{Q *}=.5$ and $\frac{T C}{T C *}=.5(2+.5)=1.25$. Similarly, if $Q=2 Q^{*}, \frac{T C}{T C *}=1.25$, also.

Equation (3.6) shows, therefore, that the total inventory cost curve is fairly flat in the region of the minimum.

${ }^{19}$ This property is of course a consequence of the particular specification of total inventory costs which assumed that the procurement cost per trip is independent of $Q$. While the admission, that $b$ may be proportionate to $Q$ will not alter the optimum condition in 3.3, the properties would be affected. 
Limitations of the Simple Model and Outline of the Problems to be Analyzed

The reality of consumer inventory behaviour is, of course, a great deal more complicated than the simple model presented above would make out. The next problem is therefore to deal with the more complex real world.

Inventory theory, as developed for the firm, provides the basic framework and direction for a Consumer Inventory Theory. But many of the problems encountered presently arise only in the context of the household. They require a new set of analytical tools to be shaped that engender solutions distinctly different from those avallable in existing inventory models.

The problems consist essentially of two different types of issues, basic ones and those relating to the specification of the model itself. They will next be enumerated under these headings and thereafter be discussed in that order. The first set of problems will be dealt with in the present chapter, while the remaining ones will be left to CHAPTER IV.

\section{Basic Issues of Household Inventory Behaviour}

The next immediate problem is that of clarifying what is meant by a shopping trip, and the goods purchased on it because of the great diversity in shopping habits, and of the goods shopped for.

Another quite obvious issue is that, contrary to our 
assumption of a single constant rate of consumption, the consumer will buy many goods and use them at very unstable rates over short periods of time. But these rates cannot be stabilized by aggregation because of the non-linearity of the procurement costs and because of the interdependence of these costs as a result of the fact that many goods are obtained on the same shopping trip.

The deterministic inventory model, exemplified by the simple approach presented above, explains only those holdings that serve to maintain a given consumption flow, at a fixed unit price, over time. Generally, however, consumption rates, and prices, will not be constant, and just as there are reasons other than the transactions, motive for holding cash, the household may add to its inventories as a precaution against unforeseen contingencies, and to earn income by speculating against continual price changes. In addition to these basic issues the model has to tackle a number of specific problems.

\section{Specification Problems}

To specify the procurment cost function it is necessary to determine not only the amount of time required for a shopping trip but also the price that is attached to the shopper's time.

Next, is the cost of holding non-durable goods which will accrue at differing rates depending on the degree of perishability of the item held. 
In addition to the interdependence of the cost functions mentioned earlier, a special problem arises out of the existence of quantity discounts. For if it pays to purchase more of a good then is needed for the consumption during the period between consecutive shopping trips, the optimum purchase frequency will differ for the various goods and will also generally be less than the shopping frequency. Further, nominal and real quantities will no longer be proportion ate.

The latter set of problems will be the concern of the next chapter after the more basic issues have been cleared out of the way in the remainder of the present chapter.

\section{Definitions}

The most immediate problem is that of clarifying what is meant by a shopping trip, and the goods purchased on it because of the great diversity in shopping habits, and of the goods shopped for.

To obtain operational concepts for our model we must create the necessary uniformity by abstraction. For this purpose, a hypothetical average trip will be defined which is best rationalized in terms of an example. Consider the case of alternating shopping trips of which one is to the nearest corner variety store, the other an extensive visit to a distant supermarket where the consumer buys the rest of the many items not available in the variety store. The definition now must provide for a theoretical average trip, which, if undertaken twice, procures the same inventory 
as the two very different trips of the example, the diversity of which cannot be handled analytically.

When using the term SHOPPING TRIP subsequently, therefore, it will be taken to mean A ROUTINE EXPEDITION WHICH EVERYTIME TAKES THE BUYER TO A SEQUENCE OF MARKET LOCATIONS SUCH THAT THE PROCURMENT COST OF ANY GIVEN ITEM IS THE SAME WHENEVER HE ACQUIRES A GIVEN AMOUNT OF THAT ITEM. 20

This definition is quite crucial for our pur poses for two reasons. First1y, adding to it the assumption of consumer rationality, and that the procurment cost incurred during a shopping trip exceeds the waiting cost $t_{\mathbf{j}}$ accuiling during the period between two consecutive trips, for holding any one good, will lead to the following corollary: THE FREQUENCY OF SHOPPING MUST ALWAYS EQUAL THE PURCHASE FREQUENCY OF THE GOOD THAT IS BOUGHT MOST OFTEN. For ingtance, let the buyer run: out of, say, toothpaste between consecutive trips and a special trip is made to secure only that one item. This trip is an irrational act, because had he picked up this Item on the previous trip, he would have incurred the smaller holding cost for the item only, and not the higher procurement cost of the trip.

Secondly, the theoretical trip also implicitly defines

${ }^{20}$ Note that it is not required that each good is actually purchased on the shopping trip, nor does the definition permit that shopping is more troublesome on, say, a Friday night, than on Tuesday afternoon. 
the type of goods to be considered. These goods will be termed NON-DURABLES and comprise all those items commonly purchased on the ROUTINE shöpping trip defined above.

Like all abstractions this definition, too, is a crude oversimplification of actual conditions. But it is a legitimate one as it eliminates a host of difficulties that are not only unmanageable, but also unnecessary at this stage of the enquiry.

The Instability of Consumption in a Deterministic Inventory Mode1

The model will be a deterministic one and its validity will depend on how stable the consumption flows are. Clearly, the shorter the time period, the greater will be the instability of the consumption rates. If goods could be aggregated to large commodity categories, we could contain within these groups a large measure of the variations caused by erratic shifts in tastes, and by relative price changes. Unfortunately, the aggregation of goods for the purpose of finding optimum holdings for these aggregates is impossible because inventory costs accrue non-1inearly to the level of holdings of each item.

Lancaster's new approach to consumption ${ }^{21}$ lends itself to a different kind of aggregation of goods in terms of the contribution these goods make to a given consumption characteristic. Once the problem of measuring these characteristics has been overcome, the inventory of a group

\footnotetext{
${ }^{21}$ Lancaster, "New Approach."
} 
of goods measured in units of a single want characteristic could be optimized relative to a given flow over time of this characteristic.

Before Lancaster's approach is operational to be useful for our purposes, variations in $q$ for a given household can be reduced by applying the model to goods only for which the scope of substitution is small eg. soap, toilet paper and flour. Variations beyond that will be treated as simply increasing our random disturbances the control of which will be discussed at greater length in CHAPTER VI.

To the extent we are successful in handling the nonconstant consumption rates with a deterministic model, we will still merely explain those holdings that serve to maintain consumption flows over time. But just as there are reasons other than the transactions motive for holding cash, the household may add to its inventories as a precaution against unforeseen contingencies, and to earn income by speculating against price changes. These types of holdings will be discussed next.

\section{Precautionary and Speculative Holdings - A Disclaimer}

As soon as there is uncertainty in the buyer's mind about consumption needs in the period between purchases he will desire to add to his holdings for precautionary reasons. The assumption of a constant rate of consumption would now have to be replaced by one that this rate follows a frequency distribution. A distribution that lends itself to describing random disturbances in flow variables is the 
Poisson distribution. Assuming that the average number of times a good is consumed between shopping trips is $N$, and that the value at each such instance of consumption is a constant $\$ a$, the standard deviation of the distribution is $\sqrt{N}$, or $\sqrt{\frac{Q}{a}}$. For simplicity, $Q$ and $q$ represent purchase size and annual consumption, respectively in dollar terms for the time being as precautionary and speculative holdings are discussed.

Suppose the household wants to ensure that the probability of running out of the good is no more than .34 (the probability that the number of times the good is consumed exceeds $N+\sqrt{N}$ ), then that household should hold a precautionary stock of $\$ \sqrt{\mathrm{aQ}}$ (ie. $\sqrt{\mathrm{N}} \mathrm{a}$ ) In addition to the stock needed to meet the average consumption of $Q$.

The difficulty now arises with the determination of optimum holdings under consideration of the holding costs added by the safety allowance $\sqrt{\mathrm{aQ}}$.

Total costs are now

$$
T C=b \frac{Q}{Q}+I \frac{Q}{2}+I \sqrt{a Q}
$$

The condition for a minimum is

$$
\frac{d T C}{d Q}=-b \frac{q}{Q^{2}}+\frac{I}{2}+\frac{I}{2} \sqrt{\frac{a}{Q}}=0
$$

but it does not yield a simple solution for Q.

Alternative probabilistic models have been devised to explain inventory behaviour under uncertainty, that circumvent the problem. But such a treatment requires new assumptions and will lead to a much more complicated, while not necessarily 
to a more powerful, model.

For these reasons Baumol chose to ignore precautionary cash holdings after having first recognized their importance. The present study follows his example but with the comforting optimism that precautionary holdings are less significant for non-durables than for cash. Shopping trips occur regularly, and are closely spaced out over time so that unforeseen consumption needs may be relatively small. Since a treatment of these holdings would be a large scale undertaking in its own right the reassuring expectation that these holdings are small is used to ignore them.

The explicit treatment of speculative inventories is analytically not any less troublesome than that of precautionary holdings. Nor are speculative purchases likely to be insignificant enough to be ignored. It is easy to see that the consumer has both opportunity and incentive to speculate against price changes.

The grocery market offers an almost unceasing flow of specials and bargains. They permit the alert buyer to accumulate his inventories at a lower price than the nonspeculating buyer.

It would be an overly ambitious venture, in the present context, to probe into the extent, and the ramifications, of consumer speculation. The very magnitude of the task puts it outside the scope of the present study.

It will be established, however, that the failure to recognize speculative holdings in the model does not impair 
the validity of its structure. The reason is that as long as price expectations are neutral in the sense discussed shortly, speculative grocery purchases tend to leave the mean inventory holdings, predicted by the model, unaltered. Their sole effect will be on the efficiency in estimating the mode1, as they increase the variation in the data.

Following T. M. Whitin's ${ }^{22}$ speculative model for the firm, the argument can be taken beyond this unconvincing intuitive statement. The subsequent demonstration modifies his model to adapt it to the household decision.

Assume unitary demand elasticity for a consumption good to leave the value of consumption unchanged as prices change. Expressing the buyer's price expectations by the expected proportionate change $\bar{\varepsilon}$ in the price $p$,

$$
\varepsilon= \pm \frac{d p}{p}
$$

the household continues to buy $\$ Q^{*}$ in the absence of any such expectations. But once the price of the good is expected to change, a value of $\$ Q_{S}$ of the good is bought just prior to the expected increase. If the buyer expects the price to decline, he' will purchase $Q_{8}$ prior to the decline and $Q^{*}$ after expectations have materialized. In any case, speculation will be rewarded by an income gain of $\varepsilon\left(Q_{s}-Q^{*}\right)$. But since speculative holdings affect procurment and holding costs, they too must enter the calculation.

22 T.M. Whitin, The Theory of Inventory Management, Princeton University Press, Princeton, New Jersey, 1957. 
The costs of shopping change by the difference between procurment costs before and after the expected price change, ie. by $\left(\frac{\mathrm{q}}{\mathrm{Q}^{*}}-\frac{\mathrm{q}}{\mathrm{Q}_{\mathrm{s}}}\right) \mathrm{b}$, but the length of time for which the change persists is given by $\frac{Q_{s}}{q}$. This ratio indicates the fraction of the consumption period during which the speculative purchase $Q_{G}$ has an effect. The change in procurment costs per period, resulting from speculation, is therefore

$$
\left(\frac{q}{Q^{*}}-\frac{q}{Q_{s}}\right) b \frac{Q_{s}}{q}
$$

Similarly, for holding costs it is true that they will change by the difference of $\frac{Q_{s}}{2} I$ and $\frac{Q^{*}}{2} I$ times the fraction of the period for which the change is effective, ie. by $\frac{I}{2}\left(Q_{s}-Q^{*}\right) \frac{Q_{s}}{q}$.

The net gain from speculation per period is the sum G of these quantities with appropriate signs: $G=\varepsilon\left(Q_{s}-Q^{*}\right)+\left(\frac{q}{Q^{*}}-\frac{q}{Q_{s}}\right) b_{q}^{Q_{s}}-\frac{I}{2}\left(Q_{s}-Q^{*}\right) \frac{Q_{s}}{q}$. The signs of the expression are easily verified by first assuming that the price is expected to rise. Then for a negative $\varepsilon$ the signs of the terms will reverse.

The optimum speculative purchase quantity $Q^{*}{ }_{s}$ is, of course, that quantity which maximizes function G. The necessary condition for a maximum is that $\frac{\mathrm{dG}}{\mathrm{dQ}}=0$.

Differentiating we obtain

$$
\frac{\mathrm{dG}}{\mathrm{dQ}_{\mathrm{S}}}=\varepsilon+\frac{\mathrm{b}}{\mathrm{Q}^{*}}-\frac{\mathrm{IQ}}{\mathrm{q}}+\frac{\mathrm{IQ}}{2 \mathrm{q}}
$$


or

$$
Q_{S}^{*}=\varepsilon^{q}+\frac{2 b q+I Q *^{2}}{2 I Q^{*}}
$$

From equation (3.2) we know that

$$
I Q *^{2}=2 b q \text { (since presently we replace } P Q \text { by } \$ Q \text { ) }
$$

so that

$$
Q_{s}^{*}=\varepsilon \frac{q}{I}+Q^{*}
$$

The relation indicates that the extent of speculative buying, or under-buying, depends on the magnitude, and direction, of expectations. If expectations are neutral over time, then

$$
\begin{aligned}
& E\left(Q_{s}\right)=Q * \text { because } \\
& E\left(\varepsilon \frac{g}{I}\right)=0
\end{aligned}
$$

and the variance due to speculation will be $\left(\varepsilon \frac{q}{I}\right)^{2}$.

It follows from this demonstration that the consumer Inventory model need not deny speculation as long as

$$
E(\varepsilon)=0
$$

It is pointed out again, however, that the problems of speculative holdings must be taken a great deal further before their full effects on the model can be reliably assessed. 
CHAPTER IV

SPECIFICATION OF THE HOUSEHOLD INVENTORY MODEL

Having examined the basic issues in CHAPTER III, the specification of the model itself can now be attempted. Procurment costs will be dealt with first by looking at both the length of time required for shopping, and the price which the shopper attaches to his time. The discussion is followed by a treatment of holding costs and of quantity discount. The introduction of quantity discounts gives rise to a varying unit price which has the consequence that the cost per period of a given level of real consumption depends on the lot size of the purchases. This additional inventory cost must therefore by analyzed. Since the specification of quantity discounts is crucial for the model, the APPENDIX will present the refined analysis on which this specification is based as well as a discussion of the allocative function of quantity discounts.

\section{Inventory Procurment Costs}

The predominant cost of acquiring goods in the supermarket is the shopper's time. To estimate the total cost 
of shopping time per period, it is necessary to determine

(1) the amount of time needed for shopping per period and

(2) the price the shopper attaches to his/or her time.

The Amount of Time Needed for Shopping

The size of the time inputs per period per unit of inventory depends on the number of shopping trips per period and on the duration of each trip.

The duration of the individual trip will depend on the location of the store relative to the shopper's residence, how much is purchased, and how long the buyer spends searching over product displays.

\section{Location}

A factor which, at first glance, appears systematically related to the length of time of a shopping trip, is the distance covered during that trip. On closer scrutiny, however, this dependency is not easily substantiated. In fact, there are two strong cases for arguing that the procurment time of a given number of goods within a city does not vary much for different buyers of varying locations.

In the first place, it appears that no substantial number of shoppers will be required to travel substantial milage in excess of the average for all residents. The reason is that prospective revenues would induce firms to locate more conveniently if a large number of shoppers 
could be attracted by diminishing their travelling milage.

A look at the existing pattern of store and supermarket locations bears out this point. If plotted as a distribution, this pattern would yield a fairly densely clustered distribution of distances travelled by shoppers. This distribution would be even denser if stores differed only by their geographic locations in the views of the buyers. -

Secondiy, assuming that buyers travel by private automobile, variations in pure travelling time, due to changes in distances travelled within cities, is likely to be small in comparison to the time required for parking and walking from and to the parking site.

The predominant component of a shopping trip, it is therefore argued, is a fixed overhead expenditure of time denoted by $b_{s}$.

Selection, Handling and Carrying of Goods

Once arrived at the store location, the shopping activity itself will require time. Goods have to be selected, handled and checked through the cashier. They have to be handled again when loading and unloading the car. The time needed will be directly related to the number, and the quantities of the goods purchased on the trip. Assuming that the time spent on these activities increases proportionately to the quantity $Q_{i}$ in units ${ }^{23}$, of good

${ }^{23}$ The rationale for defining variables in real terms will become clear subsequently when elaborating quantity discounts. 
$i$ purchased and that $n$ goods are purchased on every trip, the total time spent on each shopping trip, apart from that used for transportation, is $\sum_{\mathbf{n}} \mathrm{b}_{i} \mathrm{Q}_{\mathbf{i}}$ where $\mathrm{b}_{i}$ reflects the average amount of time needed to acquire one unit of good $i$ while at the store.

Summary Specification of Procurment Time

Total procurment time spent per shopping trip is therefore

$$
\text { (4.1) } \quad b_{\mathbf{s}}+\sum_{\mathfrak{n}} \mathfrak{b}_{1} Q_{1}
$$

and total procurment time per annum is

$$
\text { (4.2) } \quad f_{s} b_{s}+\sum_{n} f_{i} b_{i} Q_{i}
$$

where $f_{s}$ is the annual shopping frequency and $f_{i}$ the annual purchase frequency of good 1 which may or may not differ from $f_{s}$. Denoting the number of units consumed annually of good $i$ by $q_{i}$, the purchase frequencies are

$$
f_{i}=\frac{q_{i}}{Q_{i}} \quad(i=1, \ldots \ldots, n)
$$

and annual procurment time is also given by

$$
\text { (4.3) } \quad f_{s} b_{s}+\sum b_{i} q_{i} \text {. }
$$

To obtain total annual shopping procurment costs, the value of shopping time must next be discussed.

The Price of Shopping Time

The value of time will, in accordance with Becker's Theory of the Allocation of $\operatorname{Time}^{24}$ depend on the income,

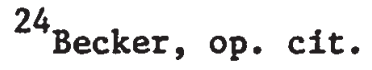


the wage rate and the amount of consumption time avallable to the household. It will further depend on which household member performs the shopping activity.

On this latter determinant, Becker's theory allocates the various activities to household members so as to maximize productivity, consistent with the principles of division of labour. Housewives clearly have a comparative advantage in shopping since it is an activity complementary to the preparation of meals. It is therefore predominantly the value of the housewife's time that is relevant and this value of time per unit will be denoted by $k$.

In anticipation of an important property of the model that precludes $K$ from having any effect on the optimum holdings of groceries, the details of a specification of $K$ need not concern us here, as it is grocery inventory equilibrium at which the subsequent investigations are directed.

The Benefits of Shopping Around in Search of Lower Prices Stigler ${ }^{25}$ has pointed out that, due to imperfect knowledge in the market place, the variations in prices asked for a product of given quality form a frequency distribution. Whatever the precise shape of that distribution of prices, the greater the search, the lower the expected

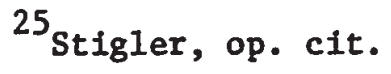


price to the buyer. But this search is subject to diminishing returns, as measured by the expected reduction in the minimum asking price.

The expected gain $G$ from an additional unit of search $\mathrm{n}$ is the differential $\frac{\mathrm{dG}}{\mathrm{dn}}$ and is equal to the quantity $Q$ purchased times the reduction in prices $P$ resulting from an additional unit of search, that is

$$
\frac{\mathrm{d} G}{\mathrm{dn}}=Q\left|\frac{\mathrm{dP}}{\mathrm{dn}}\right| .
$$

Jacob Mincer ${ }^{26}$ takes this argument further and argues that the rational shopper would carry the search to the point only where the marginal gain is equal to the marginal cost of the search. The cost of the search is the time and trouble associated with search which Mincer makes explicit. The higher the buyer's wage, the greater the cost of search due to the higher price of time. But with higher income, the quantity $Q$ purchased is likely to be greater too, thus increasing the prospective benefits from search, also.

Shopping around thus yields a net gain in the form of stochastically lower prices paid and this gain increases with the increase in the purchase quantity $Q$. This can, however, not be applied to food shopping without qualifications. The gains from shopping around for each food purchase are

$$
{ }^{26} \text { Mincer, op. cit. }
$$


probably not large enough to compensate the buyer fully for the time and trouble spent lugging around bulky merchandise.

The present study, while recognizing the StiglerMincer effect as reducing the shopping cost per dollar purchased, specified earlier as $b_{1} Q_{i}$, will nevertheless assume that it is incapable of offsetting that cost entirely.

\section{The Cost of Holding Goods}

Holding costs accrue because of deterioration, storage and foregone interest which inventory holdings incur. The three costs, expressed in terms of annual rates, will be denoted by $d, s$ and $i$, respectively.

To determine an optimal level of inventories it is desirable to relate these costs to the level of holdings. But it is not at all obvious what the functional relation should be.

Let the holdings be zero at the time of shopping. The number of units of inventory holdings immediately after the trip will be $Q$ units, and the amount of holdings at any time $t$, thereafter, will be (Q-qt) units.

If the instantaneous rate of incurring carrying charges is given by the constant $I$, the holding costs incurred during the time interval dt are $I(Q-q t) d t$ units and the inventory holding costs for the entire cycle of 
length $T=\frac{Q}{q}$, in years, is the sum

$$
\begin{aligned}
I \delta_{0}^{T}(Q-q t) d t & =I\left(Q T-\frac{q T^{2}}{2}\right) \\
& =I T \frac{Q}{2},
\end{aligned}
$$

using $T=\frac{Q}{q}$. There are $\frac{1}{T}$ cycles per annum, so that the annual holding cost is $I \frac{Q}{2}$ units, with I the total annual cost rate. I is the sum of the relative contributions made by the three types of holdings costs. This sum will of course differ for the various goods as the relative contribution of each rate will differ between goods. In symbols, the total cost rate $I_{G}$ for the grocery good $G$, to be defined below, is the sum

$$
\text { (4.4) } \quad I_{G}=d_{G}+s_{G}+i
$$

where $d_{G}$ and $s_{G}$ are the rates at which deterioration and storage costs, respectively, accrue annually for the grocery good $G$ and where $i$ is the rate of interest which the household applies to its inventory holdings.

Under the assumption of constant instantaneous rates of carrying costs, holding costs are thus seen to be proportional to the simple average holdings per cycle. But while this relation is extremely convenient, and absolutely crucial for the validity of most of the firm's inventory theory, it is untenable for a wide range of the highly perishable goods which the consumer holds.

\section{Deterioration Costs}

Note that I indicates holding costs as a proportion of 
inventory holdings at any point in time, and this ratio was assumed to be constant. Clearly, in the case of deterioration costs for some goods this ratio cannot possibly be constant at all times as it will depend on the length of time for which the inventory is held. We assume therefore, more realistically, that, at least part of, total annual deterforation costs increase at a rate e, which itself increases linearly with the length of time for which a perishable item is being kept. Specifically, let

$$
e=6 h t,
$$

where $h / 6$ is the constant of proportionality.

Holding costs per cycle, due to deterioration, are now

$$
6 h_{0} f_{t} t(Q-q t) d t=6 h T^{2}\left(\frac{Q}{2}-\frac{q T}{3}\right) \text {. }
$$

Since there are $1 / T$ cycles per year, and recalling that $\mathrm{T}=\mathrm{Q} / \mathrm{q}$, annual deterioration costs, accruing non-1inearly, are

$$
\text { (4.5) } \quad h \frac{Q^{2}}{q}
$$

Deterioration costs are thus seen to accrue to perishable inventories at a rate that increases with the level of holdings but that, as would be expected, decreases with rising consumption. The size of factor $h_{s}$ will of course depend on the degree of perishability of a good and may well be 0 for non-perishable goods.

A more intuitive argument would arrive at (4.5) by simply pointing out that total holding costs accrue to average 
holdings $\frac{Q}{2}$, at a rate that increases proportionately

with the time $\frac{Q}{q}$ for which the good is held.

\section{Storage Costs}

Storage costs will be specified as accruing porportionately to the level of holdings. It is clear that they will be difficult to disentangle, statistically, from the other linear holding costs. Fortunately, in the present context, the need for separating these costs does not arise and the problem can be ignored.

\section{Interest Costs of Inventory Holdings}

The household incurs an additional cost by holding resources in the form of inventories rather than in the form of interest bearing assets.

What is the rate at which these costs accrue? It is the rate of return which the individual could have earned, had he not withdrawn these holdings from his savings, or which he could have saved for himself, had he not borrowed.

To avoid biassing the estimation of the model it is necessary to ascertain at the outset that these interest charges per dollar of inventory investment are not correlated with any other variable of the model.

It is easily shown, however, that the cost of borrowing, from oneself, or the bank, is likely to vary with income. Assuming that the effective market rate of interest is $r$, 
it can be seen that, at a high level of income, the loss from foregoing earnings will equal the market rate of interest. But as inventory investment is financed out of dissaving, the cost of each dollar will consist of $r$ plus some risk component $\rho$ which lenders must charge to receive a net rate of return equal to the market rate $r$.

The risk of default $\rho$ increases with the size of borrowings $\mathrm{B}_{0}$ relative to income $\mathrm{y}$, or

$$
\rho=c \frac{B_{0}}{1 y}
$$

where $c_{1}$ is a known parameter (subject to estimation by bank actuaries). But from the Engel relation saving, or borrowing, is known to be

$$
S=-c_{2}+c_{3} y=-B_{0}
$$

where $c_{2}$ and $c_{3}$ again are known, so that $\rho$ can be expressed by the relation,

$$
\text { (4.6) } \begin{aligned}
q & =c_{1}\left(\frac{c_{2}}{y}-c_{3}\right) \text { and } \\
i & =r+\rho .
\end{aligned}
$$

On the other hand, it can also be argued that high income households will be able to realize higher rates of earnings on their investment than low income investors, because of their investment experience and superior information. The average cost of information per dollar of investment decreases and thus high income investors can be expected to buy more of it. A positive relation between 
$i$ and $y$ thus seems to be called for on these grounds. There are two counteracting influences on $I$ now flowing from $y$ and it is impossible to determine on a-priori grounds whether the net effect on $i$ will be positive or negative, nor what functional form it will take.

For convenience, it will be assumed that the function can be approximated by a linear relation of the form (4.7) $i=g_{1}+g_{2} y$, where the empirical test must determine sign and significance of $g_{1}$ and $g_{2}$.

\section{Cash Transactions Costs}

The maintenance of an inventory also incurs cash transactions costs which have not been considered yet. On every shopping trip, the buyer will surrender cash balances which, in turn, must be obtained at a procurment cost and which have to be maintained at the cost of foregoing interest earnings on the average balances held. The transactions costs will, however, be minimal in relation to inventory costs if the timing of income receipts and of shopping trips closely coincides and if cheques drawn on interest bearing savings accounts are used for transactions. Considering the great difficulties involved in separating the rate of foregone earnings on cash and inventory holdings, these costs will not be specified separately, but rather be subsumed in 1 . 


\section{Definition of Perishable and Grocery Good and}

\section{Specification of their Holding Costs.}

The holding costs specified will have different relative effects on total holding costs for the various goods. In fact, goods could be ranked in order of perishability to form a continuum of changing relative holding costs, in accordance with the size of factor $h$. Since the existence of a non-linear holding cost term is crucial for the determination of inventory equilibrium, it will be necessary to divide all nondurable goods into those that either have, and those that do not have, this term. Inevitably, such a grouping will raise difficulties of classification but they can of course be avolded by selecting only those goods which unambiguously fall in either group, when turning to the data.

We thus define perishables as all those goods whose holding costs, $\mathrm{HC}_{\mathrm{p}}$, can be represented by the sum

$$
\text { (4.8) } \quad \mathrm{HC}_{\mathrm{p}}=\mathrm{I}_{\mathrm{p}} \frac{\mathrm{Q}_{\mathrm{p}}}{2}+\mathrm{h} \frac{\mathrm{Q}_{\mathrm{p}}^{2}}{\mathrm{q}_{\mathrm{p}}}
$$

while grocery goods are all those goods whose holding costs, $\mathrm{HC}_{\mathrm{G}}$ are sufficiently closely approximated by

$$
\text { (4.9) } \quad \mathrm{HC}_{\mathrm{G}}=\mathrm{I}_{\mathrm{G}} \frac{Q_{G}}{2} \text {. }
$$

The subscripts $p$ and $G$ will from now on be used to denote all quantities according as they relate to 
perishables and groceries respectively. Since the many goods qualifying for either category cannot be aggregated for our analysis, to avoid vector notations, the simplifying assumption is made that we live in a 2 good world in which one is the perishable, the other the grocery good.

\section{Quantity Discounts}

A naive specification now would continue with the implicit assumption of the simple inventory model that there are no incentives to purchase any more of a good than is needed for the consumption during the period between consecutive shopping trips. But it is clear that failure to recognize the existence of quantity discounts would result in removing a major determinant of inventory holdings from the model. In fact, it can be argued, that non-durables can never be sold, except at a unit price that varies inversely with the quantity of each sale. The rigorous demonstration of this proposition is involved and will be presented in the APPENDIX TO CHAPTER IV. The intuitive reasoning however is straightforward enough. The market price of a good consists of the cost of producing a unit of the good plus a variety of marketing and packaging expenses which increase little, or not at all, as the size of an individual retail sale increases. For most non-durable goods, there is a relatively large fixed overhead per package sold, which, from the point of 
view of cost minimization, may be recovered either through a fixed charge on each unit sold, or by charging a flat amount in addition to the production costs of the units contained in the package. This latter pricing policy is tantamount to offering quantity discounts. It amounts to applying marginal cost pricing not only to the contents, but also to the overhead expenses involved in retailing a given quantity of the good. For that reason, the offering of quantity discounts is the most efficient pricing policy, and the only one the market can sustain. Consistent with this argument let there now be a fixed charge of \$B per package for wrapping materials, handling and processing, and assume that $\$ B$ is unrelated to the number of units contained in the package. If the unit price of the contents is denoted by $\pi$, the total value of an item of size $Q$ is $\pi Q+B$ so that the unit price $P_{d}$ under consideration of quantity discounts is

$$
P_{d}=\pi+\frac{B}{Q} \text {. }
$$

With this varying unit price now, real units and their money values are no longer proportional as tacitly assumed in the simple model. Another consequence is that the value of consumption, previously constant, will now enter into the determination of inventory equilibrium, and as the consumer is interested in optimizing his real holdings relative to his real consumption, the entire model must be 
cast in real terms. For this reason the variables $q_{G}$, $Q_{G}, q_{p}$ and $Q_{p}$ were defined earlier to denote real quantities.

Summary Specification of Inventory Costs

The variable unit prices of the perishable and the grocery good will be denoted by

$$
\text { (4.10) } \quad P_{d p}=\pi_{p}+\frac{B_{p}}{Q_{p}}
$$

and

$$
\text { (4.11) } \quad P_{d G}=\pi_{G}+\frac{B_{G}}{Q_{G}} \text {, }
$$

respectively, so that the household now attempts to minimize the total money costs involved in maintaining the real consumption of both goods. These costs are represented by the sum of total procurment costs, PC, total holding costs $\mathrm{HC}$, and annual consumption costs $\mathrm{CC}$, each of which is now specifled in turn.

The specification of PC follows from (4.3) by simply multiplying the total amount of time spent shopping during the year by the value of the shopper's time $K$ and, recalling that only a perishable and a grocery good are treated the subscripts $p$ and $G$ take the place of the 1 :

$$
\text { (4.12) } \quad P C=K b_{s} f_{s}+K b_{p} q_{p}+K b_{G} q_{G} .
$$

Holding costs are the sum of the money values of the holding costs of the perishable good (4.8), and of the grocery good (4.9) e.g., 


$$
\text { (4.13) } \quad \mathrm{HC}=\frac{\mathrm{hQ}^{2} \mathrm{p}}{\mathrm{q}_{\mathrm{p}}} \mathrm{P}_{\mathrm{dp}}+\mathrm{I}_{\mathrm{p}} \frac{Q_{\mathrm{p}}}{2} \mathrm{P}_{\mathrm{dp}}+\mathrm{I}_{\mathrm{G}} \frac{Q_{\mathrm{G}}}{2} \mathrm{P}_{\mathrm{dG}}
$$

and, finally, the money value of total annual consumption costs for the two goods is given by the sum

$$
\text { (4.14) } \quad C C=q_{p} P_{d p}+q_{G} P_{d G} \cdot
$$

Variations in Inventory Costs Attributable to

Differences in the Subjective Evaluation of

These Costs by Shoppers

It may be argued that the inventory costs thus specified contain a strong subjective element in that households may evaluate them differently. For example, shoppers may disagree precisely on how fresh a chicken should be when consumed.

The defense on this score will be that individual cost evaluations may deviate from the costs projected by the functions but that they will do so randomly so as to leave their expected values equal to zero. In this manner, the variations will simply find their way into the disturbance terms of the model.

Before proceeding to the determination of an inventory optimum, the theory underlying our specification of quantity discounts will be refined and elaborated in the APPENDIX TO CHAPTER IV. 
APPENDIX TO CHAPTER IV

A THEORY OF QUANTITY DISCOUNTS

We define quantity discounts as reductions in unit prices when the purchase sizes of a given good increase. As such they have little theoretical recognition in economics. Mostly they are ignored by assuming fixed unit prices. The present hypothesis is that in many cases the assumption of fixed unit prices amounts to generalizing an exception rather than the rule. Whenever a good requires a fixed outlay per sale, it can never be available except at a unit price that varies inversely with the quantity purchased. This relationship is very strong. It is borne out especially in the case of groceries where a relatively large overhead per package makes quantity discounts an unfailing condition of retail sales.

The Unvarying Market Price with Fixed Packaging Costs Suppose a firm supplies a good in packages of 
various sizes $Q_{i}, i=1,2, \ldots \ldots n$ as demanded by $n$ households. Let there be a fixed charge of $\$ B$ per package for wrapping materfals, handling and processing and assume that $B$ is unrelated to the number of units contained in the package.

Now consider what happens if the good is to be sold at a constant unit price, denoted by P. The firm has to determine an average unit charge that it must add to all other unit costs, denoted by $\pi$, so that it can recover its total outlays incurred by supplying packages.

If the firm were to serve consumer $i$ only, the unit cost of packaging charged on every unit he bought would be $\frac{B}{Q_{1}}$. But since there are $n$ consumers the cost of packaging per unit of contents is $\frac{n B}{\sum_{i=1}^{n} Q_{i}}$. This amount

will have to be charged on every unit of the good sold, regardless of the size of each retail sale.

The $Q_{i}$ and $n$ are given exogenously to the firm so that the average unit cost of packaging can be written as $k B$, where $k=\frac{n}{\sum_{i=1}^{n} Q_{i}}$. The fixed total unit price is then given by the sum

$$
\mathbf{P}=\pi+\mathrm{kB},
$$

where $\pi$ reflects all other unit costs incurred during production, distribution and inventory operation. 
Using a Becker-type household production model it can now be shown that this constant unit price is not only welfare inefficient but also that the competitive market will not sustain it.

The Household Production Approach to Household Behaviour

An expanding literature on household production formalizes the common sense notion that market goods have to be processed and improved before they can be consumed.

The analytical tools of production apply fully to the productive activities of the household. In the present case, a packaged good, or more specifically a package and its contents, can be treated much like any other pair of complementary market inputs that aid in the production of consumable output. Jointly they render a service which may be called 'Convenient Availability For Home Consumption', CAHC, for short. The package affords convenience in handling, while the contents facilitates the consumption flow of the good itself.

Like most other inputs package and contents are also substitutable in production. Under the present assumptions a package may contain any number of units $Q$ 
of the good. The fraction of a package that is acquired with each unit of $Q$ is $\frac{1}{Q}$. This makes the locus of all feasible combinations of good and package a rectangular hyperbola.

To define the appropriate isoquant it is necessary to associate the relevant input dimensions with the annual rate of production of this inventory service. The services rendered by the contents of the package are expressed in terms of the average holdings of the good. In keeping with Baumol's and other simple inventory models these holdings are assumed to be $\frac{Q}{2}$ units. The annual rate of use of packaging is $\frac{q}{Q}$ units because it is the fraction $\frac{1}{Q}$ of a package needed per unit of the contents times $q$ the total number of units of contents facilitated in consumption during the time interval.

Figure 1 shows the household production isoquants of the total annual services jointly rendered by packaging and contents.

The Welfare Economics of Quantity Discounts

Continuing for the time being with the assumption of a fixed unit price $P$, firms must recover their packaging expenses by a constant unit charge. This means that regardless of the proportion in which a household actually uses packaging and contents, that household will be charged for a fixed fraction $k$ of a unit of packaging 
FIGURE 3

HOUSEHOLD PRODUCTION OF INVENTORY SERVICES

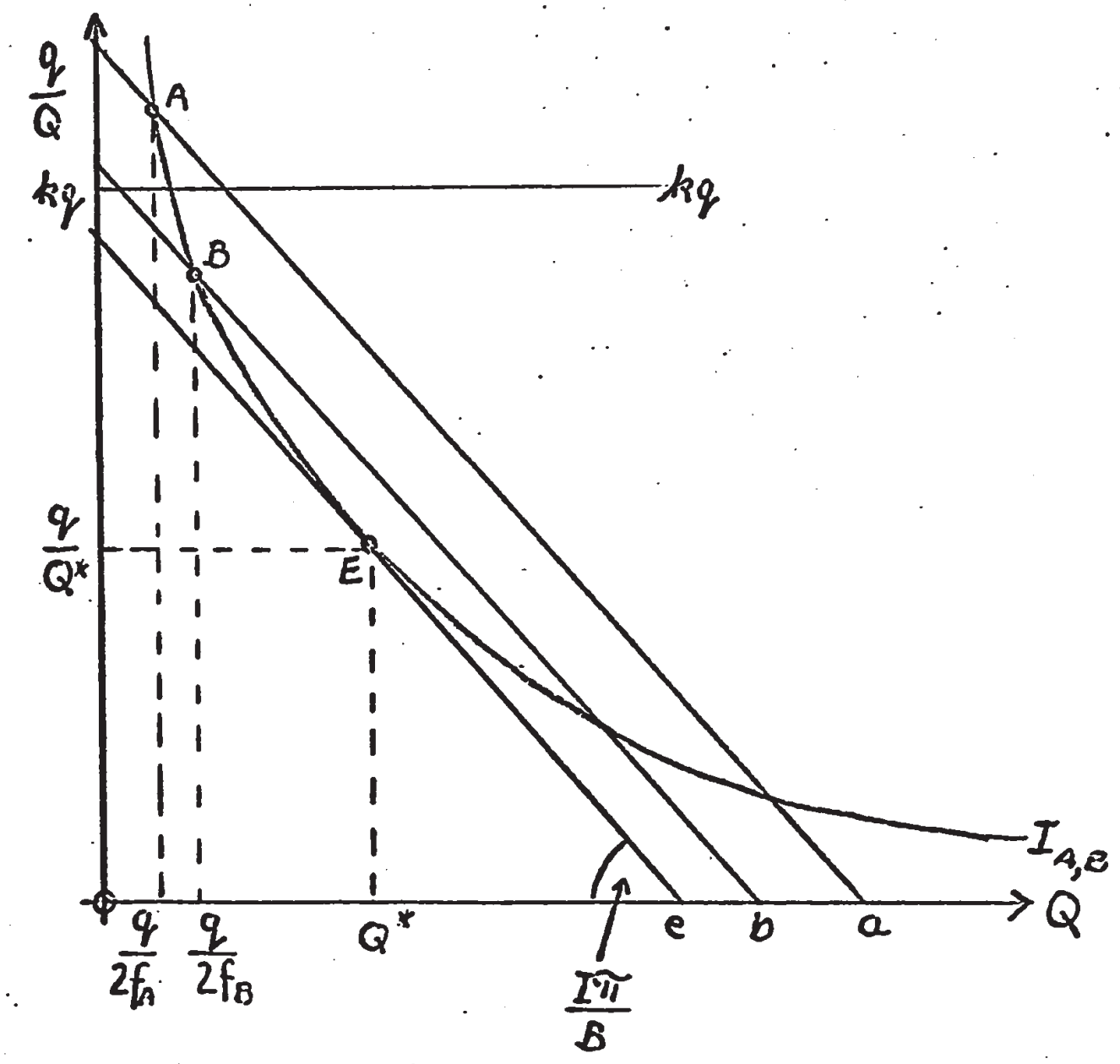


per unit of contents purchased. Annually therefore the household is charged for $\mathrm{kq}$ units of packaging. It is shown in Figure 1 by the horizontal line of the same height and the households which may be using more or less of packaging are indicated by $A$ and $B$ as explained next.

The rational household attempts to minimize total annual costs of providing for a given level of consumptton. Annual costs of packaging and consumption are $(\pi+B k) q$ and invariant. But average holdings $\frac{Q}{2}$ can be minimized, and so can the opportunity costs of holding, if no more is bought on each shopping trip than is needed for the consumption between consecutive trips. This minimum purchase quantity is given by $\frac{q}{f}$, where $f$ is the annual shopping frequency.

Assume for simplicity now there are only two households both consuming the good at the same rate $q$, while going shopping at different frequencies $f_{A}$ and $f_{B}, f_{A}>f_{B}$. Purchase quantities are now given by $\frac{q}{f_{A}}$ and $\frac{q}{f_{B}}$, average holdings by $\frac{g}{2 f_{A}}$ and $\frac{g}{2 f_{B}}$ and the packaging inputs by the ordinates to points $A$ and $B$ on the isoquant $I_{A, B}$ respectively.

It is clear that while both pay exactly the same packaging costs $\mathrm{qkB}$, household $\mathrm{A}$ uses more of these resources than B, and is in effect subsidized by B. But the total costs of producing these services for both are 
greater than they would be if the inputs were priced Independently so that both households could choose their own optimum combinations.

This efficient usage of both inputs is in effect realized when the firm adds its overhead of $\$ B$ to the value of the contents $Q$ sold in every package. This new pricing policy is tantamount to offering quantity discounts because with a fixed charge per package, unit price $P_{d}$ declines as the quantity $Q$ purchased increases, i.e.

$$
P_{d}=\frac{B}{Q}+\pi \text {. }
$$

To prove that quantity discounts lead to increased efficiency, let the household's outlay constraint be $C_{0}$ and the money value of the opportunity costs of holding one unit of the good be $I$, where $I$ is the fraction of a unit of the good which it annually costs to hold that unit and" the price of that unit. The household now maximizes output of the inventory service under constraint $C_{0}$ by maximizing function $\mathrm{V}$,

$$
V=\frac{q}{Q} Q+\lambda\left(C_{0}-\frac{q}{Q} B-Q I \pi\right),
$$

where $\lambda$ is the Lagranglan multiplier. It yields the condition

$$
\frac{q_{2}}{Q^{2}}=\frac{I \pi}{B^{\prime}} \text {, }
$$

which, in geometric terms, is of course the point of tangency at $\mathrm{E}$. 
For a comparison of total annual costs at $\mathrm{E}$ and those at $A$ and $B$ the units on the horizontal axis are used as numeraire. Under a fixed unit price the total value of the resources used up by all households is $a+b$. This amount constitutes the true cost of the inefficiently used resources. The households pay for them by contributing to the suboptimal average cost of packaging and by incurring higher than necessary opportunity costs on inventory holdings.

After the introduction of quantity discounts households use resources in the amount of $2 \mathrm{e}$ only to produce the same level of services. The magnitude of this efficiency gainwill vary with the relative price of packaging and with differing levels of consumption. But it will always be positive for a positive relative price. The introduction of quantity discounts is thus seen to result in a welfare gain.

\section{Market Forces and Quantity Discounts}

From the point of view of cost minimization firms are Indifferent whether to offer quantity discounts or not as they recover their packaging expenses by either pricing policy. Households, on the other hand, stand to gain the full amount of resource savings and can be expected to express their preferences in the market accordingly. 
To be sure, not every household will benefit from quantity discounts. Under a fixed unit price the socially inefficient small buyer may enjoy a subsidy of such a size that his annual production costs would increase under quantity discounts despite the efficiency gains that accrue to him privately. Losing from quantity discounts he would take his business to firms selling at fixed unit prices.

But it is also true that those households gaining from quantity discounts are attracted to firms offering them. And the result of this switching is a net increase in demand to the latter firms because the volume of total purchases benefiting from quantity discounts exceeds that which stands to lose.

The firms refusing to offer quantity discounts now face a double dilemma. They experience a net loss of demand. And also, by attracting exclusively buyers who lose from quantity discounts, these firms must now raise their average charge $\mathrm{kB}$ to recover packaging expenses. But this very increase in $\mathrm{kB}$ will make quantity discounts beneficial to the largest buyers of their remaining clientele, thus losing additional sales and requiring $\mathrm{kB}$ to be ralsed even further.

Clearly, this increasing drain of sales and profits will precipitate action by the firms still selling at 
fixed unit prices. Assuming costs were previously minimized by all firms and that their products are homogeneous in every respect, the only option available to them is to offer quantity discounts as well, or to go out of business.

\section{Evidence}

It is to be noted that these results hold for perfect and Imperfect competition. They hinge merely on the ratio $\frac{B}{\pi}$, the value of the packaging costs relative to the unit cost of the contents.

This ratio will be particularly large for groceries because of elaborate packaging in comparison to the relatively inexpensive contents. The high cost of grocery packaging is explained by the fact that this type of packaging is not entirely functional. It is also used as an instrument of deliberate sales policy aimed at psychological product differentiation. In accordance with the model this relativeiy high promotional cost per package must lead to pervasive quantity discounts in the grocery market. This prediction is fully borne out in the real world.

Quantity discounts cannot be ignored on the ground that they perform a petty allocative function in a social perspective. Garbage disposal has become a mounting 
problem precisely because of the volume of useless containers and fancy trimmings associated with modern consumption. Quantity discounts allocate most efficiently among consumers the vast resources society decides to channel into packaging. Judged in terms of the wastes that would be created if flxed unit prices prevented this allocation, quantity discounts are seen to perform a substantial allocative role in our society. 
CHAPTER V

THE DETERMINATION OF HOUSEHOLD INVENTORY HOLDINGS

The specification of the various cost functions is now complete and optimum holdings of the perishable and grocery good can now be determined.

\section{The Model}

Just as the rational household attempts to minimize the money expenditure on two goods to attain a given level of satisfaction, that household will also tend to minimize the total money costs, TC, involved in maintaining the consumption flows of these goods over time, Since TC is the sum of procurment costs, PC, holding costs, $\mathrm{HC}$, and consumption costs, CC, specified by relations (4.12), (4.13) and (4.14), respectively,

$\mathrm{TC}=\mathrm{Kb}_{\mathrm{s}} \mathrm{f}_{\mathrm{s}}+\mathrm{Kb}_{\mathrm{P}} \mathrm{q}_{\mathrm{p}}+\mathrm{Kb}_{G} \mathrm{q}_{G}+\frac{h \mathrm{q}_{\mathrm{p}}^{2}}{\mathrm{q}_{\mathrm{p}}} \mathrm{P}_{\mathrm{dp}}+$

$I_{p} \frac{Q_{P}}{2} P_{d p}+I_{G} \frac{Q_{G}}{2} P_{d G}+q_{G} P_{d p}+q_{G} P_{d G}$.

Combining and expanding terms leads to the total cost 
relation, TC:

$$
\begin{aligned}
& \text { (5.1) } \quad \mathrm{TC}=\mathrm{Kb}_{\mathrm{s}} \mathrm{f}_{\mathrm{s}}+\mathrm{Kb}_{\mathrm{p}} \mathrm{q}_{\mathrm{p}}+\mathrm{Kb}_{\mathrm{G}} \mathrm{q}_{\mathrm{G}}+\frac{\mathrm{hQ}_{\mathrm{p}}^{2}}{\mathrm{q}_{\mathrm{p}}} \pi_{\mathrm{p}}+ \\
& \frac{h Q_{p}}{q_{P}} B_{p}+I_{p} \frac{Q_{p}}{2} \pi_{p}+I_{p} \frac{B_{p}}{2}+\frac{I_{G} Q_{G} \pi_{G}}{2}+ \\
& \frac{I_{G B G}}{2}+q_{p} \pi_{p}+\frac{q_{p}}{Q_{p}} B_{p}+q_{G} \pi_{G}+\frac{q_{G}}{Q_{G}} B_{G} .
\end{aligned}
$$

The aim is to find the optimal shopping frequency, as well as the optimum purchase frequencies for the grocery and perishable good that minimize TC. These frequencies are of course, not the same as with the availability of quantity discounts, the household has inducements to purchase an amount greater than that needed for consumption between consecutive shopping trips. The induced increase in the purchase size, and, consequently, the induced decrease in the purchase frequency will vary for the grocery and perishable good if there are differential quantity discounts for the two.

Let the purchase frequency of the grocery good be denoted by $f_{G}$ and that of perishables by $f_{p}$, and let the two differ by a multiple $M$ such that

$$
\text { (5.2) } \quad \mathrm{f}_{G} \mathrm{M}=\mathrm{f}_{\mathrm{p}} \text {, }
$$

with the restriction that

$M>$ I.

While this restriction can be rationalized as a narrowing down of the economic range over which the optimum will occur for the subsequent cost function, the intuitive 
rationale that perishables are bought more often than groceries will here be relied upon as justification.

An earlier corollary has established that the shopping frequency can never exceed the purchase frequency of the good that is bought most often. Accordingly,

(5.3) $\quad \mathrm{f}_{\mathrm{s}}=\mathrm{f}_{\mathrm{p}}$,

and therefore,

$$
\text { (5.4) } \quad f_{G}=\frac{f_{S}}{M} \text {. }
$$

With this background it is now possible to redefine TC as a function of two variables $f_{s}$ and $M$, only. Using ralations

$$
\text { (5.5) } \quad Q_{p}=\frac{q_{p}}{f_{s}}
$$

and

$$
\text { (5.6) } \quad Q_{G}=\frac{q_{G}}{f_{s}} M
$$

we get:

$$
\begin{aligned}
& \text { (5.7) } \quad \mathrm{TC}=\mathrm{Kb}_{\mathrm{s}} \mathrm{f}_{\mathrm{s}}+\mathrm{Kb}_{\mathrm{p}} \mathrm{q}_{\mathrm{p}}+\mathrm{Kb}_{\mathrm{G}} \mathrm{q}_{\mathrm{G}}+\frac{\mathrm{hq_{ \textrm {p } }}}{\mathrm{f}_{\mathrm{s}}^{2}} \pi_{\mathrm{p}}+\frac{\mathrm{hB}_{\mathrm{p}}}{\mathrm{f}_{\mathrm{s}}}+ \\
& \frac{I_{p} q_{p} \pi_{p}}{2 f_{s}}+\frac{I_{p} B_{p}}{2}+\frac{I_{G} q_{G} M_{G}}{2 f_{s}}+\frac{I_{G} B_{G}}{2}+q_{p} \pi_{p}+ \\
& f_{s} B_{p}+q_{G} \pi_{G}+\frac{f_{s} B_{G}}{M} \text {. }
\end{aligned}
$$

This cost function is minimized by applying the first

necessary conditions for a minimum, e.g.

$$
\frac{\partial T C}{\partial f_{s}}=0 \text { and } \frac{\partial T C}{\partial M}=0
$$


and solving the resulting equations, simultaneously, for $\mathrm{f}_{\mathrm{s}}$ and $\mathrm{M}$ :

$$
\begin{aligned}
\frac{\partial T C}{\partial f_{s}}= & k_{s}-\frac{\left.2 h q_{p}\right]_{p}}{f_{s}^{3}}-\frac{{ }^{B}{ }_{p}}{f_{s}^{2}}-\frac{I_{p} q_{p} \pi_{p}}{2 f_{s}^{2}} \\
& -\frac{I_{G} q_{G}{ }^{M} \pi_{G}}{2 f_{s}^{2}}+B_{p}+\frac{{ }_{G}^{B}}{M}=0 \\
\frac{\partial T C}{\partial M}= & \frac{I_{G} q_{G}{ }^{\pi} G}{2 f_{s}}-\frac{f_{s}{ }^{B} G}{M^{2}}=0
\end{aligned}
$$

Solving condition (5.9) first for $M$ we get

$$
M^{*}= \pm \sqrt{\frac{{ }^{2 B} G}{I_{G}{ }^{q} G^{\pi} G}}
$$

Substituting (5.10) for $M$ in condition (5.8) eliminates all grocery inventory parameters from that condition, so that it reduces to

$$
K b_{s}-\frac{2 h q_{p}{ }^{\pi} p}{f_{s}^{3}}-\frac{1}{f_{s}^{2}}\left(h B_{p}+\frac{I_{p} q_{p}{ }^{\pi} p}{2}\right)+B_{p}=0
$$

from which the optimum shopping frequency would now have to be computed.

This sole dependence of the optimum shopping frequency on the inventory parameters of the perishable good has the consequence that it dichotomizes inventory equilibrium for the perishable and grocery good. Substituting (5.6) into the optimum for $M$ given by (5.10) leads to the simple independent inventory optimum for the grocery good 
(5.12) $\quad Q_{G}^{*}=\sqrt{\frac{2{ }_{G} q_{G}}{I_{G} \pi_{G}}}$

with all the analytical conveniences which this optimum affords. (5.12) closely resembles the optimum of the simple model given by (3.3), except that the value of $B$ is now deflated by the unit price of the contents, $\pi_{G}$, so that the procurment cost now has the interpretation of being the number of units of the contents that must be sacrificed for the marketing overhead expenses with each purchase.

Thus, despite the fact that we have set out from a much more generous set of assumptions, the qualitative characteristics of the simple inventory model have remained invariant.

\section{Results and Properties of the Model}

The results of the model now require elaboration especially in the light of the corollary and the assumption from which they appear to follow. To recall this corollary

$$
\text { (5.3) } \quad f_{p}=f_{s}
$$

and the assumption

$$
\text { (5.2) } \quad f_{G} M=f_{p} \quad M>1
$$

it is important to realize that the model determines the optimum value of this multiple, 1.e. $M^{*}$, and that the model demonstrates that

$$
\underset{P}{f *}=\mathrm{f}_{S}^{*}
$$


where the stars indicate optimum values of these frequencies. These results are not at all obvious, nor anticipated by (5.2) and (5.3). On the contrary, the fact that a grocery good is bought along with the perishable good would lead us :0 expect that the optimum shopping frequency involving both goods exceeds the purchase frequency of the perishable good as the grocery good adds to holding costs which can be reduced by going shopping more often.

The properties of the general model are illustrated by way of FIGURE 4 . The total inventory cost function is shown as a surface in $f_{s}-T C-M$ space whose vertical and horizontal locations depend on $\mathrm{B}_{G}$ only; the other parameters being fixed by assumption. The optimum $M *$ is located along a ray from the origin in the $f_{s} M$ plane at the point of intersection with $\mathrm{f}_{\mathrm{s}}^{*}$. The slope of that ray is given by $\sqrt{\frac{{ }_{I_{G}{ }^{2}{ }_{G} \pi_{G}}^{2 B}}{1}}$ and this quantity changes, of course, with $B_{G}$. These surfaces project into the TC-M and TC- $f_{s}$ planes as illustrated by FIGURES $5 a$ and $5 b$, respectively.

Relation (5.12) was derived under the restriction that $M>1$. It thus explains the demand for grocery holdings up to, but not including, the point where groceries are purchased on every shopping trip, that is when

$$
Q=\frac{{ }^{q_{G}}}{f_{s}}
$$


69

FIGURE 4

THE HOUSEHOLD INVENTORY COST SURFACE

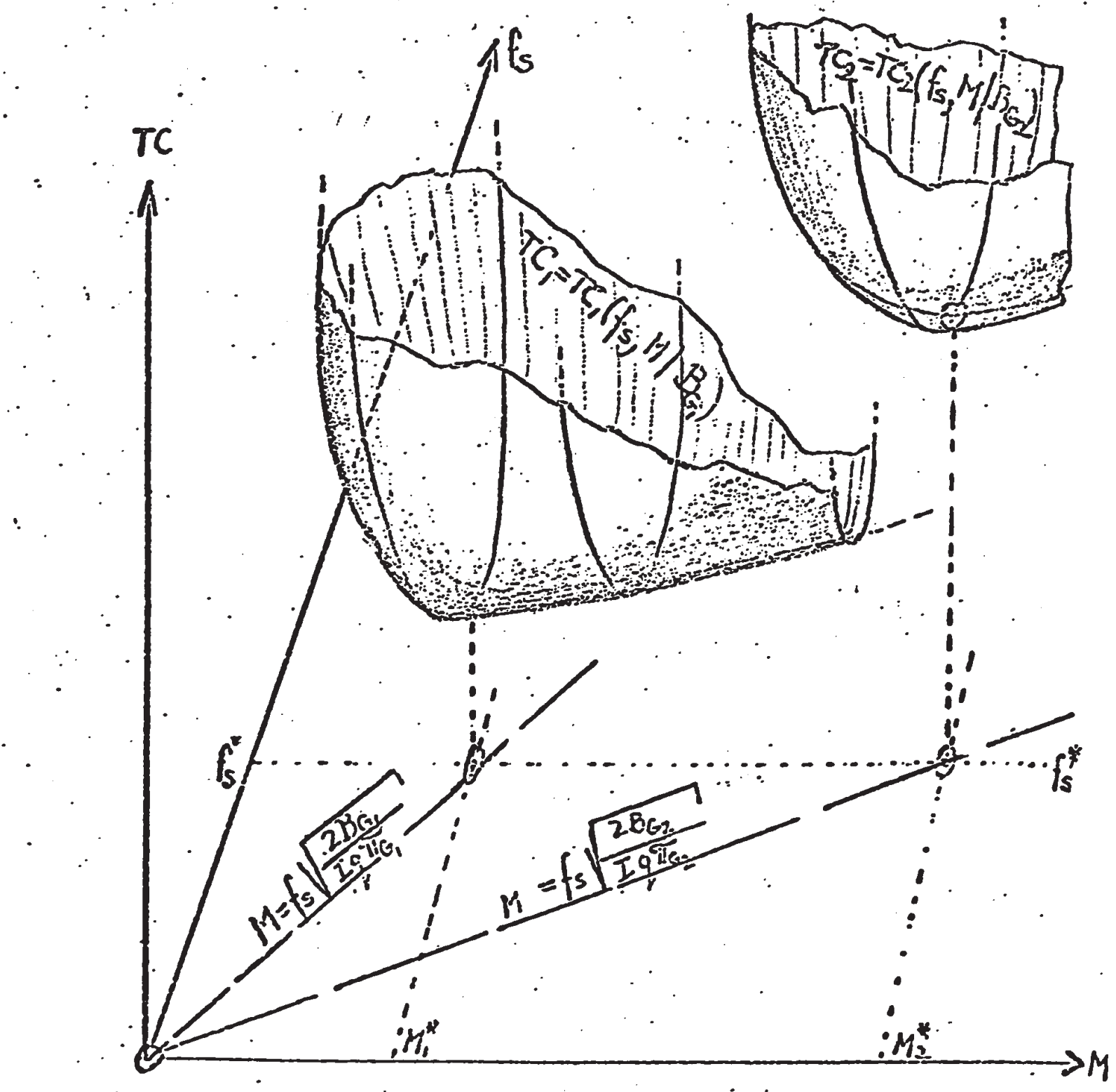


FIGURE 5
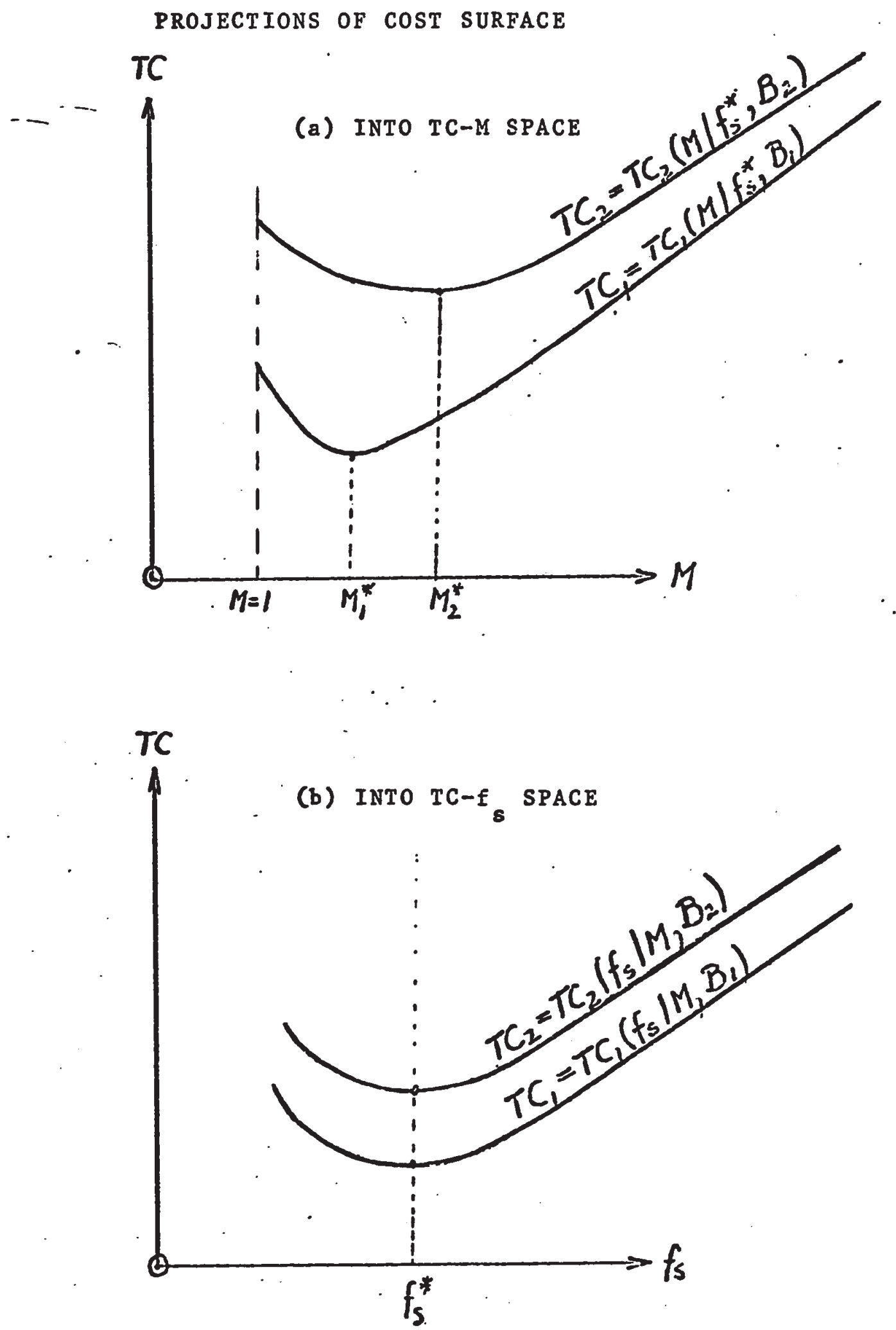
For this quantity and any purchase quantity smaller than this, the shopping frequency $\mathrm{f}_{s}$ is no longer determined solely in the perishable. sector. For this rarige, grocery inventory parameters do enter into the determination of the shopping frequency $f_{s}$ either simultaneously along with perishables, or as sole determinant of $\mathrm{f}_{\mathrm{s}}$ if $\mathrm{M} \leqslant 1$.

\section{Merits and Drawbacks of the Present Model}

Having developed the model under restrictive conditions it is now well to discuss its merits and problems. There are essentlally two sources of contention when applying the model generally without regard to the restrictions under which it was derived. (1) The problems arising out of the definitions and specifications used and (2) the model's inability to cope with the effect of rigid indivisibilities in the available purchase sizes on inventory holdings, as these indivisibilities were assumed away.

1. The major problem that emerged in the course of the study is that the model does not succeed in explaining the shopping frequency within the present frame of analysis. The prime obstacle is the dependence of the cost of a shopping trip on the timing of that trip. It is clear that shopping under the congested conditions of a Friday night, for example, is a great deal more time consuming than 
shopping, say, on a Tuesday morning, a fact the earlier definition of shopping abstracted from. Any implicit treatment of timing, however, would require a whole new set of determinants to be introduced, in particular, institutional factors such as pay day and working hours. They would all greatly complicate the model with a poor chance of making much headway towards this very difficult problem.

Seen in this light, the independence property permits the study to keep clear of these difficulties and to proceed nonetheless, with exploring a very significant aspect of consumer inventory behaviour.

The independence is of course a result of the initial specifications and must be defended on those grounds. Some subtle modification in the basic relations yields a hopelessly unmanageable model as can be seen from the special conditions under which the simple solution, (5.12), was possible.

While it may be arguable whether such modifications reflect any more realistically actual conditions, the overriding objective of the present model is its simplicity and qualitative properties, and on this score its case is very strong.

So is its intuitive appeal. Perishable goods do bear overwhelmingly on the decision how often the household 
should go to the store during a period. Once this decision has been made, an arrangement has come into existence which permits the household to obtain all other grocery goods on these trips. It lowers procurment costs for non-perishables to a level that is miniscule in comparison to the cost if special trips had to be made for them. In a sense, therefore, the operation of an inventory of perishables bestows externalities on grocery inventories. The spill-overs occur internally to the same household but grocery inventory behaviour is unaffected, by them. 2. The problem of indivisibilities has as yet not emerged as it was assumed that packages were available in a continuous range of different sizes of Q. In this way, a discrepancy between available sales quantities and desired purchase quantities could not occur. But suppose a grocery good is available only in one rigid size which is larger than the one desired. In that case the household would operate an inventory larger than that predicted by the model and to the extent that such indivisibilities are a pervasive phenomenon of the grocery market, the present model contributes little towards an understanding of household inventory behaviour.

Returning to the household production model developed earlier to analyze quantity discounts, the same forces which compelled firms to offer quantity discounts now, by symmetry, 
come to bear also on the purchase size they offer. If the purchase size available were so as to prevent the household from reaching its optimum, any competing firm offering a more suitable size would attract that household's business without having to lower the unit price. Thus, unless the market is dominated by a monopolist, there is a tendency for the purchase sizes offered to correspond to those desired.

This is not to deny that the individual household's inventory may be affected by indivisibilities. Since packages are by necessity available only in a limited number of sizes, the household may, in fact, be prevented by some measure from attaining a desired level of holdings. But the deviation from the optimum should not be large and will be random, so as to make their expected value equal. to zero. 
TEST OF MODEL

The purpose of the present chapter is to test the theoretical model developed previously. First the data is examined and thereafter the various error sources affecting our estimation are investigated. Such a discussion is necessary because it will place into perspective the question of the demands that can reasonably be made on the model. Against this background the test is then designed and applied and the results interpreted.

\section{Description of Data}

In contrast to the great wealth of data available on consumption habits, information on how the consumer actually purchases the goods he consumes, is difficult to obtain because of its great market value. Retailers invest substantial amounts in consumer surveys and for this reason guard the information against uses by others. A set of data that has become available, and that will be used presently, is that collected by the Chicago Tribune Consumer Panel 
from January 1, 1960 to December 31, 1961.

Some 2,500 households were asked to participate in that survey by recording numerous details about themselves and their grocery purchases. While the majority of households did not cooperate, the information provided by those who did was compiled on IBM punch cards and magnetic tapes. The cards record detailed social and economic characteristics of the approximately 1,000 participating households in the Chicago area Including their incomes, while 4 magnetic tapes 1ist every purchase of a large number of brands of approximately 85 grocery goods, made by these households throughout this period of two years. In particular, the purchase records specify:

1. the type of good bought,

2. the brand purchased,

3. the date of the purchase,

4. the total value of the purchase,

5. the number of units purchased,

6. the number of packages bought.

The Chicago Tribune collects this data in a continuing series, but only those obtained for 1960/61 have become available freely for non-commercial uses.

Before attempting to evaluate this information a series of problems must be considered. 


\section{Statistical Problems in the Empirical Investigation}

of Household Inventory Behaviour

A perfectly specified model is of course easily confirmed by the degree of correspondence of the parameters which the model estimates from the above data and those externally known. However, besides not having any external values for these parameters, there is a host of difficulties in the way of such a straightforward test.

There are three types of disturbances that affect our estimation and that must be dealt with before deciding on what is an appropriate test.

\section{Shortcomings of the Sample Data}

The test will involve cross-sectional comparisons. Unfortunately, panel-type consumer surveys commonly suffer from large reporting errors so that behavioural tendencies can be expected to emerge only if the sample sizes are sufficiently large. This rules out the use of narrowly defined income groups for the present set of data because the frequencies of responses for these groups is very small. But even if no reporting errors were to occur, it is still doubtful that small income groups could reveal homogeneous behavioural properties in as much as the reported incomes will include transitory components. Larger groupings such as obtained when bi-secting the reported income range into low and high incomes are preferable. The problem with 
this dual grouping is however, that the number of households in the extreme ranges is very small in comparison to those originating with the centre income groups. With this proportioning in favour of a series of adjoining centre income groups, an undiscriminating use of the data will be biased against finding cross-sectional differences in inventory behaviour if they exist.

For these reasons it will be necessary to eliminate the contributions made by these centre income groups and to select fairly large subgroups of households from each end of the income scale. Cross-sectional comparisons will thus be made for two groups only, for households whose incomes are below $\$ 6,000$ and for those whose incomes exceed $\$ 11,000$.

Behavioural Variations in the Data

Even if a total and precise enumeration of the population were available, an empirical study would still have to rely on estimates of population parameters because of large variations in the purchase pattern, and in the population parameters themselves.

Property 3 of the simple inventory model of CHAPTER III suggested that because of the flatness of the Total Inventory Costs Curve in the region of the optimum Q*, large deviations from the optimum resulted in only small increases in inventory costs. In other words, if the consumer is viewed as minimizing inventory costs by trial and error, he is likely 
to fall short, or overshoot, the optimum purchase size by large margins before he becomes aware of cost increases, that would induce him to adjust his purchase size.

The rate of holding cost $I$ is also likely to differ between households for two reasons. The interest rate is one of the components of $I$ and It, as well as the other holding costs may vary with income. Furthermore, households subjectively evaluate their deterioration and storage costs as well as the extent of quantity discounts avallable so that these quantities may all differ randomly between households.

Finally, there is the downright irrational response which, while defying explanation, may loom large in the area of shopping habits.

Disturbances originating with the descriptive inadequacy of the model

With the present amount of experience in this area, it need hardly be pointed out that the model is a very crude approximation to a much more complex decision process and that failure to understand it fully mist give rise to additional disturbances.

As an example, the assumption that $q$ remains constant over time, proves particularly troublesome, as in reality consumption by a household of any given item will vary greatly over time. The consumer tends to switch continually 
between goods and brands that satisfy a given consumption need. By selecting goods for which the scope of substitution is small, e.g. soap, toilet paper, or coffee, varlations In $q$ for a given household can probably be reduced. On the other hand, the problem that remains is that consumer - panels are conducted on behalf of a number of sponsoring firms and that if the consumer switches to a non-sponsored brand, it will appear from the data as if consumption fell. off to zero for that period. The consequences of this on the model are severe.

The effect can be studied by the following diagrams In FIGURE 6. Since the model assumes a constant $q$, the purchased stock $Q$ will be depleted at rate $q$ at all times. Average holdings will be $Q / 2$ as shown in part A. Total annual holding costs will be $I \frac{Q}{2}$. Now suppose consumption falls off to 0 , after the first period to stay 0 for the ensuing two periods, and to go back up. to the initial rate of $q=q^{0}$ as shown in part $B$ of FIGURE 6. Average holdings now will be lower than before, e.g. $a<\frac{1}{2}$ and 30 will be total holding costs.

The data now will show two purchases per year, or an annual average consumption of $2 Q$. Average holdings will be taken as $\frac{Q}{2}$ as before so that the model imputes a total annual holding cost in excess of that actually incurred. As a consequence, the model's estimate if I will now be biassed downward for the reason that the imputed level of 
RIGURE 6

ESTIMATING BIAS CAUSED BY THE ASSUMPTION OF

CONSTANT ANNUAL CONSUMPTION, WHEN, IN FACT,

CONSUMPTION VARIES

Panẹ (a)

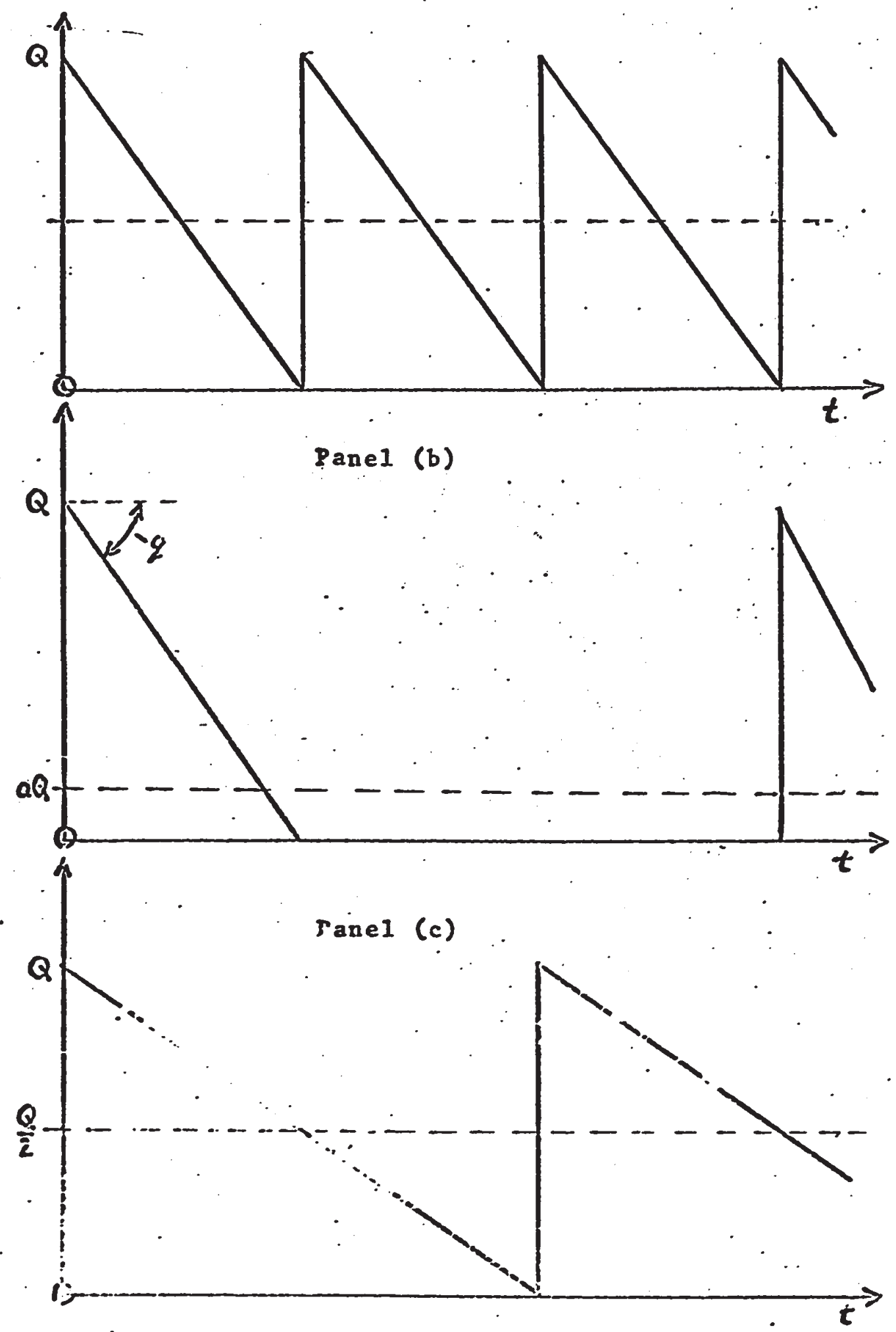


holding is larger than the actual which in turn reduces the annual rate necessary to incur a given level of holding costs. Furthermore, with the average q smaller than the actual, recorded purchase sizes appear large relative to consumption again resulting in a downward bias of the rate I which the household applies.

\section{Test Objective and Extended Hypothesis}

Singling out only the most devastating disturbances affecting our model, it is clear that the variations in $q$, and the errors caused by the inadequately specified model, exert distorting influences on absolute parameter estimates so as to leave them of very little use. The requirements on the test therefore had to be scaled down and it was felt that, as a first step, the successful demonstration that the model anticipates, qualitatively, the right sort of behaviour, would be an ambitious enough goal at the present state of research in this area. We recall that the model defined $I_{G}$ as the rate at which holding costs accrued to the household for grocery good G. Since this rate will vary between households we denote that rate for household $k$ as $I_{G k}$ which is now the sum

$$
\text { (6.1) } \quad I_{G k}=d_{G k}+s_{G k}+I_{k} \text {. }
$$

$d_{G k}$ and $s_{G k}$ denote the constant annual rates at which household $k$ evaluates deterioration and storage costs for 
good $G$ while $i_{k}$ denotes the rate of interest which household $\mathrm{k}$ applies to inventory holdings.

In an effort to simplify future notations let

$$
\text { (6.2) } \quad R_{G}=\frac{B G}{\pi_{G}}
$$

so that $R_{G}$ has the interpretation of being a measure 27 of the amount of quantity discounts offered in the sale of good G. Since good $G$ will be sold in various brands, and since the size of the quantity discounts available with these brands will vary in the estimation of households, $\mathrm{R}_{\mathrm{Gbk}}$ will represent the size of the quantity discounts household $\mathrm{k}$ believes it getswith the purchase of brand $\mathrm{b}$ of good G. Solving relation (5.12) for I using (6.2) and affixing appropriate subscripts, we get

$$
I_{G k}=\frac{2 R_{G b k} q_{G k}}{Q_{G j k}^{2}}
$$

where $q_{G k}$ is the total annual consumption of good $G$ and $Q_{G j k}$ the $j$ th purchase size of good $G$ by household $k$.

$R_{G b k}, q_{G k}$ and $Q_{G j k}$ can be obtained directly, or indirectly, from the data so that the test narrows down to an investigation of the $I_{G k}$ 's imputed on the basis of (6.3). As $I_{G k}$ in (6.3) is the same as that in (6.1) the proposition to be verified is the following BASIC HYPOTHESIS:

\footnotetext{
$27 \frac{B_{G}}{\pi_{G}}$ represents the number of units of a package's contents that have to be sacrificed with each purchase of good $\mathrm{G}$.
} 
FOR ANY NUMBER OF RANDOMLY SELECTED GROUPS OF

HOUSEHOLDS EACH OF SIZE $n$, THE GROUP AVERAGES OF

ANNUAL RATES OF WAITING COSTS $\overline{\mathrm{I}}_{G}$, INCURRED BY

HOLDING GOOD G AND GIVEN BY

$$
\bar{I}_{G}=\frac{\sum_{k=1}^{k=n} I_{G k}}{n}
$$

CONVERGE TOWARD EACH OTHER AS n INCREASES.

In order to track down cross-sectional differences in the I's at the same time as this BASIC HYPOTHESIS is tested, the subgroups of households are selected on the basis of income. Cross-sectional variations of holding cost rates were suggested earlier in connection with the discussion on interest rates in CHAPTER IV. It is to be noted, however, that this method of selecting household groups will not jeopardize the test objective. Verification of the BASIC HYPOTHESIS is still achieved by simply proving that the ratio of the rates of holding costs $\bar{I}_{G L}$ to $\overline{\mathrm{I}}_{\mathrm{GH}}$, for low and high income households, respectively, converges to some constant $c_{G}$ different from 1 as: $n$ increases. In symbols

$$
\text { (6.4) } \quad \lim _{n \rightarrow \infty} \frac{\overline{\bar{I}}_{\mathrm{GL}}}{\overline{\bar{I}}_{\mathrm{GH}}} \rightarrow \mathrm{c}_{\mathrm{G}}
$$

Even though the estimates of $c_{G}^{28}$ may differ, the stability that dominates their distribution is a compelling criterion for concluding that the properties of grocery shopping 28 To be obtained by estimating $\overline{\mathrm{I}}_{\mathrm{GL}}$ and $\overline{\mathrm{I}}_{\mathrm{GH}}$ separately for each $G$. 
behaviour are in fact broadly being captured by the model. At the same time the values of $c_{G}$ provide an additional information on cross-sectional inventory behaviour which will be investigated in the APPENDIX TO CHAPTER VI.

The entire testing procedure and the statistical techniques used now should be judged in terms of the test objective. Since we are not considering absolute values for the parameters, we need not get involved in the intricate theoretical problems either, which their estimation poses. For suppose a bias, or some other distorting influence were to affect the absolute levels of the estimates of $I$. To the extent we are merely interested in whether or not $c_{G}$ is constantly different from $I$, such influences will not inhibit our ability to draw conclusions, as long as these influences have either a random effect on $I$, or one that affects the estimates for both groups in the same direction. Thus, while our limited objective helps us circumvent the immense statistical problems which the model poses, it can provide powerful support for its qualitative properties if the direction by which $c_{G}$ differs from 1 reproduces itself consistently throughout vast masses of data.

Rejection of a Plausible Counter-Hypothesis

While testing the data we can strengthen the case for the model by rejecting, at the same time, the common 
counter-hypothesis that households tend to purchase a given good in sizes proportionate to annual consumption. In fact, this is implicitly being assumed whenever consumption theory is resorted to for explanations of consumption expenditures.

In this case, of course, relation (6.3) becomes an identity and I, being without life of its own, would simply take on whatever value was needed to satisfy the non-existing optimum (5.12). $C_{G}$ would not converge to any stable value but would rather have an infinite variance. Using a different line of attack, it is assumed for a moment that, consistent with the counterhypothesis, $Q=\mathrm{kq}$, with $\mathrm{k}$ a constant. It would now also require that the purchase frequency $f$ was constant, 1 .e. since $f=\frac{q}{Q}$, it follows that $f=\frac{1}{k}$. Both requirements are simply not borne out when looking at the averages presented in TABLES 5 through 8 of the APPENDIX TO CHAPTER VI. They suggest, without exception, that a non-linear relation exists between $Q, f$ and $q$. Despite the absence of significance levels it is very unlikely that the behaviour of these numerous averages could have been generated by sampling errors alone.

\section{Evaluation of Data}

The aim of our testing procedure now is to try and circumvent the problems posed by our ignorance of $\mathbf{R}_{\mathrm{Gbk}}$. 
This parameter clearly plays an important explanatory role in the model and, keeping it constant, must increase the unexplained variation in the $\overline{\mathrm{I}}_{G}$ 's. However, for reasons of convenience we set out from this crude assumption and build up from it, following the logic in which the three different approaches themselves evolved.

Procedure 1:

Test of the hypothesis by assuming that the quantity discount parameter $R$, and the overhead per package $B$ are constant for all households buying a given good.

The present assumptions can only be rationalized by the simplicity they afford. However, should the model broadly describe the inventory pattern contained in the data, a general tendency, bearing up this relation, should still emerge. Recalling that the variables appearing in (6.3) are in real terms, we want to transform these quantities into dollar dimensions. Familiarity with the data shows that severe additional errors are introduced by using the household's purchase record in a variety of real units rather than those records which the household indicates in easily understood dollar terms. ${ }^{29}$

${ }^{29}$ For example, households report a pattern of instant coffee purchases in dollar terms that is fairly consistent judged by the distribution their responses form. However, using the corresponding real quantities, households report, a very unlikely pattern emerges because of an unreasonable divergence of dollar values and quantities reported, sometimes representing package sizes not commonly sold on the market. 
Ignoring for the manipulations the subscripts we can rewrite $(6.3)$ as

$$
I=\frac{2 B f^{2}}{q \pi},
$$

recalling that $f=\frac{q}{Q}$ and $R=\frac{B}{\pi}$. Further, from (4.11) we know that

$$
\pi=P-\frac{B}{Q}
$$

and the simple expression for $I_{G k}$, re-introducing the appropriate subscripts, can now be derived. Denoting the purchase frequency by $f_{G k}$, the dollar value of annual consumption by $\$ q_{\mathrm{Gk}}$, and the overhead cost per package by $B_{G}$, with all variables referring to good $G$, this expression is simply

$$
\text { (6.5) } \quad I_{G k}=\frac{2 f_{G k}^{2} B_{G}}{\$ q_{G k}-f_{G k} B_{G}}
$$

The intuitive meaning of $(6.5)$ is of course that the dollar value of annual consumption is now being adjusted for the packaging outlays, $f_{G k}{ }^{B}$, for the same period.

The only quantity in (6.5) not directly observable is $B_{G}$, presently assumed constant for good $G$. But since the relative level of $\bar{I}$ is only of concern to us here, any value for $B$, within its economic range, can be used without affecting the direction in which the two I's differ. A series of values for $B$ are listed in TABLE 11, and the value for $\mathrm{B}_{\mathrm{G}}$, within the estimated range, was taken as $\$ .07$. 
The ratio of the averages of $\bar{I}_{G L}$ and $\bar{I}_{G H}$, obtained for low and high income households, respectively, computed on the basis of $(6.5)$ are listed on TABLE 1 together with their $t$-values, indicating the significance of the differences between the estimates obtained for both groups. 30 The values obtained for the 5 goods indicate consistently that $\mathrm{C}_{\mathrm{G}}>1$. Furthermore, the values appear remarkably stable, considering the fact that the ratio must vary for the various goods as the composition of holding costs also varies between goods.

However, the approach does not warrant any definite conclusions yet. Since we failed to include the explanatory capacity of the quantity discount parameter $R$, variation still looms large as the low t-values indicate.

Aside from the poor significance levels, it may also be contended that the differences in the I's are probably attributable to the fact that the $\mathrm{R}_{\mathrm{Gbk}}$ 's were constant, because they vary cross-sectionally too and would have offset the observed differences in the c-ratios had their appropriate values been assigned.

30

The computation of the $t$-values does not make allowance for heteroscedasticity which may have an effect on these significance levels. For a discussion of this problem see B. Ostle, Statistics in Research, The Iowa State University Press, Ames, Iowa, 1963. 
TABLE 1

COMPARISON OF THREE DIFFERENT ESTIMATING PROCEDURES

IN THE ESTIMATION OF THE RELATIVE RATE OF

BOLDING COST OF LOW AND HIGH INCOME

HOUSEHOLDS (1961 purchases only)

\begin{tabular}{|c|c|c|c|}
\hline $\begin{array}{l}\text { Type of } \\
\text { Good }\end{array}$ & $R$ is constant & $\begin{array}{l}\text { R computed for } \\
\text { major brands and } \\
\text { used in the com- } \\
\text { putations of I }\end{array}$ & $\begin{array}{l}\text { Relative holding } \\
\text { cost computed for } \\
\text { buyers of } 10 \\
\text { major brands. }\end{array}$ \\
\hline $\begin{array}{l}\text { Instant } \\
\text { Coffee }\end{array}$ & $1.12(t=.55)$ & $1.44 \quad(t=1.25)$ & $\begin{array}{l}1.38 \text { (no signif- } \\
\text { Icance level) }\end{array}$ \\
\hline Tea & $1.32(t=1.20)$ & $1.48 \quad(t=1.22)$ & 1.28 \\
\hline Flour & $1.31(t=1.45)$ & $1.31 \quad(t=1.56)$ & 1.52 \\
\hline $\begin{array}{l}\text { Toilet } \\
\text { Soap }\end{array}$ & $1.28(t=1.66)$ & $1.33 \quad(t=1.83)$ & 1.16 \\
\hline Liquor & - & $1.69(t=2.51)$ & - \\
\hline
\end{tabular}


The next approach will effectively deal with this possible bias by estimating $R_{G b k}$ for every brand $b$ of good $G$. To have some information as to the cross-sectional behaviour of $R$, the average $\bar{R}_{G}$, the amount of units of good $G$ a household sacrifices, on average, in the annual purchases of good $G$ is next being computed for flour and soap for the two income groups, again denoted by adding subscripts $L$ and $H$ to $G$. The two goods were chosen because they showed particularly high $t$-values for the difference $\bar{I}_{G L}-\bar{I}_{G H}$. Thus, if $\bar{R}_{G L}$ was consistently smaller than $\bar{R}_{G H}$, the assumption of constant $R^{\prime}$ 's could in fact have caused the differences in the I's.

TABLE 2 on page 92 lists these values for $R$ and for the two goods considered at least, it is not apparent that the $R$ 's exerted the systematic cross-sectional influence that caused the estimates of $\mathrm{C}$ to be consistently greater than 1. For such a conclusion the evidence would have to indicate consistently that $\overline{\mathrm{R}}_{\mathrm{GL}}>\overline{\mathrm{R}}_{\mathrm{GH}}$.

Procedure 2:

Test the BASIC HYPOTHESIS by first estimating the R's for all major brands of the goods in the sample and then computing the c-ratios on the basis of the I's obtained for these brands.

If parameter $R$ has the explanatory power attributed to it by the model, the significance levels should improve 
TABLE 2

COMPARISON OF AVERAGE MEASURE OF QUANTITY

DISCOUNTS EXPERIENCED BY LOW AND

HIGH INCOME HOUSEHOLDS

\begin{tabular}{l||c|c}
\hline $\begin{array}{l}\text { Gi jcery } \\
\text { Good }\end{array}$ & $\overline{\mathrm{R}}_{\mathrm{GL}}$ & $\overline{\mathrm{R}}_{\mathrm{GH}}$ \\
\hline \hline Flour & 2.14 & 2.27 \\
\hline Soap & 3.76 & 3.64 \\
\hline \hline
\end{tabular}


appreciably by using an estimate of this $R$ in explaining individual purchase sizes.

The estimates of $R$ are 1isted on Table 11 in the appendix. These estimates raise a host of new problems as far as their absolute levels, and the representation of $R$ by means of averages, are concerned: These problems will not be discussed, however. We only want to improve on our previous techniques and of that we can be certain, even if only the direction of the change in $Q$ is explained by a change in the direction of $R$.

The $I_{G k}$ imputed for every purchase $j$ now will be obtained on the basis of relation (6.3). These quantities are then averaged for the two groups, and estimates of the ratio $c_{G}$ are calculated as before. As seen on TABLE 1 significance levels are substantially improved, and on this account, the present approach would seem superior to the previous one. The calculations of this method, however, are very tedious and the sheer magnitude of the job Involved in extending this approach to more commodities prompted the search for yet another method to be discussed next.

\section{Procedure 3:}

In testing the BASIC HYPOTHESIS ensure $R$ is constant by estimating $c$ in accordance with the brands households buy.

The final method is important in that it confirms, 
conclusively, the earlier findings by using an approach quite independent from the previous ones.

Abstracting from variations in pricing policies by retailers, R will be constant for a given brand, and computing $c$ for that brand, we know that it is unaffected by R. Holding $R$, in addition to a given level of annual consumption $q$, constant, the optimum purchase size for a household cannot change either. But since a brand will generally be available in a few discrete sizes only, the purchase size $Q$ will not even be subject to continuous random deviations. Consistent with it, we may therefore make the further convenient assumption that the size in which a household purchases a particular brand is constant. To the extent that actual behaviour does not bear out this assumption, an additional random disturbance is created. But it will affect both household groups equally, leaving again the estimate of c largely unaffected.

Rewriting (6.3) in terms of $f$ and $Q$ only, we get

$$
I_{G k}=\frac{2 R_{G b k} f_{G k}}{Q_{G j k}}
$$

which, under our present assumptions, yields the convenient expression for our estimating purposes

$$
\text { (6.6) } \quad I_{G k}=2 R_{G b k}\left(\sum_{j=1}^{j=f} \frac{1}{Q_{G j k}}\right) \text {. }
$$


Averaging these $I_{G K}$ 's for low and high income households, and computing their ratios as before, we have another estimate of $c$. TABLE 1 lists the estimates from this method for the same 5 commodities and again the results consistently bear out the earlier findings. Significance levels could not be computed, however, for lack of storage space on the computer. Comparison of the results from the three largely independent approaches provides substantial support for the model's qualitative characteristics. The estimates of $c$ are consistently greater than 1 .

In an effort to build up a conclusive set of evidence, procedures 1 and 3 were used to estimate $c$ for the 33 major commodities of the survey, covering the entire purchase history from January 1960 to December 1961. TABLE 3 and TABLE 4 list the results for procedures 1 and 3, respectively, and conclusively demonstrate that the values for $c$ consistently reproduce themselves through a vast mass of data.

The $t$-values of TABLE 3 for the difference $\bar{I}_{G L}-\bar{I}_{G H}$ for the 33 commodities varied widely, and in a number of cases even reversed the expected direction. But these exceptions can have little impact on the total result. Assuming the Null-Hypothesis is true, i.e. that there is no difference between the I's, the distribution of the $t$-values should be approximately normal around a mean of 0 . Thus, the mean of the individual t-quantities, $\bar{t}$ should 
TABLE 3

ESTIMATES OF $c_{G}$, THE RELATIVE RATE OF HOLDING

COST FOR LOW AND HIGH INCOME HOUSEHOLDS,

FOR VARIOUS GOODS G

( $R$ = constant; 1960/61 Purchases)

\begin{tabular}{|c|c|c|}
\hline Type of Good & $\begin{array}{c}\text { Relative Holding Costs } \\
C_{G}\end{array}$ & t - value \\
\hline $\begin{array}{l}\left.\begin{array}{l}\text { Regular Coffee (P) } \\
\text { Instant Coffee (P) } \\
\text { Tea (P) } \\
\text { Flour (All Purpose) } \\
\text { Pancake Flour } \\
\text { Cake Mixes } \\
\text { Roll Mixes } \\
\text { Margarine (P) } \\
\text { Peanut Butter (P) } \\
\text { Meat, Fish and } \\
\text { Poultry Pies (P) }\end{array}\right\} \\
\text { Fish Sticks (P) } \\
\text { Dinners, Frozen (P) } \\
\text { Instant Potatoes } \\
\text { Packaged Desserts } \\
\text { Toilet Soap } \\
\text { Packaged Soap and } \\
\text { Detergent } \\
\text { Scouring Cleansers } \\
\text { Liquid Detergents } \\
\text { Peaches } \\
\text { Pineapple } \\
\text { Fruit Cocktail } \\
\text { Fruit Frozen (P) } \\
\text { Concentrated Fruit) } \\
\text { Juices } \\
\text { Pork and Beans* } \\
\text { Canned Corn* } \\
\text { Tomatoe Paste* } \\
\text { Vegetable Juice* } \\
\text { Vegetables Frozen (P) } \\
\text { Chile Con Carne* } \\
\text { Canned Tuna* } \\
\text { Toilet Paper* } \\
\text { Paper Napkins* } \\
\text { Cleansing Tissue* }\end{array}$ & $\begin{aligned} 1.00 \\
1.07 \\
1.19 \\
1.29 \\
.94 \\
1.24 \\
1.41 \\
1.18 \\
.85 \\
1.19 \\
1.27 \\
.88 \\
1.41 \\
1.49 \\
1.36 \\
1.28 \\
1.10 \\
1.12 \\
1.51 \\
1.09 \\
1.26 \\
1.08 \\
.93 \\
.98 \\
1.36 \\
1.63 \\
1.43 \\
1.03 \\
.52 \\
1.52 \\
1.32 \\
1.14 \\
1.16 \\
\end{aligned}$ & $\begin{array}{l}+.03 \\
+.59 \\
+1.24 \\
+2.84 \\
-\quad .46 \\
+2.77 \\
+2.60 \\
+1.91 \\
-1.81 \\
+1.16 \\
+1.64 \\
-1.04 \\
+2.72 \\
+3.17 \\
+3.08 \\
+3.28 \\
+ \\
+1.11 \\
+1.46 \\
+4.55 \\
+.83 \\
+1.97 \\
+\quad .74 \\
-\quad .55 \\
+ \\
+2.11 \\
+2.50 \\
+2.07 \\
+.19 \\
+\quad .52 \\
+3.03 \\
+1.74 \\
+1.66 \\
+1.60\end{array}$ \\
\hline * 1960 Purchases Only & & $\frac{\bar{t}}{\bar{s}}=5.68$ \\
\hline
\end{tabular}


TABLE 4

ESTIMATES OF $c_{G}$ FOR VARIOUS GOODS $G$,

ESTTMATED BY BRANDS

(1960/61 Purchases)

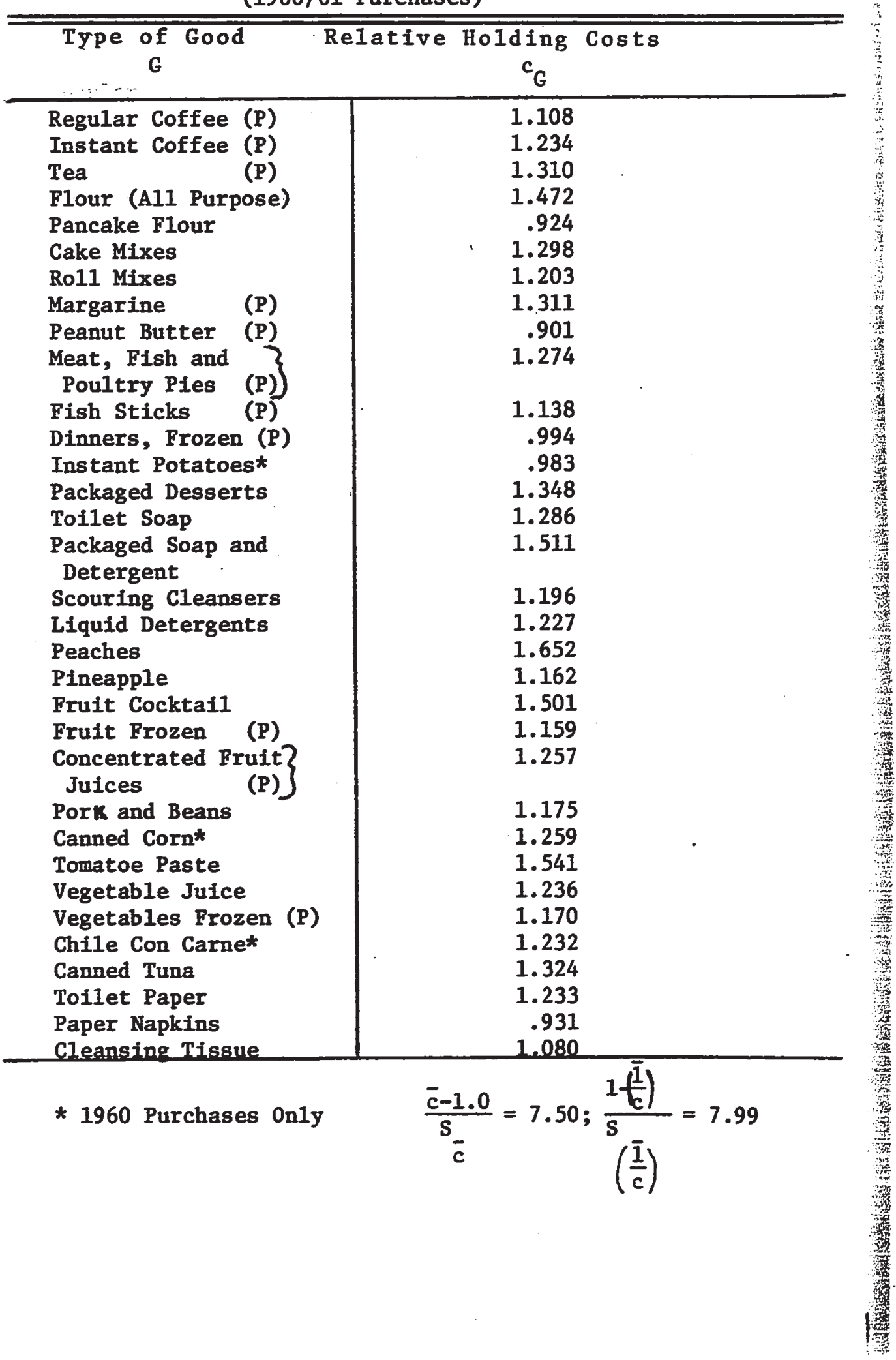


not be significantly different from 0 , either. Computing $\frac{\bar{t}}{s_{\bar{t}}}$, however, where $s_{\bar{t}}$ is the standard deviation of the distribution of these means, a value of 5.6 is obtained, clearly ruling out any doubt that the differences in the observed holding cost rates I may be the result of sampling errors.

More impressive is the result for the third procedure on TABLE 4. Not having been able to compute significance levels for the individual c's, an inference about the variation inherent in this method is possible by looking at the variance of the distribution of the final estimates of $c$ themselves. Assuming these $c$ values are normally distributed around a mean of 1 , in accordance with the Nul1-Hypothesis, we obtain a $t$-value of 7.10 for this in fact to be true.

This type of significance level dispels the doubts, the statistical problems of ratio estimates raise. As pointed out by Cochrane ${ }^{31}$ the distribution of ratio estimates has proved annoyingly intractable. He is able to show that it approximates the normal distribution for large sample sizes n. But ratio estimates are also biased. In fact, the present choice of numerator and denominator would mean

\footnotetext{
31 See W. G. Cochrane, Sampling Techniques, J. Wiley
} and Sons, Inc., New York, 1966, CHIV. 
a definite bias in favour of finding that $c>1$, were the sample size not as large as it is. However serious the problem in the present context, the ratios were reversed; $1 / c$ was computed for every good and the significance level applied on the difference $1-\left(\frac{\overline{1}}{c}\right)$. While this quantity was smaller than $1-\bar{c}$, the margin by which it was significantly different from 0 increased to 7.993 , as shown on the bottom of TABLE 4 . 
APPENDIX TO CHAPTER VI

The data contains a great deal more information on household inventory behaviour than has been utilized in connection with the text. It is very interesting, for example, to investigate the question of how the crosssectional difference in holding costs manifests itself in shopping habits across households as far as purchase frequencies, purchase sizes and unit prices are concerned. This will present1y be done by studying various summary statistics. But the approaches will be designed also to obtain reinforcing evidence for the properties of the model.

Comparison of Shopping Behaviour of High and Low Income, and Black, Households

In order to demonstrate any trends from the data, the vast number of purchases must somehow be aggregated and averaged. It is to be recalled, however, that theory suggests a non-1inear relationship between the variables so that averaging the relevant observations will obscure, rather than manifest, the relation that is supposed to prevail. In an effort to minimize this problem, 3 separate 
group averages are obtained for the purchase quantity Q, the unit price $P$ and the annual purchase frequency $f$ for households consuming small, medium and large quantities of a given good. Since it is clear that the smaller the variation in consumption within these groups, the greater the usefulness of the averages, it was attempted to select the groups judiciously with a view to maximizing uniformity in q. Group averages were calculated first for 1960 and 1961 separately, and then for both years together and noticing that variations in consumption increased for the two year period, annual averages were preferred, that is the averages for the years whose variation was smallest. The consumption intervals of the groupings were chosen so as to have approximately the same number of households falling within the consumption levels of each group. The three sets of averages obtained now in effect represent geometrically three discontinuous linear approximations to what is theoretically a parabola. In an effort to study cross-sectional differences, these groups were broken down into three subclasses separating high income white, low income white, and black households. High and low incomes are defined as $\$ 11,000$ and over, and $\$ 6,000$ and less, respectively as discussed earlier. This division also has the merit of reducing the variation within the consumption groups as the three groups 
of households will normally purchase differing qualities of a given good which in turn will make for differences in prices and hence in the value of consumption and in purchase sizes.

\section{Results and Their Interpretation}

TABLES 5 through to TABLE 9 summarize the results of the averages calculated for the 5 commodities indicated. They appear to confirm the property of the model that consumption, and the purchase size, follow a non-linear relation. Similarly, the results indicate that the relation between $q$ and $f$ is also non-linear as expected. Consistent with the quantity discount hypothesis, unit prices also seem to decrease as purchase quantities increase.

FIGURE 7 sketches the findings so as to emphasize the properties and to highlight the differences in behaviour between the groups. The data seems to indicate that for a given consumption level $\mathrm{q}^{0}$ the optimum purchase sizes of black, low income and high income white households are $Q_{B}, Q_{1 Y W}$ and $Q_{H Y W}$, respectively. This apparent tendency is reinforced by the behaviour of the frequency for the same groups as the relation between : and $\mathrm{f}$ again appears strongly non-1inear. Further, the data reveal a definite trend toward declining unit prices as the purchase quantities increase. 


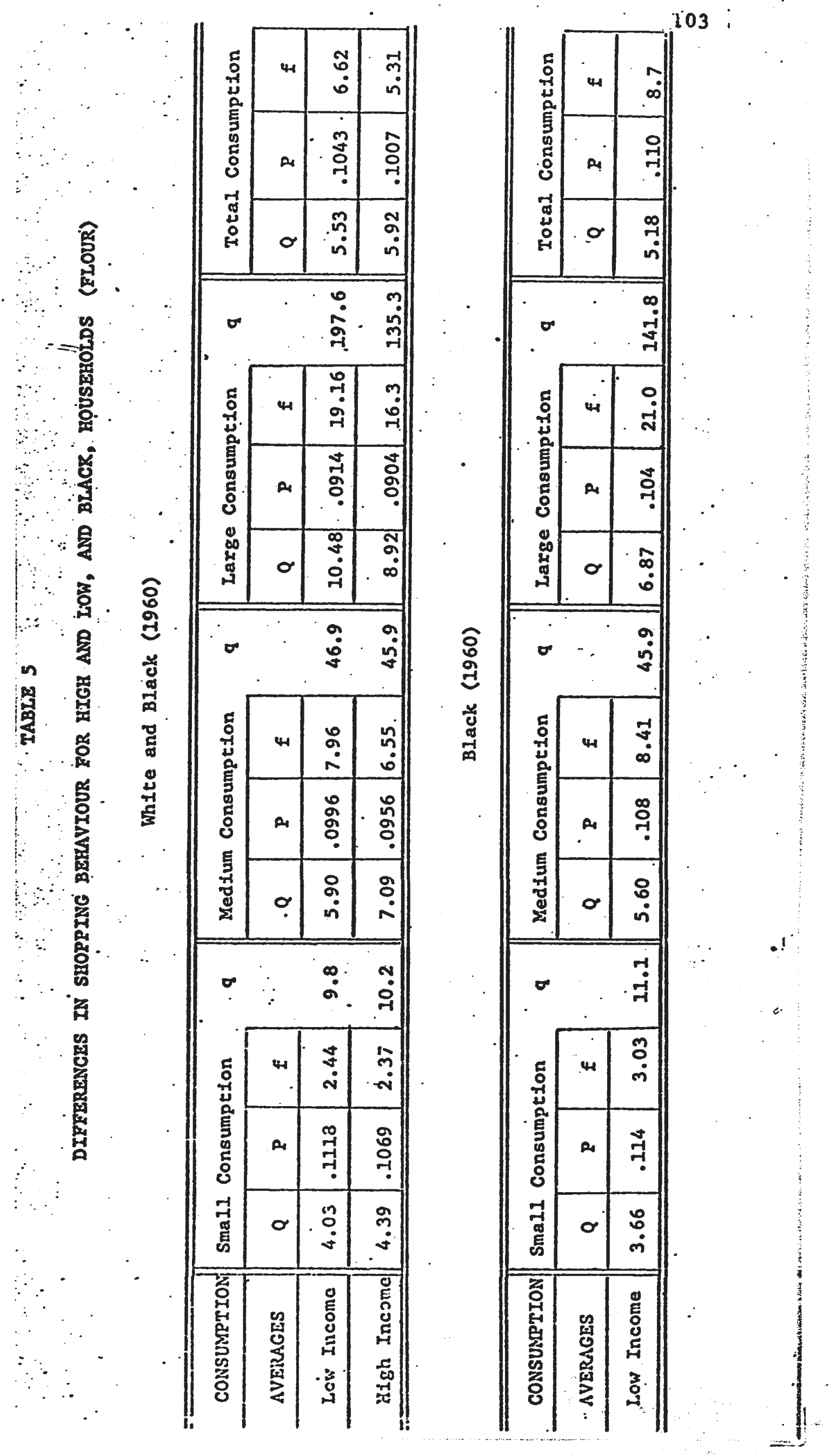




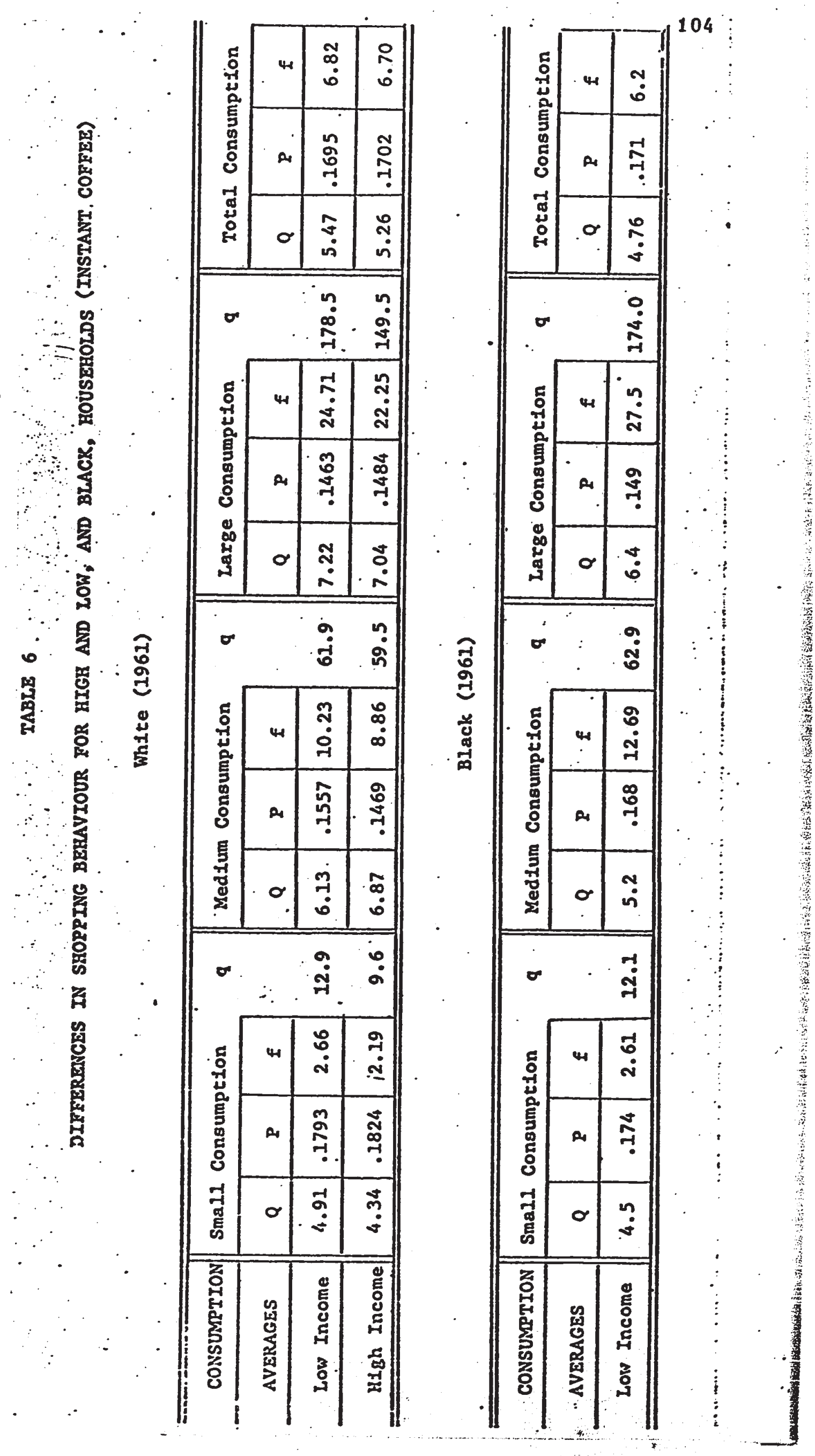




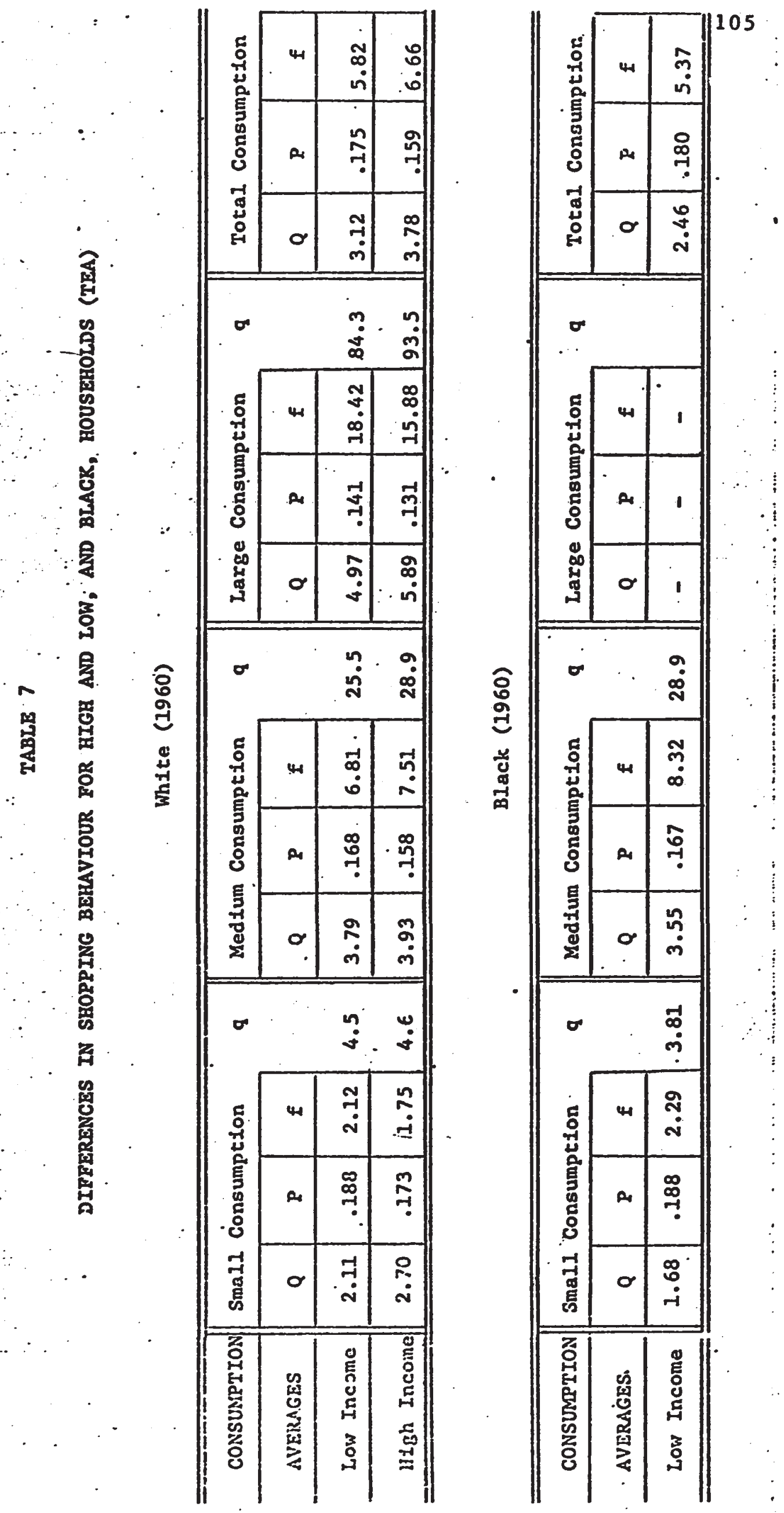




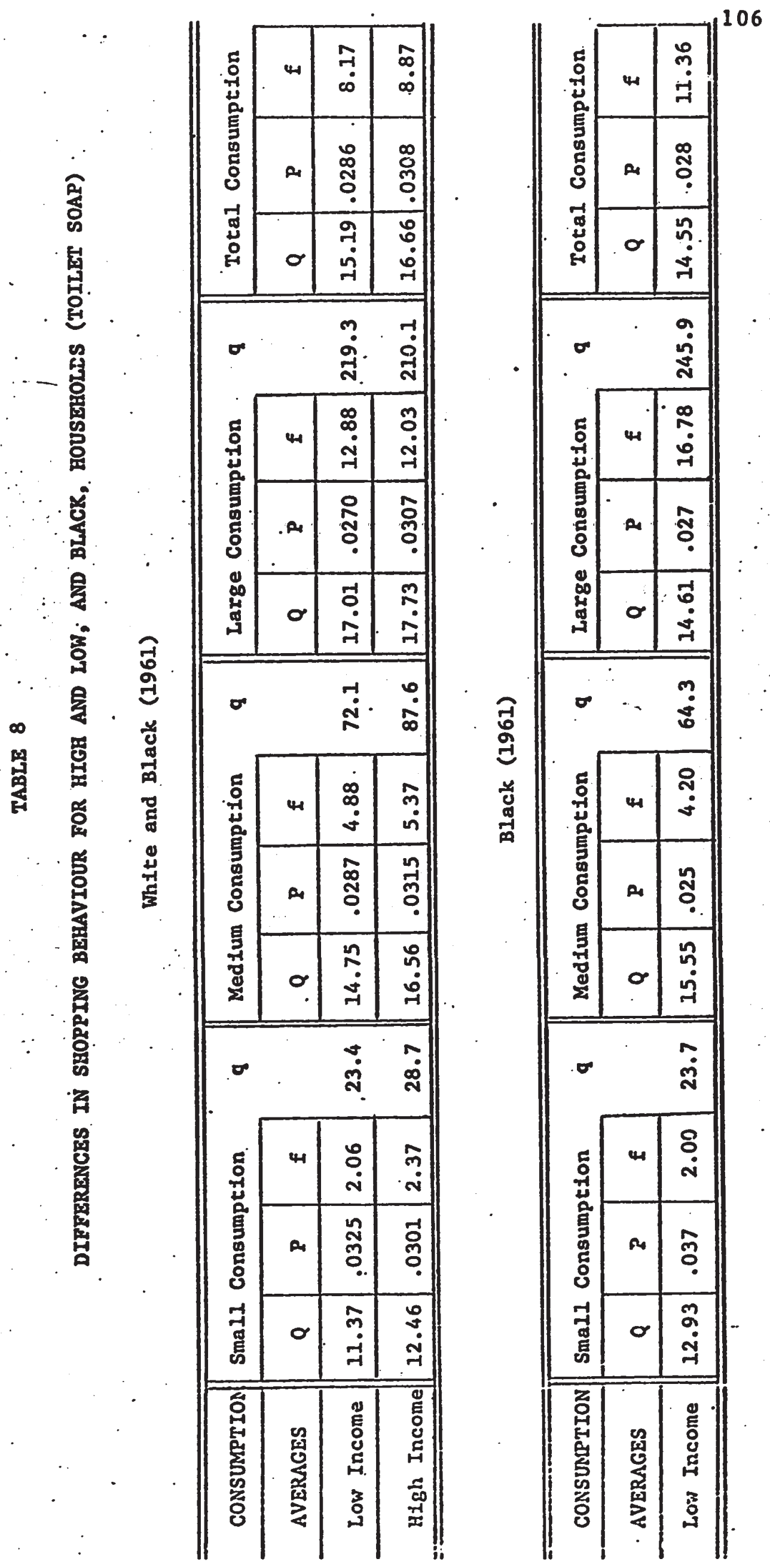




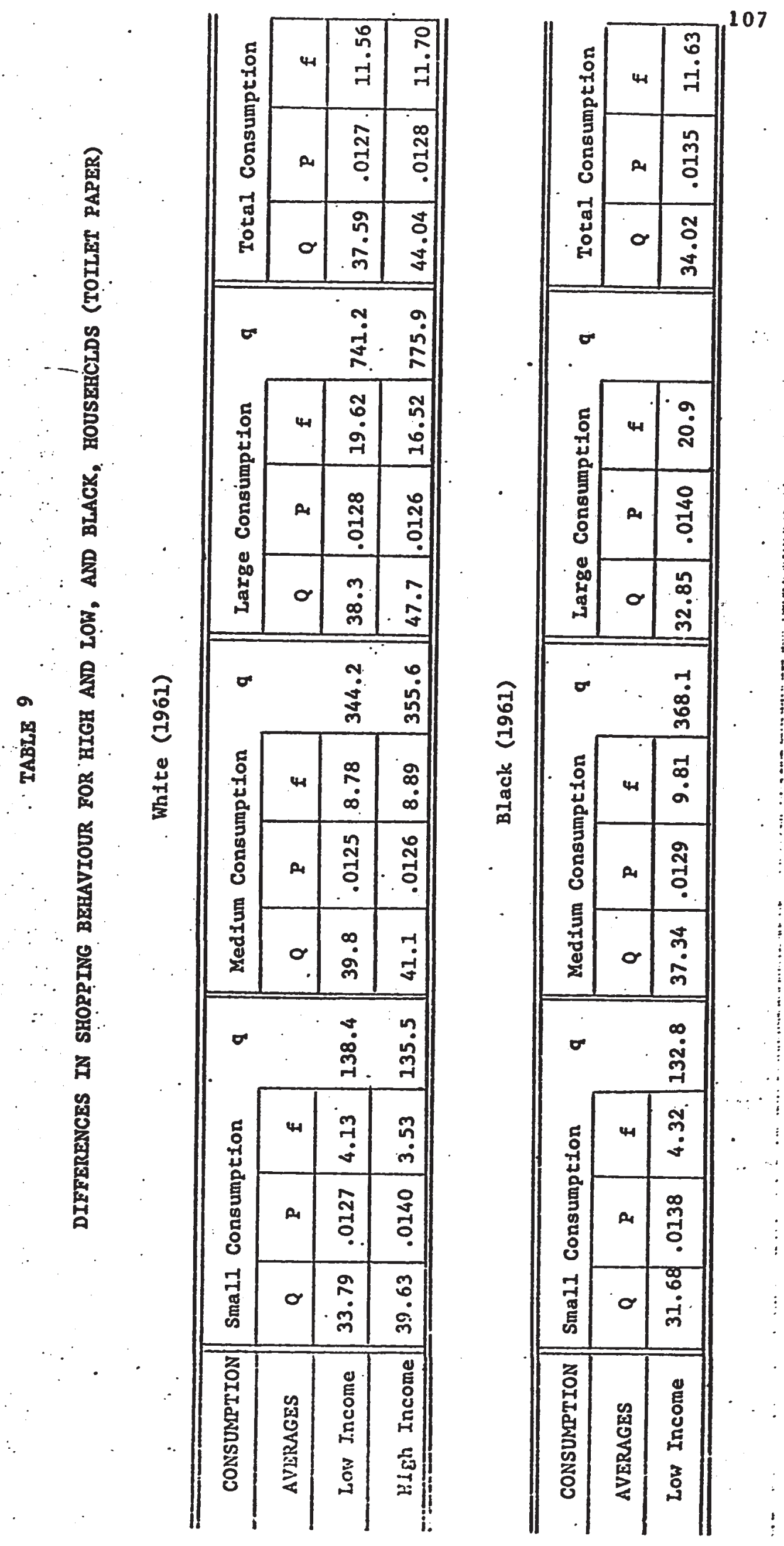




\section{FIGURE 7}

\section{SKETCH ILLUSTRATING DIFFERENCES IN SHOPPING}

BEHAVIOUR APPARENT FROM THE DATA

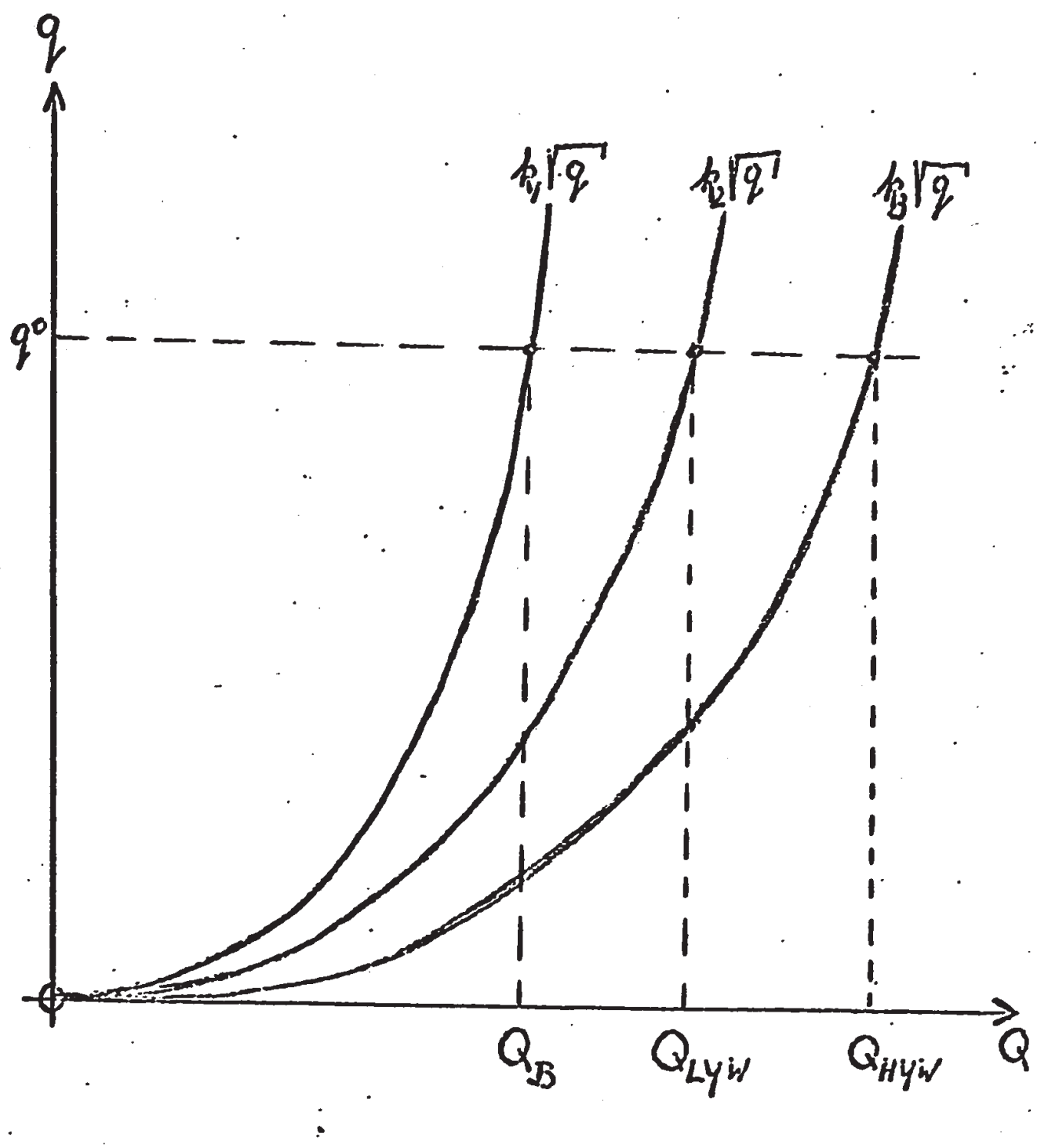




\section{The Significance of Decreasing Prices}

In an effort to obtain significance levels for the decreasing unit prices, the sample was extended to December 61 to cover the entire purchase history for the 5 commodities using the high and low income grouping only. The additional breakdown by race was not continued with as the number of black households was too small in relation to the variation in their responses to obtain meaningful_significance levels.

TABLE 10 1ists the results. The differences between the unit prices paid for successively higher purchase quantitles by the two groups are highly significant in most cases, while those between income groups permit no conclusions as yet. The former finding is fully consistent with the Quantity Discount Hypothesis. The inconclusive latter result will require a further test.

In an attempt to obtain independent support from a different approach to the issue of quantity discounts, additional calculations were performed. Recalling the definition of $R_{G}(621) R_{G}=\frac{B_{G}}{\pi_{G}}$ we know that a positive value for $\mathrm{R}_{\mathfrak{G}}$ indicates that the unit pirices decline with the purchase of larger quantities.

This value of $R_{G}$ was computed for the major brands of the five commodities previously under consideration. Under the assumption that the overhead cost $B_{G}$ of the grocery 
TABLE 10

AVERAGE PRICES PAID BY BUYERS IN ACCORDANCE WITH PURCHASE SIZE AND INCOME

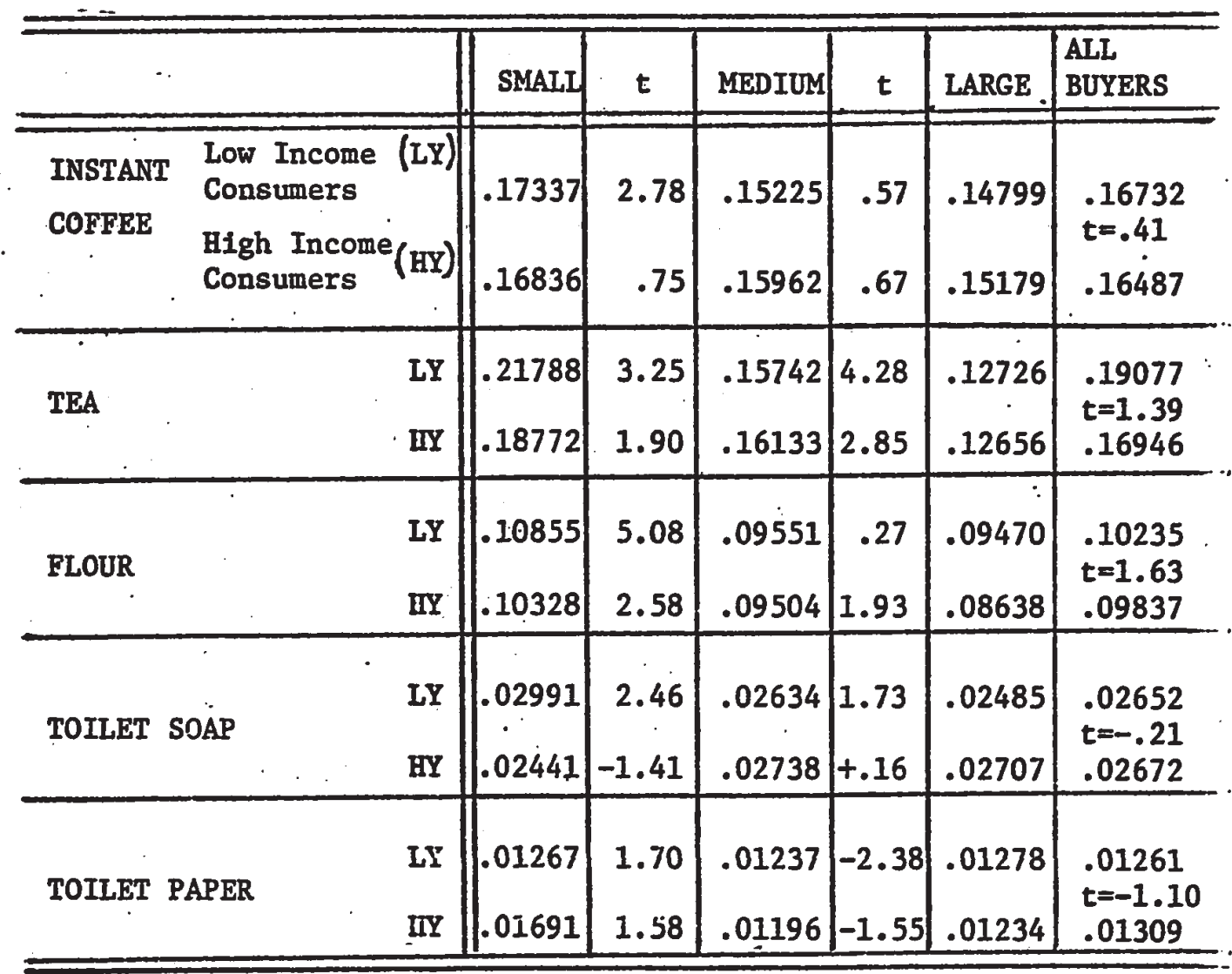


package is constant for the various purchase quantities of a given brand, the ratio of the coefficients of the simple regression $V$ on $Q$ as 11 lustrated in FIGURE 8 i.e., of the dollar value, $V$, of a given purchase, on $Q$, the total number of units purchased of a given brand each time, should provide an estimate of $R_{G}$.

TABLE 11 lists the estimates and it is noteworthy that, without exception, ${ }_{G}{ }_{G}^{1 s}$ significantly greater than 0 , lending support to the earlier hypothesis that grocery goods cannot be available except at a unit price that varies inversely with the purchase size $Q$. The evidence in support of this quantity discount hypothesis is therefore seen to be very strong considering the significance levels. The values obtained for $B_{G}$ are of course smaller than the overhead cost actually incurred with each purchase. The reason is that contrary to the assumption of a constant overhead cost per package of a given brand, B with the size of the purchase quantity. In fact, the values obtained for ${ }^{B}{ }_{G}$ should be interpreted as the overhead costs of carrying an individual sales quantity, even if that item would require no packaging and no physical handling at all.

\section{The Poor Pay More}

In an effect to probe deeper into the significance of the difference in average prices paid by high and low income 
PIGURE 8

ESTIMATION OF QUANTITY DISCOUNT PARAMETER

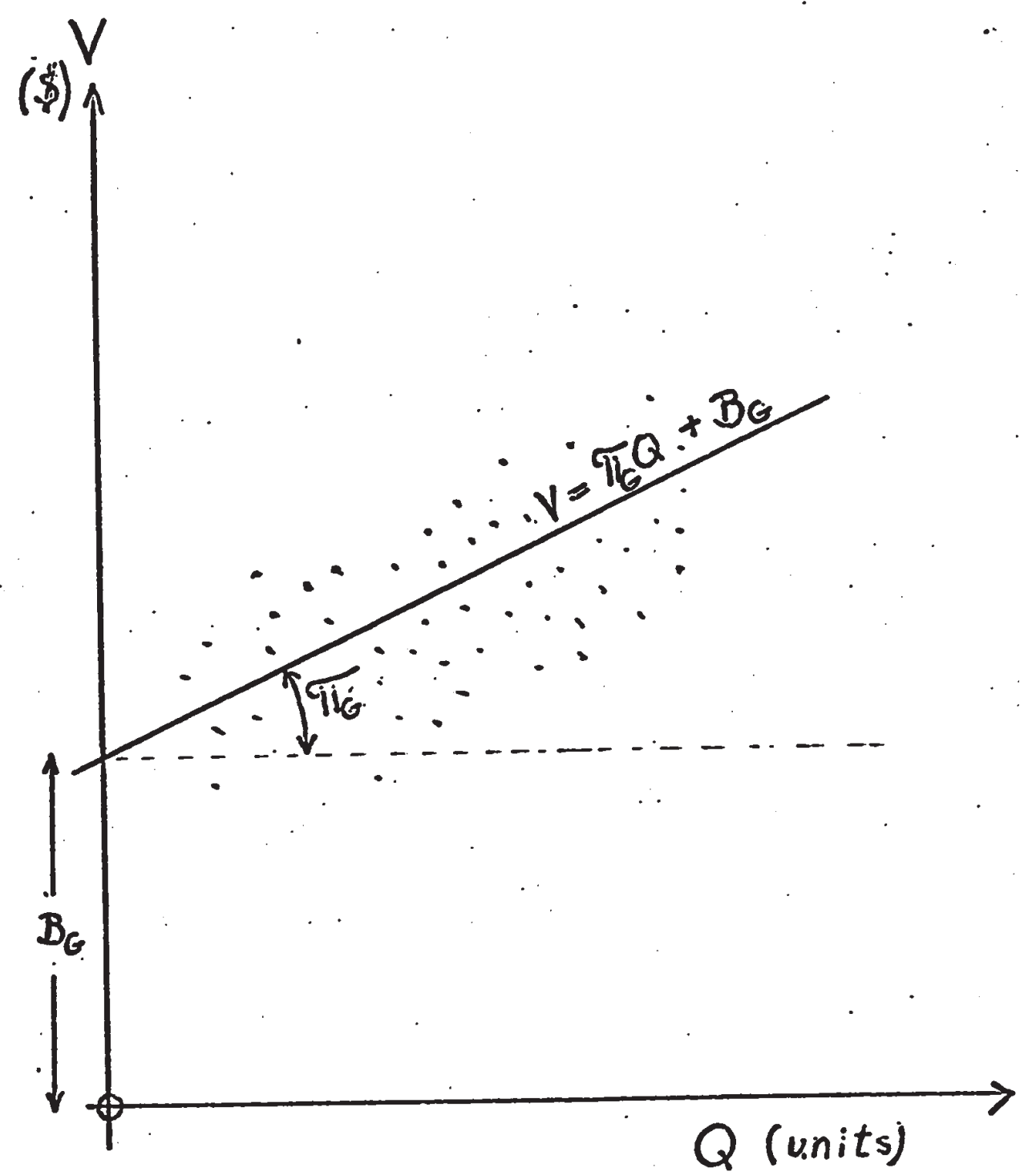




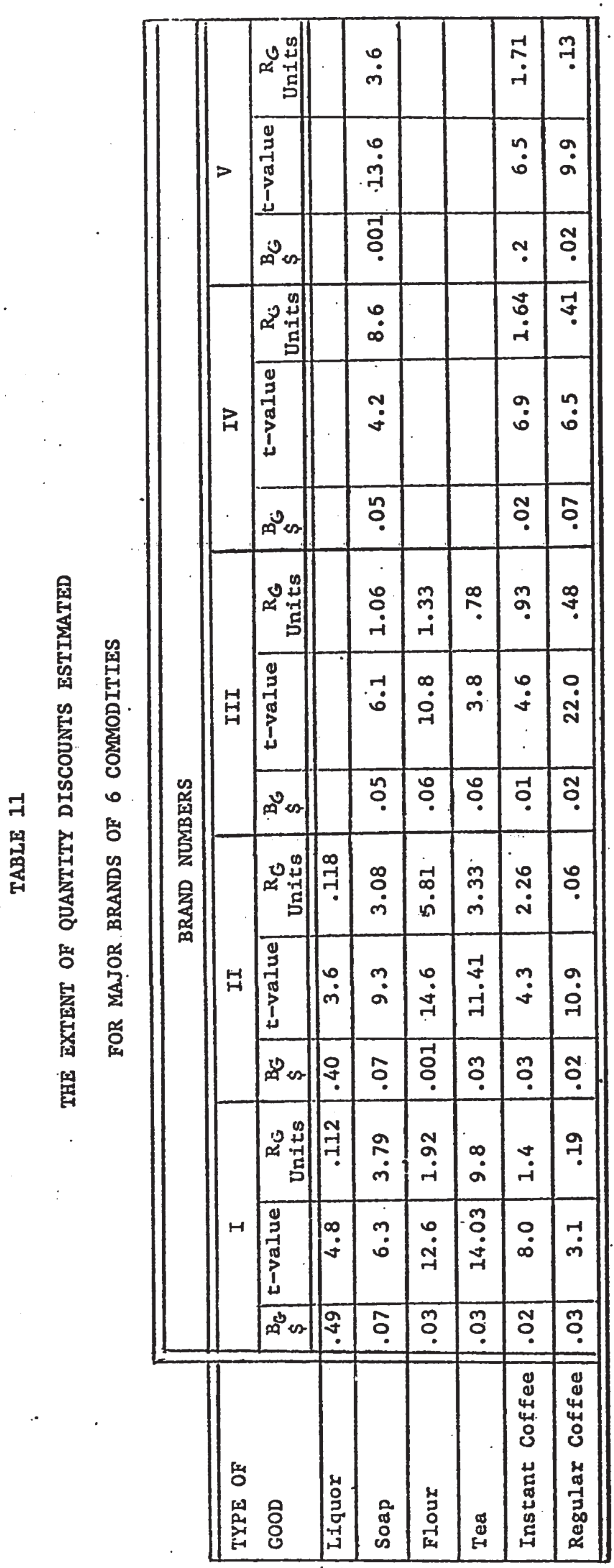

i13 
consumers an additional test was made.

The purchase quantity of the consumer is determined in accordance with (5.12) so that the poor would be expected to buy in smaller quantities because the rate of holding costs they apply is higher than, their grocery consumption is somewhat lower than, and the quantity discounts they are confronted with is not very much different from, those values for high income households.

If we now could hold constant in the data the quality of the goods purchased by high and low income households we should be able to show that low income households pay higher unit prices for identical goods. This in fact was done by computing the ratios of unit prices paid by low and high income consumers, as defined above, for 10 brands of each good. As TABLE 12 indicates the poor indeed do pay more as the significance level of the difference from 1 of the mean ratio indicates. 
TABLE 12

LOW INCOME HOUSEHOLDS PAY MORE FOR IDENTICAL BRANDS

\begin{tabular}{|l||cc|}
\hline GOODS & $\begin{array}{l}\text { X }=\text { ratio of } \\
\text { prices paid by } \\
\text { 1ow to those paid } \\
\text { by high incomes }\end{array}$ & $\begin{array}{l}\text { i number of } \\
\text { are based on }\end{array}$ \\
\hline Regular Coffee & 1.032 & 4881 \\
Instant Coffee & 1.068 & 1552 \\
Tea & 1.096 & 1845 \\
Flour (All Purpose) & 1.051 & 2437 \\
Pancake Flour & 1.036 & 958 \\
Cake Mixes & .983 & 356 \\
Roll Mixes & .997 & 1154 \\
Margarine & 1.003 & 3153 \\
Peanut Butter & 1.011 & 1725 \\
Meat, Fish and Poultry Pies & 1.010 & 435 \\
Fish Sticks & 1.012 & 389 \\
Dinners, Frozen & .938 & 596 \\
Instant Potatoes & 1.012 & 550 \\
Packaged Desserts & 1.035 & 1961 \\
Toilet Soap & 1.039 & 3633 \\
Packaged Soap and Detergent & 1.023 & 3026 \\
Scouring Cleansers & 1.026 & 4351 \\
Liquid Detergents & 1.015 & 1960 \\
Peaches & -1.010 & 2018 \\
Pork and Beans* & 1.007 & 1288 \\
Canned Corn* & 1.008 & 1949 \\
Tomatoe Paste* & 1.334 & 3292 \\
Vegetable Juice* & 1.018 & 1431 \\
Vegetables Frozen* & 1.015 & 3626 \\
Chile Con Carne* & .993 & 367 \\
Canned Tuna* & .992 & 1866 \\
\hline
\end{tabular}

* 1961 purchases only

$\overline{\mathrm{X}}=\frac{\sum \mathrm{nX}}{\sum \mathrm{n}}=1.0457 ; \quad t=\frac{\overline{\bar{X}-1}}{\mathrm{~S}_{\overline{\mathrm{X}}}}=2.88$ 
On the basis of our research it is concluded that household grocery inventory behaviour does in fact have definable properties which the model successfully anticipates. Notwithstanding the difficulties in the way of solid quantitative results, the findings clearly discredit a common attitude that purchase behaviour is not a major concern for economists either because it is an adjunct of consumption behaviour, or because the rational aspects of household behaviour have all been exhaustively treated by the sophisticated consumption theory. The insights gained, and questions raised, by the present study of purchase behaviour bear witness of this general conclusion.

Inventory Adjustments by Consumers as a Factor

Contributing to the Instability of Short Term Consumption Expenditures

An expenditure change resulting from a change in real consumption is the sum of two components $\left(\Delta q_{G}+\Delta \mathrm{H}\right) \mathrm{P}_{\mathrm{G}}$, i.e. 
the expenditure change that results from the change in consumption itself, $\Delta \mathrm{q}_{G}$, and the inventory adjustment, $\Delta \mathrm{H}$, to which this consumption change also gives rise, times the unit price $\mathrm{P}_{\mathrm{G}}$.

$\Delta \mathrm{q}_{G}$ and $\Delta \mathrm{H}$ are non-linearly related because by letting $\Delta q_{G}=q_{2}-q_{1}$ for a given period, $\Delta H$ will be

$$
\frac{Q_{2}^{*}}{2}-\frac{Q_{1}^{*}}{2}=\sqrt{\frac{B_{G}}{2 I_{G}}}\left(\sqrt{q_{2}}-\sqrt{q_{1}}\right),
$$

so that the expenditure change for the first shopping period, during which the consumption change occurs, is

$$
\left(\Delta q_{G}+\Delta \mathrm{H}\right) P_{G}=\left[q_{2}-q_{1}+\sqrt{\frac{B_{G}}{2 I_{G}}}\left(\sqrt{q_{2}}-\sqrt{q_{1}}\right)\right] P_{G}
$$

This quantity always exceeds the consumption expenditure response that would be predicted on the basis of an income change whatever the specific form of the short run consumption function. Traditional consumption theory fails to make allowance for expenditures resulting from inventory adjustments.

Since the demand for inventory holdings and consumption will always change in the same direction, inventory adjustment expenditures tend to enhance fluctuations in expenditures resulting from changes in consumption. The present inventory consumption approach thus is capable of accounting for part of the erratic short term expenditure fluctuation unexplained by traditional consumption theory. 


\section{Economies of Scale in Consumption}

The total cost of maintaining the flow of a unit of grocery consumption per period declines as the consumption per period increases. This decrease is the result of a decline in average annual inventory. costs.

Minimum grocery inventory costs per annum, $\mathrm{TC}_{G}$, are obtained by substituting the optimum value of $Q_{G}$ given by (5.12) into relation (5.1). Ignoring the costs of perishables this manipulation yields the sum

$$
\mathrm{TC}_{G}=\sqrt{{ }^{2 B_{G} q_{G}{ }^{I}{ }_{G}{ }_{G}}}+\frac{I_{G} B_{G}}{2}+\left(k b_{G}+\pi_{G}\right) q_{G},
$$

so that average total inventory costs for groceries,

$$
\begin{aligned}
\operatorname{ATC}_{G} \text {, are } & \begin{aligned}
\operatorname{ATC}_{G} & =\frac{\operatorname{TC}_{G}}{q_{G}} \\
& =\sqrt{\frac{2 B_{G} I_{G}{ }^{\pi} \cdot G}{q_{G}}}+\frac{I_{G}{ }_{G}}{2 q_{G}}+k b_{G}+\pi{ }_{G}
\end{aligned}
\end{aligned}
$$

which decline inversely with consumption. To the extent that $I_{G}$ and $1 / q_{G}$ are negatively related to income, economies of scale to increasing income expenditures are more pronounced, while the positive correlation of the value of time $K$ and income tends to diminish this crosssectional differential in $\operatorname{ATC}_{G^{*}}$. 


\section{Differential Rates of Holding Costs}

\section{Across Households}

The investigation of the data succeeded in showing that the model broadly captured the behavioural properties displayed by a vast mass of purchase records. At the same time, the investigation turned up an interesting piece of evidence, by showing that the rate of total waiting costs, which households apply on their grocery holdings, varies negatively with their incomes. This tendency emerged from 3 largely independent estimating procedures with overwhelming consistency.

\section{Cross-Sectional Variations in the Rate of}

\section{Foregone Earnings}

To the extent that deterioration and storage costs do not vary systematically with income, the differential in the rates of waiting costs is a consequence of an even larger differential in the interest rates that prevail across households. In order to establish the predominance of the rate of interest as causal influ, ace, we must therefore show that deterioration and storage costs of a given amount of a given good, vary little with the income of a household. But this is easily shown by simply looking at the behaviour of our estimate of $\&$. which, to recall, was the ratio of $\overline{\mathrm{I}}_{\mathrm{GL}}$ to $\overline{\mathrm{I}}_{\mathrm{GH}}$, i.e. the holding cost 
rates of low income and high income households, respectively, and to see whether or not this ratio remains constant as the two non-interest components of holding costs are changed. For if each holding cost component made the same relative contribution to the cross-sectional differential in the I's, c should remain constant as the size of deterioration and storage costs changes relative to interest costs. To this end all sampled goods on TABLE 3 and TABLE 4 are divided into two groups, one group singling out a11 those items that are unambiguously more perishable, denoted by $P$ in parenthesis, than the remaining goods, which form the other group. It is now clear that the relative share of deterioration costs is larger for the former group than for the latter. But the same must hold true for storage costs which must be larger for the more perishable group because these items tend to compete for a limited refridgeration space, while the nonperishable goods are easy to store away, at least the goods in our sample which are of the non-bulky variety.

Now computing the average values of $c$ for the two groups, utilizing both the estimates obtained through procedure 1 and 3 , the mean ratio calculated for the group of relatively perishable items is 1.108 while that for the other group is 1.252 with the difference significant at the $t=2.79$ level. This clearly traces the cross-sectional 
differences in the rates of holding costs to the existence of an even larger cross-sectional difference in the rate at which households forego earnings when holding grocery goods.

This finding, even though not anticipated by the model itself, can be rationalized in terms of its general approach. The act of borrowing, namely, involves opportunity costs, just as the purchase of any other good does, so that the nominal interest rate cannot be taken as a proxy for the total cost incurred.

In the first instance, the opportunity cost of procuring a loan must be recognized because there is time, trouble and direct expenses involved in making a loan at financial institutions.

Secondly, a most important opportunity cost is incurred by using up part of the limited credit available to the household at any one time. The reason is that the household is generally not free to borrow all it wants at a given credit cost and that, as a consequence, the household will determine a shadow price for borrowed funds to optimize their uses.

This point is illustrated in FIGURE 9. Suppose the total demand for credit is given by $D$ and that the household is good only for a credit indicated by $B_{0}$, which is available at rate $r_{0}$. Even though the household needs 
FIGURE 9

DEMAND FOR CONSUMER CREDIT WITH A CEILING ON THE AMOUNT AVAILABLE

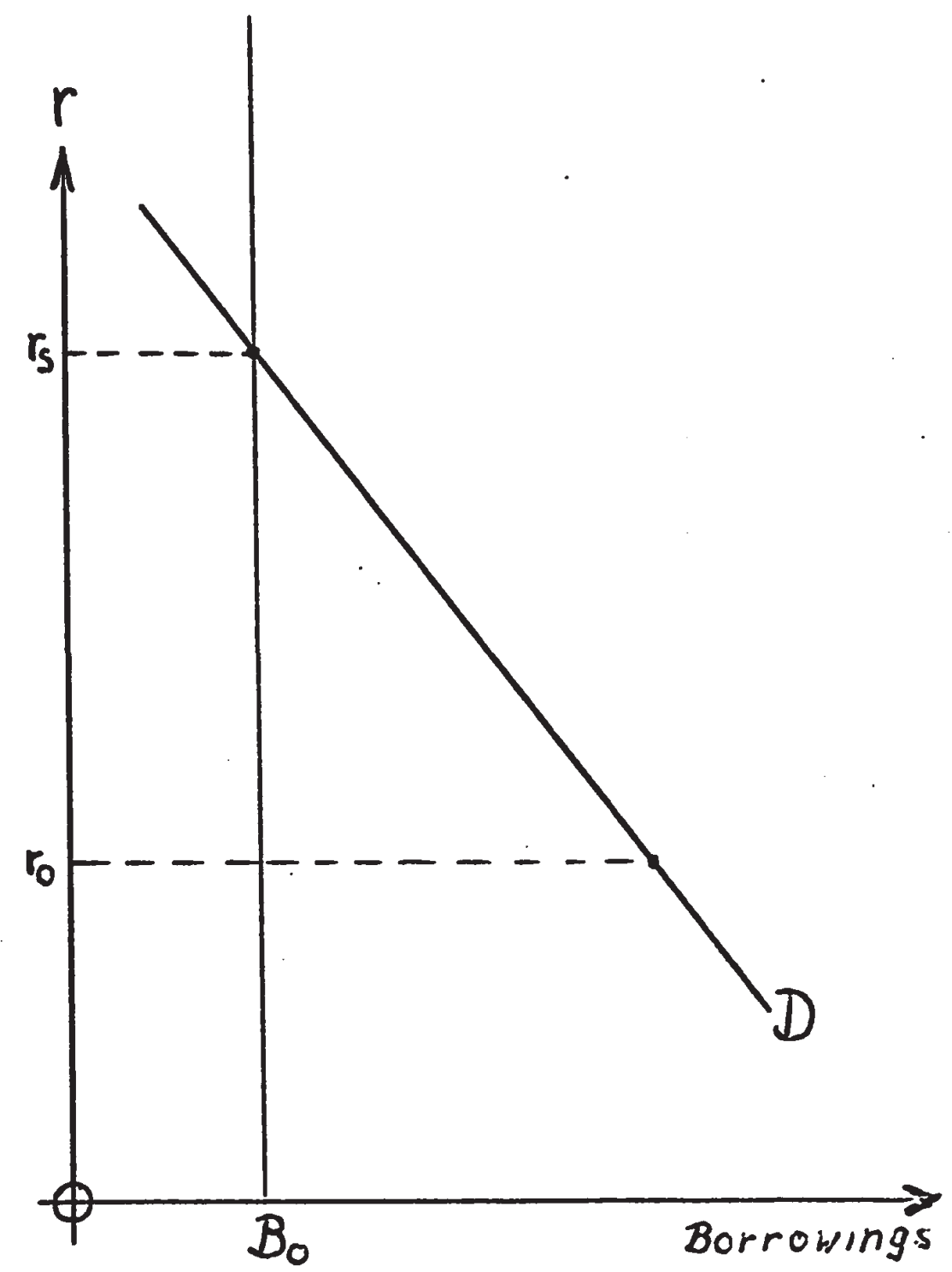


only pay $r_{0}$ to outside sources, the rate, which the household charges internally, when allocating $B_{0}$ to competing uses, is $r_{s}$.

\section{A New Approach to the Study of Consumer Credit}

The study thus points to an entirely new method of estimating the rate of discount which the household applies internally, and which is relevant for the household's time preference.

We set out from the premise that the consumer can borrow from two competing sources of credit. He can borrow from the finance company and he can borrow by reducing his grocery inventory investment. The rate of discount he reveals to charge himself on this commodity inventory investment is therefore a direct measure of this internal rate of discount. It must be equal to the rate he pays to outside sources, plus the additional opportunity costs per dollar of borrowing reflecting time and trouble of getting the loan, as well as the value of foregone investment alternatives.

A set of data particularly suited for such an investigation is the frequency, and value, of postage stamp purchases available for a cross-section of Canadian communities because the cost of holding stamps consists mainly of foregone interest earnings. Average incomes are known for these communities and a follow-up study is planned to investigate cross-sectional differences from this aggregated data. 


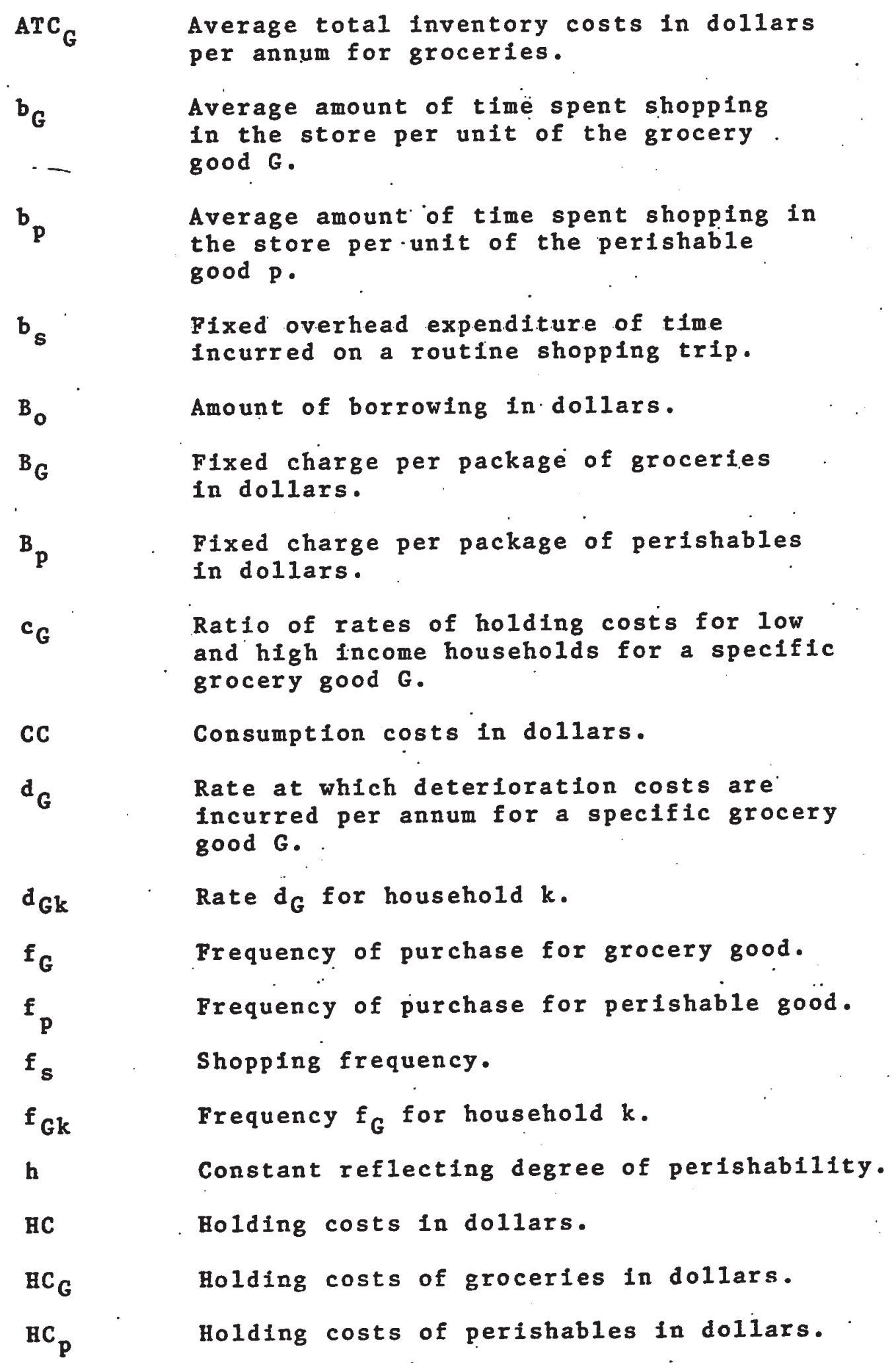




\section{GLOSSARY OF SYMBOLS \\ (continued)}

\begin{tabular}{|c|c|}
\hline 1 & Rate. of interest \\
\hline$i_{k}$ & Rate of interest applied by household $k$. \\
\hline $\mathbf{I}_{\mathbf{G}^{-}}$. & $\begin{array}{l}\text { Total annual holding costs for a specific } \\
\text { grocery good. }\end{array}$ \\
\hline$I_{\mathbf{p}}$ & $\begin{array}{l}\text { Rate at which the linear component of } \\
\text { annual holding costs of a specific perishable } \\
\text { good accrues. }\end{array}$ \\
\hline $\mathbf{I}_{\mathbf{G k}}$ & $\begin{array}{l}\text { Rate } I_{G} \text { as subjectively evaluated by } \\
\text { household k. }\end{array}$ \\
\hline$I_{G}$ & Mean rate of totalholding costs for good G \\
\hline & average over a group of $n$ households. \\
\hline$\overline{\mathbf{I}}_{\mathrm{GL}}$ & $\begin{array}{l}\text { ean rate of total holding costs for good } G \\
\text { averaged over a group of low income } \\
\text { households. }\end{array}$ \\
\hline$\overline{\mathbf{I}}_{\mathbf{G H}}$ & $\begin{array}{l}\text { Mean rate of total holding costs for good G } \\
\text { averaged over a group of high income } \\
\text { households. }\end{array}$ \\
\hline $\mathbf{k}$ & The price of a shopper's time. \\
\hline $\mathbf{M}$ & $\begin{array}{l}\text { Multiple by which the shopping frequency } \\
\text { exceeds the purchase frequency of the } \\
\text { grocery good. }\end{array}$ \\
\hline$P_{d G}$ & $\begin{array}{l}\text { Unit price of the grocery good under } \\
\text { consideration of quantity discounts. }\end{array}$ \\
\hline $\mathbf{P}_{\mathbf{d p}}$ & $\begin{array}{l}\text { Unit price of the perishable good under } \\
\text { consideration of quantity discounts. }\end{array}$ \\
\hline $\mathbf{P}_{\mathbf{G}}$ & $\begin{array}{l}\text { Price index for grocery goods as they enter } \\
\text { the short run consumption function. }\end{array}$ \\
\hline PC & Procurement costs in dollars. \\
\hline D & Purchase quantity in units of black households. \\
\hline$Q_{\dot{G}}$ & Purchase quantity of the grocery good in units. \\
\hline Q & $\begin{array}{l}\text { Purchase quantity of the perishable good } \\
\text { in units. }\end{array}$ \\
\hline
\end{tabular}


126

GLOSSARY OF' SYMBOLS

(continued)

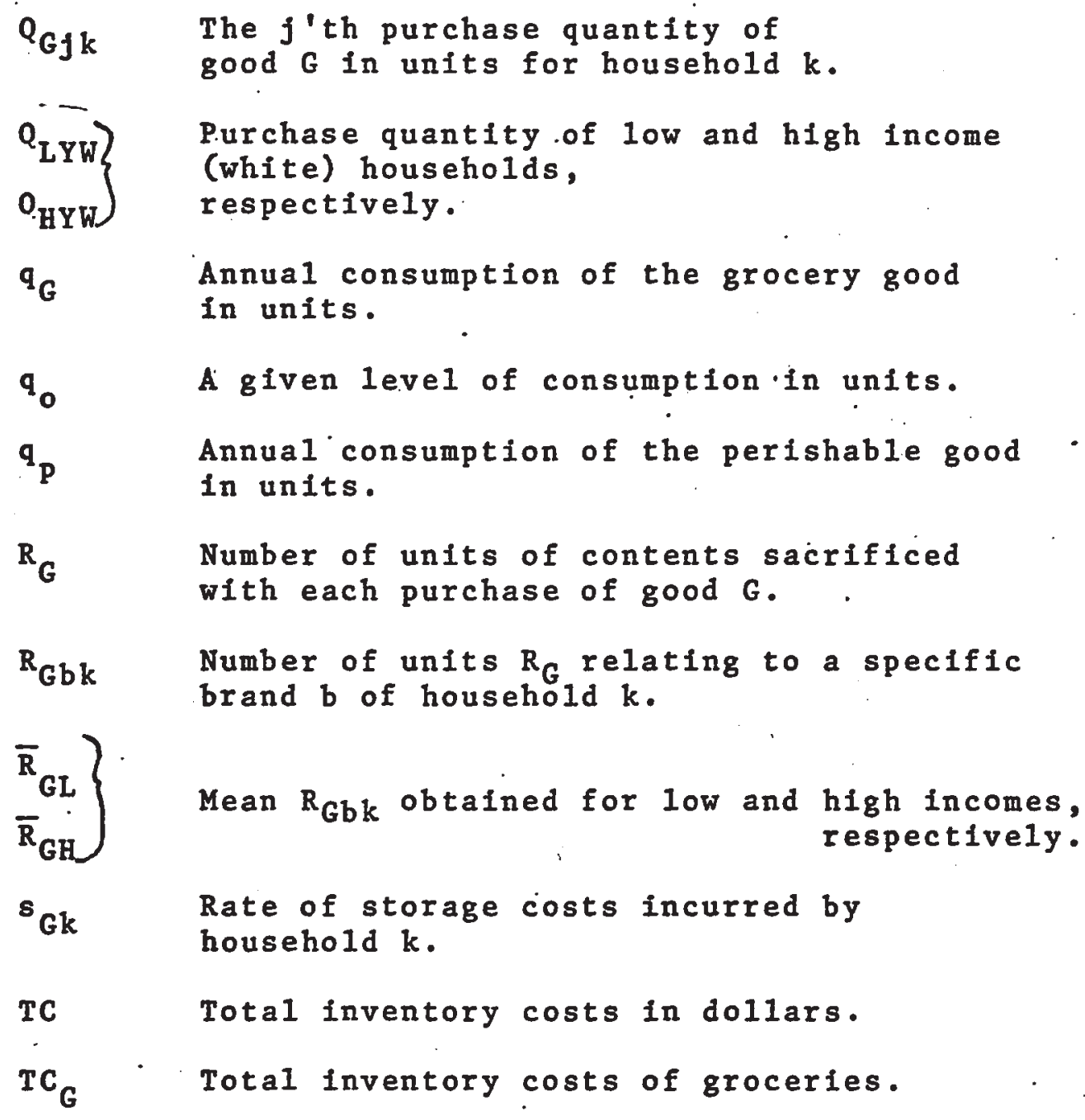


BIBLIOGRAPHY

Arrow K., Karlin S., Scarf S.M., Studies in the Mathematical Theory of Inventory and Production, Stanford University Press, Stanford, Cal., 1958

Allen R.G.D., Mathematical Analysis for Economists, MacMillan Co., London, 1964

Baumol, W.J., "The Transaction Demand for Cash: An Inventory Theoretical Approach," Quarterly Journal of Economics, LXI (November, 1952)

, and Ide J., "Variety in Retailing" in Mathematical Models and Methods in Marketing, R.D. Irwin Inc., Homewood, I11., 1961 .

Becker G.S., "A Theory of the Allocation of Time," Economic Journal, LXXV (September 1965)

Boulding K.E., "An Application of Population Analysis to the Automobile Population of the United States," Kyklos, (1955).

Brown G.H., "Brand Loyalty," Advertising Age, XXII (June 9, 1952)

Brunner Karl and Meltzer A.H., "Economies of Scale in Cash Balances," Quarterly Journal of Economics, LXXXI (March 1967)

Bushaw D. W. and Clower R. W., Introduction to Mathematical Economics, R.D. Irwin, Homewood I11., 1957

Canadian Daily Newspaper Association, Canadian Consumer Survey, Toronto, 1957, 1959, 1961, 1963, 1965, 1967,1969

Canadian Grocer, Survey of Shopping Habits, McLean Hunter, Toronto, (July 1967) 
Clower R.W., "Stock-Flow," Encyclopedia of the Social Sciences, Collier MacMillan, New York, 1966

, "On the Technology of Exchange," Unpublished paper, 1969

, "Is There an Optimal Money Supply?" Journal of Finance, XXV (May 1970)

and Johnson B.M., "Income, Wealth and the Theory of Consumption," in Value and Growth, Wolfe ed., 1968

Cochrane W.G., Sampling Techniques, John Wiley and Sons Inc., New York, 1966

Cunningham R.M., Brand Loyalty - What, - Where, - How Much?" Harvard Business Review, XXXIV (January - February 1956)

Farley J.U., "Brand Loyalty and the Economics of Information," Journal of Business, XXXVIII (September 1965)

Feige E.L. and Parkin M., "The Optimal Quantity of Money, Bonds, Commodity Inventories, and Capital," American Economic Review, Vol. LXI (June 1971)

Gronau R., The Value of Time in Passenger Transportation: The Demand for Air Travel, NBER, occasional paper 109, New York 1970

Hadar J., "A Note on Stock-Flow Models of Consumer Behaviour," Quarterly Journal of Economics, LXXIV 1965

Hicks J.R., Value and Capital, Oxford University Press,

Johnson Bruce M., "Travel Time and the Price of Leisure," Western Economic Journal, 1966

Johnson H.G., "Is there an Optimal Money Supply? - Comment," Journal of Finance, Vol. XXV (May 1970)

Johnston J., Econometric Methods, McGraw Hill, New York, 1963

Lancaster K.J., "A New Approach to Consumer Theory," Journal of Political Economy, LXXIV( 1966). 
Lipsey G.R. and Rosenbluth G., "A Contribution to the New Theory of Demand: A Rehabilitation of the Giffen Good, Canadian Journal of Economics, IV (May 1971)

Lloyd C., "The Real Balance Effect and the Slutsky Equation," Journal of Political Economy LXXII, 1964

May F.E., "On Shopping Behaviour," Journal of Business, XXXVIII (October 1965)

Melvin J.R., "A Theory of Leisure," unpublished paper, 1970

Mills E.S., Price, Output and Inventory Policy: A Study In the Economics of the Industry and Firm, Wiley and Sons, New York, 1962

Mincer J., "Market Prices, Opportunity Costs and Income Effects," in Measurements in Economics, eds. Christ, Patinkin et. al., Stanford University Press, Stanford, 1963

Morgan J.N., "Consumer Investment Expenditures," American Economic Review, XLVIII (December 1958)

Morris W.T., "Some Analysis of Purchasing Policy," in Mathematical Models and Methods in Marketing, R.D. Irwin Inc., Homewood, I11., 1961

Muth R.F., "Household Production and Consumer Demand Functions," Econometrica, 1966

Nelson P., "Information and Consumer Behaviour," Journal of Political Economy, LXXVII 1970

Ostle B., Statistics in Research, The Iowa State University Press, Ames, Iowa, 1963

Owen J.D., The Price of Leisure: An Economic Analysis of the Demand of Leisure Time, McGill-Queen's University Press, 1970

Oxenfeldt A., "Consumer Knowledge: Its Measurement and Extent," Review of Economics and Statistics, XXXII (November 1950)

Prais J.S. and Houthakker H.S., The Analysis of Family Budgets, Cambridge, England, 1955 
Progressive Grocer, Consumer Dynamics in the Super Market, New York, 1966

Reid M.G., "Consumption," Encyclopedia of the Social Sciences, Collier MacMillan, New York, 1966

, "Consumer Response to the Relative Price of Store vs. Dellvered Milk," Journal of Political Economy, LXXI, 1963

Sharir Shmuel, Consumer Buying Behaviour and the Structure of Retail Industries, unpublished Ph.D. dissertation, Columbia University, 1970

Stigler J.G., "The Economics of Information," Journal of Political Economy, LXIX (June 1961)

Tobin J., "The Interest Elasticity of the Transactions Demand for Cash," Review of Economics and Statistics, XXXVIII(1956).

Whitin T.M., "Inventory," Encyclopedia of the Social

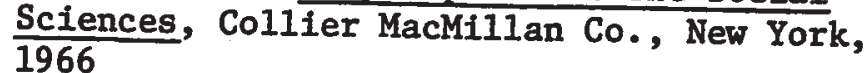

, The Theory of Inventory Management, Princeton University Press, Princeton, New Jersey, 1957

and Hadley G.R., Analysis of Inventory Systems, Printice Hall, Englewood, 1963 